\title{
Place Matters
}

\author{
Elena Lioubachevskaia
}

A thesis submitted to the Faculty of Graduate and Postdoctoral Affairs in partial fulfillment of the requirements for the degree of Master of Architecture

in

Master of Architecture - Professional Stream

Azrieli School of Architecture and Urbanism

Carleton University

Ottawa, Ontario, Canada

(C) 2013, Elena Lioubachevskaia 


\begin{abstract}
This thesis explores past and present directions of architectural theories and designs of libraries with a focus on the study of the progression of cultural transmission methods, from oral to written and from written to digital. Traditionally, cathedrals have communicated religious knowledge through architectural elements such as artistic stained glass, frescos, mosaics, and expressive structures, while libraries have housed books and other mediums that conveyed knowledge primarily through texts. However, as recorded memory shifts from physical mediums to digital media in a virtual space that has infinite capacity, many connections, and no shared time, the amount of physical space needed for housing the information diminishes. The tension between spatially embodied memory (ie. cathedrals and libraries) and digital memory (ie. cyberspace) raises a critical question: 'WHAT IS THE CONTEMPORARY LIBRARY?' We are witnessing a fundamental change in the way people share information. The impact of the current "information age" on architectural design will be examined through a three part structure: the first chapter will discuss Architectural Medium as the Message and the Message without the Architecture, the second chapter will examine Architecture that Houses the Message as well as the Message without the Architecture, and the third chapter will discuss the proposed Contemporary Library project.
\end{abstract}




\section{Acknowledgements}

I would like to thank my parents, Irina and Mikhail Lioubachevski and all my friends for their support during my studies at Carleton University. I would also like to thank my thesis advisor, Federica Goffi, and my mentors, Laura Urrechaga and Brian Clark for their endless guidance and support. 


\section{Table of Contents}

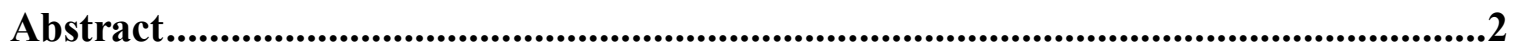

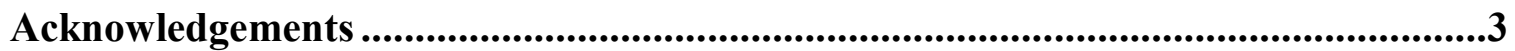

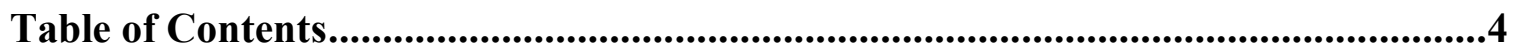

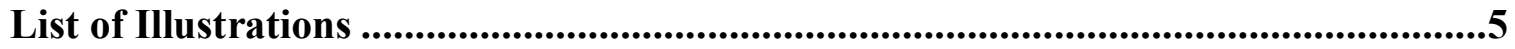

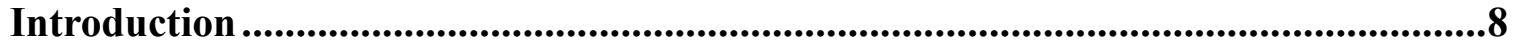

1 Chapter: The architectural medium is the message ...............................................10

1.1 Transfering knowledge through physical surfaces by reading the building through the physical elements, senses and experience. Notre Dame Cathedral as example.

1.2 Physical experience $\rightarrow$ Reading text. Implication of reading a book about a Cathedral

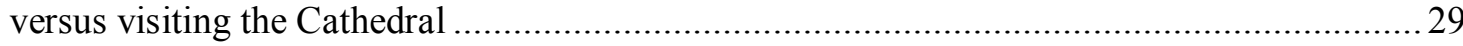

1.3 Physical experience $\rightarrow$ Digital translation. Viewing virtually from a distance through

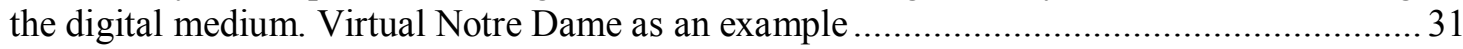

2 Chapter: Architecture that houses the message ...................................................36

2.1 Container: Ancient Library of Alexandria \& Phillips Exeter Academy, Library by

Louis I. Kahn \& Eberswalde Library by Herzog \& de Meuron ............................................ 38

2.2 Content: Phillips Exeter Academy, Library by Louis I. Kahn ................................. 47

2.3 Physical versus Digital in the Digital Age: Digital Age \& Ottawa Public Library...... 61

3 Chapter: The Contemporary Library.....................................................................73

3.1 Intent of the proposed project as a forum and nodes ........................................ 75

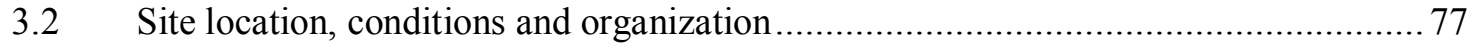

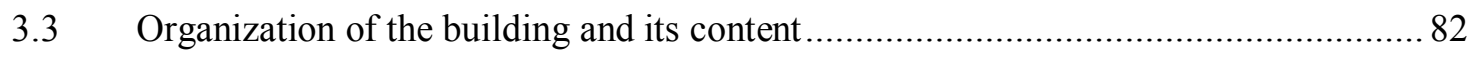

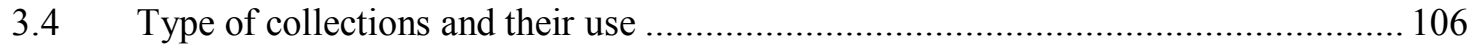

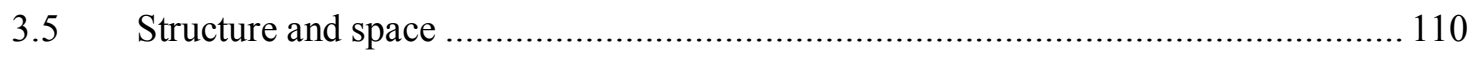

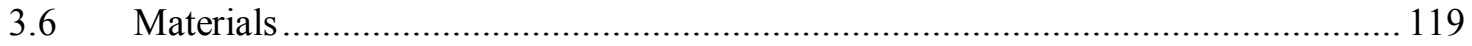

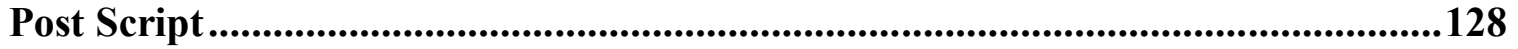

Terms

Bibliography and References .....................................................................................132 


\section{List of Illustrations}

\section{Illustration 1 Sample of caption for Illustration in Chapter $1 \ldots \ldots \ldots \ldots \ldots \ldots \ldots \ldots \ldots \ldots \ldots \ldots \ldots \ldots . . .1$}

Fig. 1

Notre Dame Cathedral, Paris - Nave interior: Sketch by author of thesis.

Fig. 2

Notre Dame Cathedral, Paris - West facade of Notre Dame Cathedral

Photos: Notre Dame Cathedral. Sacred Destinations, 2005-13. 〈http://www.sacred-destinations.com/france/paris-notre-damecathedral/photos>. IMG_2690 (Accessed on 26/03/2013).

Fig. 3

Notre Dame Cathedral, Paris - Virtual Tour: Rougier, Eric. Virtual tour: Notre Dame. From Paris, The City of Light. 〈http://www.fromparis.com/virtual-tour-notre-dame/〉. (Accessed on 26/10/2013).

Fig. 4

Notre Dame Cathedral, Paris - South Rose Window (c.1260): Photos: Notre Dame Cathedral. Sacred Destinations, 2005-13. 〈http://www.sacred-destinations.com/france/paris-notre-dame-cathedral/photos〉. IMG_9834 (Accessed on 26/03/2013).

Fig. 5

Notre Dame Cathedral, Paris - South Rose Window (Detail): Photos: Notre Dame Cathedral. Sacred Destinations, 2005-13. 〈http://www.sacred-destinations.com/france/paris-notre-dame-cathedral/photos〉. IMG_9839 (Accessed on 26/03/2013).

Fig. 6

Notre Dame Cathedral, Paris - South Rose Window (c.1260): Photos: Notre Dame Cathedral. Sacred Destinations, 2005-13. 〈http://www.sacred-destinations.com/france/paris-notre-dame-cathedral/photos〉. IMG_9233 (Accessed on 26/03/2013).

Fig. 7

Notre Dame Cathedral, Paris - Last Judgment Portal (c.1230): Photos: Notre Dame Cathedral. Sacred Destinations, 2005-13. 〈http://www.sacred-destinations.com/france/paris-notre-dame-cathedral/photos〉. IMG_2624 (Accessed on 26/03/2013).

Fig. 8

Notre Dame Cathedral, Paris-Last Judgment Portal: Christ in Majesty: Photos: Notre Dame Cathedral. Sacred Destinations, 2005-13. 〈http://www.sacred-destinations.com/france/paris-notre-dame-cathedral/photos〉. IMG_9935 (Accessed on 26/03/2013).

Fig. 9

Church of the Light: apse end and cross: Photograph by Tomio Ohashi. Kazukiyo Matsuba. 1998. Ando: Architect. New York, United States of America: Tokyo, Kodansha International. Pg 133.

Fig. 10

Church of the Light: detail of pews and wooden flooring: Photograph by Tomio Ohashi. Kazukiyo Matsuba. 1998. Ando: Architect. New York, United States of America: Tokyo, Kodansha International. Pg 131.

Fig. 11

Church of the Light, Ibaraki (Osaka): sanctuary, looking toward chancel: Photograph by Tomio Ohashi. Kazukiyo Matsuba. 1998. Ando: Architect. New York, United States of America: Tokyo, Kodansha International. Pg 130.

Fig. $12,13 \& 14$

Notre Dame Cathedral, Paris - sketch by author of thesis.

Fig. 15

Notre Dame Cathedral, Paris - Virtual tour options to explore on a virtual tour: Rougier, Eric. Virtual tour: Notre Dame. From Paris, The City of Light. 〈http://www.fromparis.com/virtual-tour-notre-dame/〉. (Accessed on 26/10/2013).

Fig. 16

Notre Dame Cathedral, Paris - Virtual tour entrance: Rougier, Eric. Virtual tour: Notre Dame. From Paris, The City of Light. 〈http://www.fromparis.com/virtual-tour-notre-dame/〉. (Accessed on 26/10/2013).

\section{Illustration 2 Sample of caption for Illustration in Chapter 2}

Fig. 17

Phillips Exeter Academy Library interior atrium: Sketch by author of thesis. 
Fig. 18

The Great Library of Alexandria: Artistic Rendering of the Library of Alexandria, based on some archaeological evidence. By O. Von Corven, Tolzmann, Don Heinrich, Alfred Hessel and Reuben Peiss. The Memory of Mankind. New Castle, DE: Oak Knoll Press, 2001. 〈http://en.wikipedia.org/wiki/File:Ancientlibraryalex.jpg). (Accessed on 25/06/2013).

\section{Fig. 19}

Book Vending Machine: Gatwick Airport (altered by author of thesis):Jessica Spengler. Book Vending Machine: Gatwick Airport. Taken on April 4, 2007. Yahoo. 2013. 〈http://www.flickr.com/photos/wordridden/448145509/> (Accessed on 25/06/2013).

\section{Fig. 20}

Phillips Exeter Academy Library - Exterior elevation: Buttiker, Urs, and Translation by David Bean. 1994. Louis I. Kahn: Light and Space. New York, United States of America: Whitney library of design an imprint of Watson-Guptill Publications. Pg 128.

Fig. 21

Eberswalde Library - Entrance elevation: Picture credit to Margherita Spiluttini. From book Mack, Gerhard and Valeria Liebermann. 2000. Eberswalde Library: Herzog \& de Meuron. London: Architectural Association and the Authors, AA Publications. Pg 17.

Fig. 22

Eberswalde Library - Plans: Picture credit to Margherita Spiluttini. From book Mack, Gerhard and Valeria Liebermann. 2000.

Eberswalde Library: Herzog \& de Meuron. London: Architectural Association and the Authors, AA Publications. Pg 16.

Fig. 23

Eberswalde Library - Exterior façade at night: Picture credit to Thomas Ruff. From book Mack, Gerhard and Valeria Liebermann. 2000. Eberswalde Library: Herzog \& de Meuron. London: Architectural Association and the Authors, AA Publications. Pg 14.

\section{Fig. 24}

Eberswalde Library - Pictorial programme on the façade (altered): Picture credit to Margherita Spiluttini. From book Mack, Gerhard and Valeria Liebermann. 2000. Eberswalde Library: Herzog \& de Meuron. London: Architectural Association and the Authors, AA Publications. Pg 24.

Fig. 25

Eberswalde Library - Palazzo at Colle Ameno, Bologna: Picture credit to Thomas Ruff. From archive. From book Mack, Gerhard and Valeria Liebermann. 2000. Eberswalde Library: Herzog \& de Meuron. London: Architectural Association and the Authors, AA Publications. Pg 36.

Fig. 26

Eberswalde Library - Pieter Potter, Vanitas: Picture credit to Thomas Ruff. From archive. From book Mack, Gerhard and Valeria Liebermann. 2000. Eberswalde Library: Herzog \& de Meuron. London: Architectural Association and the Authors, AA Publications. $\operatorname{Pg} 36$.

Fig. 27

Exeter Academy Library - Diversion of light : Buttiker, Urs, and Translation by David Bean. 1994. Louis I. Kahn: Light and Space. New York, United States of America: Whitney library of design an imprint of Watson-Guptill Publications. Pg 131.

\section{Fig. 28}

Exeter Academy Library - Diversion of light: Buttiker, Urs, and Translation by David Bean. 1994. Louis I. Kahn: Light and Space. New York, United States of America: Whitney library of design an imprint of Watson-Guptill Publications. Pg 131.

\section{Fig. 29}

Exeter Academy Library - Reading niche: Buttiker, Urs, and Translation by David Bean. 1994. Louis I. Kahn: Light and Space. New York, United States of America: Whitney library of design an imprint of Watson-Guptill Publications. Pg 130.

Fig. 30

Exeter Academy Library - Light penetration: Buttiker, Urs, and Translation by David Bean. 1994. Louis I. Kahn: Light and Space. New York, United States of America: Whitney library of design an imprint of Watson-Guptill Publications. Pg 130.

Fig. 31

The Warburg Library - Diagram of organization scheme: Pattuelli, M. Cristina. The Warburg Library: Morphology of a Library as a 'Laboratory Of the Mind'. $19^{\text {th }}$ Annual Conference of the Society for the History of Authorship, Reading and Publishing (SHARP).

Washington. New York: Pratt Institute. July 14-17, 2011. Pg 9.

Fig. 32

Exeter Library - Access arcades as an encompassing circle: Image from the Louis I. Kahn Collection, University of Pennsylvania and Pennsylvania Historical and Museum Commission. From book Gast, Klaus-Peter. 1998. Louis Kahn: The Idea of Order. Basil, Switzerland: Birkhauser Verlag. Pg 83.

Fig. 33

Exeter Library - Second floor plan: Buttiker, Urs, and Translation by David Bean. 1994. Louis I. Kahn: Light and Space. New York, United States of America: Whitney library of design an imprint of Watson-Guptill Publications. Pg 128. 
Fig. 34

Exeter Library - Building section: Buttiker, Urs, and Translation by David Bean. 1994. Louis I. Kahn: Light and Space. New York, United States of America: Whitney library of design an imprint of Watson-Guptill Publications. Pg 129.

Fig. $35,36,37,38 \& 39$

Ottawa Puplic Library: Atrium space: Photo taken by author of thesis. (20/06/2013).

Illustration 3 Sample of caption for Illustration in Chapter 3 ....................................

Fig. 40

Picture of the Hub's location and context: Taken by Krista Smith. (18/05/2013).

Fig. 41

Map of downtown Ottawa with the Hub location and a couple of potential nodes connected to the Hub: Altered Google map with author of thesis sketches on top.

Fig. 42

Map of downtown Ottawa with the Hub location: Altered Bing map with author of thesis sketches on top.

Fig. 43

Scale Comparison: By author of thesis.

Fig. 44

Confederation Boulevard Grand route (altered by author of thesis): "Confederation Boulevard." Canada's Capital Region: Canadian, Just like You. Ottawa: The National Capital Commission. 〈http://www.canadascapital.gc.ca/places-to-visit/confederation-boulevard〉. (Accessed on 24/09/2012).

Fig. $45,46,47 \& 48$

By author of thesis.

Fig. 49

Different methods of accessing the site: Altered Google map with author of thesis sketches on top.

Fig. 50

By author of thesis.

Fig. $51-74$

By author of thesis.

Fig. 75

Map of public and private libraries in Ottawa: Altered Google map with author of thesis sketches on top.

Fig. $76-81$

By author of thesis.

Fig. 82

Canal in the Winter: Photo taken by author of thesis (03/02/2013).

Fig. 83

Canal in the Summer: Photo taken by author of thesis (18/05/2013).

Fig. 84

Parliament Hill from rear showing locks and Entrance Bay (Circa1880): Photo taken by William James Topley, Library and Archives PA-012385. Rideau Canal: A post-War of 1812 waterway built at a huge human cost. Canada's History magazine, online extension. Canadian Heritage, 2013. 〈http://www.canadashistory.ca/Magazine/Online-Extension/Articles/Canal-Rideau.aspx〉. (Accessed on 03/02/2013) 


\section{Introduction: Place matters}

The library proposed in this thesis manifests itself as dispersed nodes throughout the city with a single central Hub tying them together, as opposed to a static library that attempts to contain its collections within a single building. The proposal plans a central Hub in Canada's national capital City of Ottawa that ties private collections located throughout the city together with existing public libraries and museums. The intention is to sustain the social interaction and physical connection between people, allowing for the transfer of knowledge while still embracing the advancements of technology.

The transfer of knowledge has changed throughout history. This is due to, amongst other things, progressions and advancements in technology. The current impact of such advancements can be seen through our social interactions and our physical connection to places. The evolution of the library as a place of knowledge transfer is one instance of how technology has impacted the built environment and changed the use, connection, and meaning of place. The library is a place to house books. Technology however, enables us to access books online quickly and easily. This advancement is challenging the design and use of physical libraries. This brings us to a central question: what is the contemporary library?

In the proposed design the contemporary library is a network of dispersed nodes throughout the city. This is a consequence of the technological advancements that allow us to access information from anywhere. As a result, the library as a building is no longer the only place we can access information. Today people can access information from their home, an internet café, and their mobile phone. This means a library can be anywhere because it exists in the nowhere of cyberspace. 
Since we cannot ignore the importance of social interaction and physical connection with one another, we need to find a way to incorporate both the evolution and development of technology within the physical library.

In order to develop this project, knowledge transfer in relation to architecture using the gothic cathedral as an example is examined. This will allow establishes the social interaction and physical connection between people, knowledge and architecture. Next, I will examine knowledge transfer in relation to the written word using the library as an example. This will address establishing the impact of technology on the physical library. Finally, a discussion of the project, dealing with the city as a library with a central hub connecting people and technology in one place, will be developed. The objective is to illustrate that the contemporary library sustains social interaction, allows for physical connections, and supports technological developments all in support of knowledge transfer. 


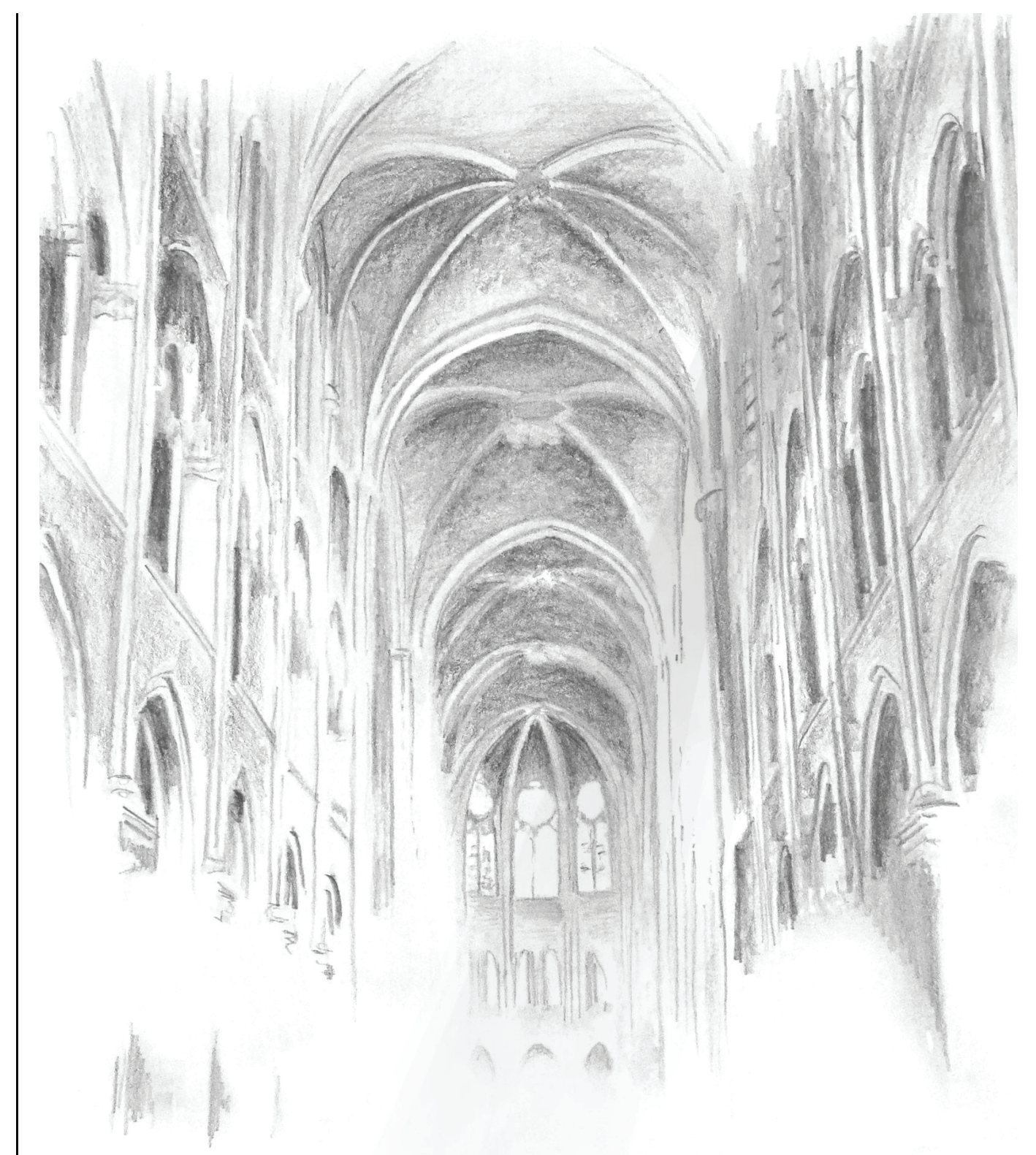

01

CHAPTER

Figure 1

"The role of line, which multiplies and takes over the visible interior structure, transforming it from an inert mass into an elegant configuration of lightweight, dynamic form.",

${ }^{1}$ Trachtenberg and Hyman 2003: 224. 


\section{Chapter: The architectural medium is the message}

Gothic cathedrals were designed and built as one type of medium through which knowledge could be transferred from the built elements to the viewers. This was important because few people in the Middle Ages were literate. ${ }^{2}$ The cathedral allowed knowledge to be transferred through a form of visual literacy. Notre Dame Cathedral, Paris is an example of this (see fig. 2). ${ }^{3}$ Comparing direct personal multi-sensory on-site experience to the virtual tour of this cathedral, which is available to 'online tourists'

"Cathedrals contain a wide complex of ideas that would fill volumes were they written down. They can be read by the literate and the illiterate alike, and they are destined for both. The Middle Ages were concerned with techniques that would enable man to remember and to compare many such areas of ideas."

McLuhan 1962: 109.

(see fig. 3), this section will examine the importance of physically experiencing architecture with all of the senses, demonstrating how the Cathedral's surface, light and structure are an important part of the experience, and how physical experience differs from a virtual tour of the same Cathedral.

Notre Dame Cathedral, Paris - West facade of Notre Dame Cathedral

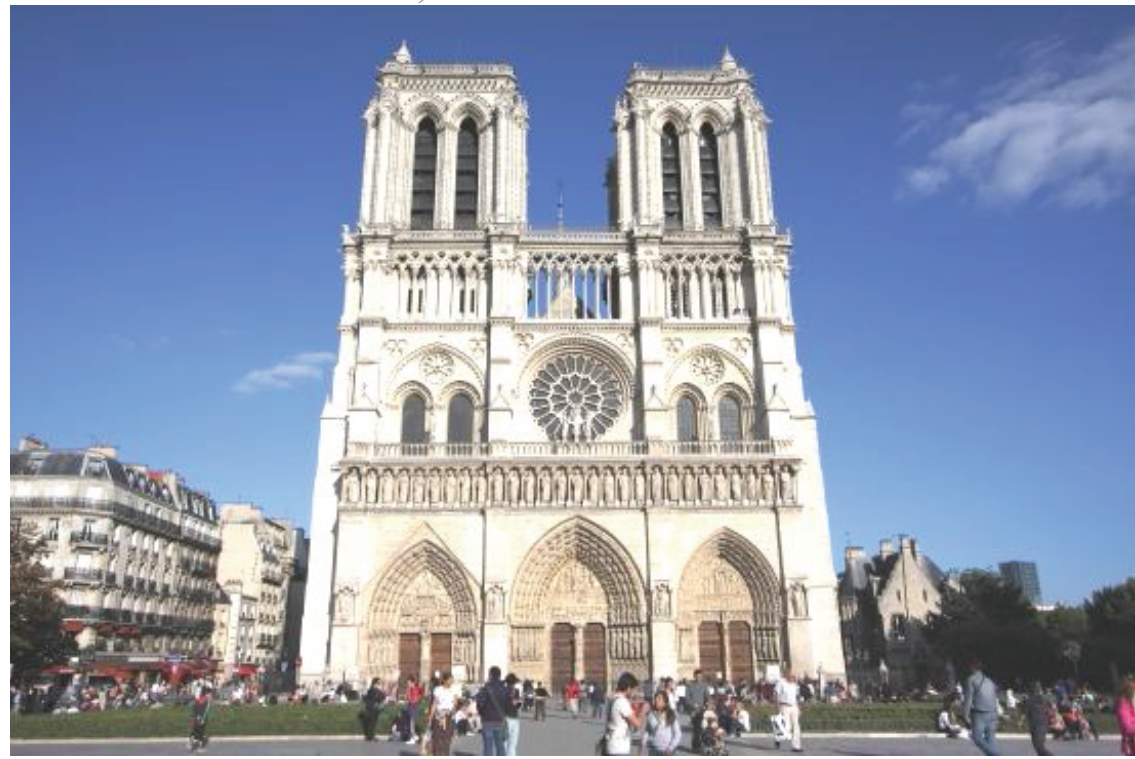

Figure 2

\footnotetext{
${ }^{2}$ McLuhan 1962: 109.

${ }^{3}$ The author of this thesis visited Notre Dame's Cathedral on February 2011.
} 


\section{Notre Dame Cathedral, Paris - Virtual Tour}

\section{$<$ http://www.fromparis.com/virtual-tour-notre-dame/>}

Figure 3

The Gothic cathedral clearly attests to its religious significance, offering an example of physical architecture's ability to transfer knowledge. This transfer of knowledge has been achieved through the stories displayed in the building's own body, itself a physical embodiment of the story directly experienced by a viewer, a tourist or a faithful person. These stories, based on Christian theology, gave a glimpse of heaven on earth, using architecture to echo God's kingdom and human relationship to that kingdom.

\footnotetext{
"As the house of the Lord on earth, the cathedral must attain an otherworldly appearance - in its statuary and stained-glass, in its sheer scale and magnificence, and, most crucially, and it's inspired and calculated formal transcendence of earthly limitations. It is medieval humanity's visionary conception of transcendental reality, the ultimate architecture of the age of faith."
}

Although the cathedral expressed the idea of a heavenly perfection unmatched here on earth, it is through the experience of the earthly architecture with its use of proportions, expressive structure, incoming light and pictorial storytelling on mosaics and stained glass, that a sense of divine beauty and perfection is conveyed. In this example, architecture is physically rooted and acts as a vehicle connecting the reality of everyday life with a religious experience of the Christian church through various layers of meaning. ${ }^{5}$

\footnotetext{
${ }^{4}$ Trachtenberg and Hyman 2003: 225.

${ }^{5}$ Trachtenberg and Hyman 2003: 225.
} 


\subsection{Transferring knowledge through physical surface by reading the building through the physical elements, senses and experience. Notre Dame Cathedral as example.}

Stained glass offers a window to the literate and illiterate alike. Through its craft and biblical stories, it exhibits manifestations of human needs, thoughts and knowledge in a particular time and religion for the people viewing it.

"Cathedrals embody man's relation to the divine. Images impress themselves upon the mind..... They can be read by the literate and the illiterate alike, and they are destined for both" 6

The physical architecture and its elements contained information on its surfaces. The information here refers to signifiers and signifieds. Signifiers are the materials and enclosures such as surfaces, spaces, volumes, tactility, noise, kinesthetic qualities and colour. Signifieds are the ideas, values and ways of life reflected in social customs, manifested through iconological meanings. ${ }^{7}$ Reading entails deciphering meanings that have been bestowed into materials and elements through material and physical transformation. In this case architecture is the medium for transferring knowledge to people by their reading the messages on its surfaces.

In John Hendrix's book, Architecture as Cosmology: Lincoln Cathedral and English Gothic Architecture, the author explains that the Gothic cathedral architecture is an expression of theological, epistemological (scholastic), and philosophical ideas. ${ }^{8}$ To him the cathedral's architecture is not merely about structural need but expresses metaphysics and perception in human reason. ${ }^{9}$

\subsection{1}

Reading physical surfaces and elements
"Elements original to Gothic buildings,
including flying buttresses, Windows with
tracery, and piers composed of colonnettes
or shafts bundled around a corner... One
can define Gothic buildings by their spatial
characteristics, which tend to emphasize the
vertical, consist of articulated but unified
cells of space, and have a sense of openness
afforded by the construction system. Lastly,
the style can be seen as a reflection of the
historical era and religious imagery of that
in which it was built."
Fazio, Moffett and Wodehouse 2009: 213 .

\footnotetext{
${ }^{6}$ McLuhan 1962: 109.

${ }^{7}$ Broadbent, Bunt and Jencks 1980: 73-74.

${ }^{8}$ Hendrix 2011: 3 .
}

${ }^{9}$ Hendrix 2011: 22. 
They communicate the universal structure by what he calls an "intelligible structure" that is combined with its physical form. ${ }^{10}$ The form is not only a structural necessity, but rather it expresses a "disjunction between form and function, for the purpose of expressing an idea. ${ }^{11}$ One idea is that God's spiritual light is transformed into mathematics and geometry. ${ }^{12}$ This is conveyed by figures, lines, and organization in the building and by dematerialization of the visual experience through stained-glass windows. ${ }^{13} \mathrm{He}$ discusses the ascension of the intellect into the spiritual from the physical and how the cathedral design accomplishes this. The visitors focus on geometry and mathematical structure as a result of the pattern of light entering into the stained-glass windows and this, in turn, leads the person through ascension to God. This ascension encompasses scholastic characteristics evident in compartmentalization and dematerialization, in order to develop higher intellect. ${ }^{14}$

Even though it can be said that the stained glass windows such as those at Notre Dame (see fig. 4 \& 5) are like a "Bible for the illiterate", without inscriptions that identify figures within these windows, it is difficult to know definitely if they were actually understood. The significance of light within these spaces could have also been difficult to comprehend. However, the meaning of windows could not be missed entirely. The stories within the stained glass were a means of conveying the metaphoric concepts of Christian theology to the people going to the cathedral. The stained glass images told a story and the filtering of light through the glass filled the cathedral with immaterial colours creating an

\footnotetext{
${ }^{10}$ Hendrix 2011: 4.

${ }^{11}$ Hendrix: 9.

${ }^{12}$ Hendrix: 3 .

${ }^{13}$ Hendrix 2011: 24.

${ }^{14}$ Hendrix 2011: 5 .
} 
effect of unearthly light that added to the overall experience. ${ }^{15}$ The position of windows was important to capture the sun's rays at specific times of the year and day. This served to illuminate and create the atmosphere for the story. ${ }^{16}$

\section{Notre Dame Cathedral, Paris - South Rose Window (Detail)}

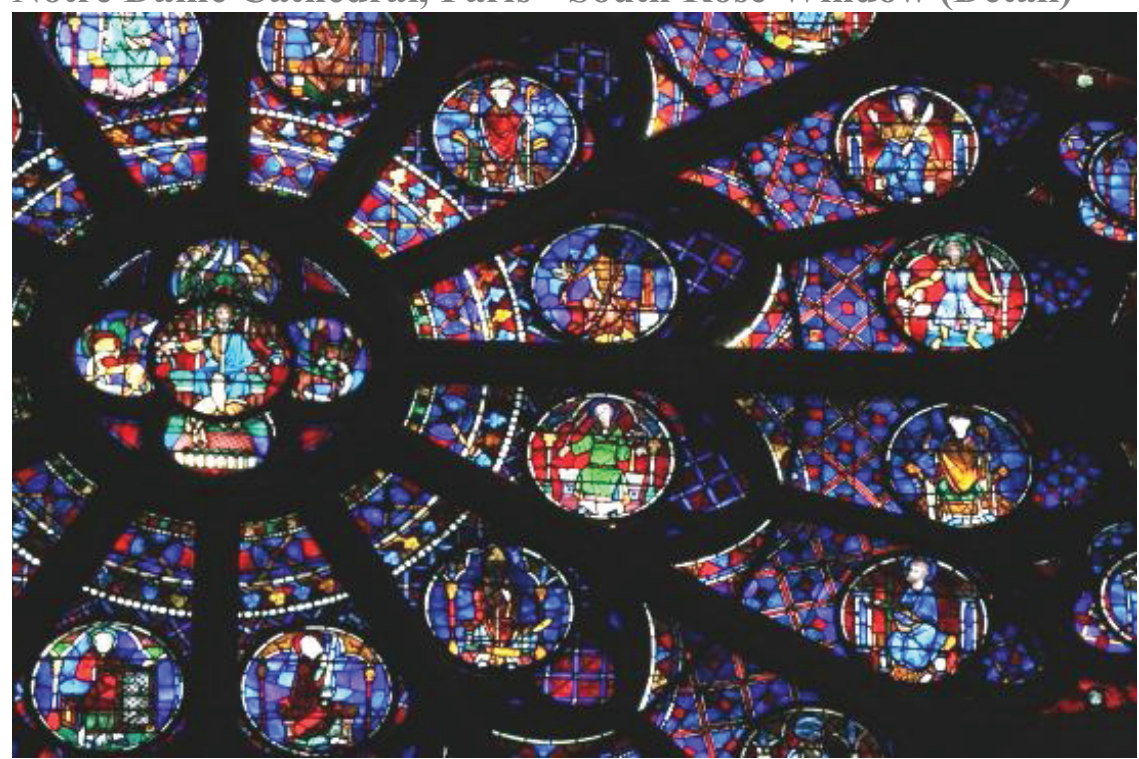

Figure 5
Notre Dame Cathedral, Paris - South Rose Window (c.1260)

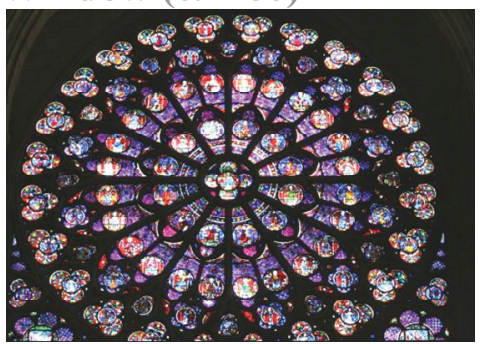

Figure 4

"The south rose window, donated by King St. Louis and installed c.1260. Its general themes are the New Testament, the Triumph of Christ, and the symbolic number four.... In the third and fourth circle are scenes from the Life of St. Matthew that date from the 12th century..... The original medallions surrounding it include: 12 apostles (in the first and second circles), 20 angels carrying a candle, two crowns and a censer (fourth circle); the Wise Virgins; biblical scenes including the flight into Egypt, healing of the paralytic, Judgement of Solomon, and Annunciation (third and fourth circle); saints and martyrs including Lawrence with his grill, Denis holding his head, Pothin (Bishop of Lyon), Marguerite and a dragon, Blandine and two lions. George, Ambrose, and Eustacius; scenes of exceptional quality dating from the 12th century, depicting the Life of St. Matthew (third and fourth circle). The corner pieces depict: the Descent into Hell (left) with Moses and Aaron (top) and temptation of Adam and Eve (bottom); and the Resurrection of Christ (right) with Peter and Paul (top), and Mary Magdalene and John (top).'

〈http://www.sacreddestinations.com/france/paris-notre-damecathedral-photos/slides/xti 9834 (Accessed on 26/03/2013)

\footnotetext{
${ }^{15}$ Honour and Fleming 2005: 381.

16 "The windows admit far less light than one might expect. They act meaning as diffusing filters to change the quality of daylight, giving it the poetic and symbolic values... The sensation of ethereal light dissolves the physical solidity of the church and, hence, the distinction between the temporal and the Divine realms. This "miraculous light" creates the intensely mystical experience that lies at the heart of the Gothic spirituality.... use otherworldly light to convey spiritual messages: on the one hand, filtering through stainedglass, and on the other, reflected off gold-glass mosaics." Davies, Denny, Hofrichter, Jacobs, Roberts and Simon 2007: 400-401.

${ }^{17}$ Davies, Denny, Hofrichter, Jacobs, Roberts and Simon 2007: 400-401.
} 
Rose windows are significant because they not only express a biblical tale but they are a story in themselves. The techniques and materials in which the biblical story was set also told the story of the period's architectural advances and achievements. This is evident in the complex stone tracery (See fig. 6) that was filled with stained glass to create a thinned out wall of stone lines that allowing light to pass through instead of having a visually heavy solid surface. Great technical skill was required to create this effect. Making the stained glass windows was difficult because of the large scale and mapping of the design that was required before the work could begin. The window planning necessitated coordination with the overall design so that the geometric relationships of the individual windows related to those of the building. ${ }^{18}$

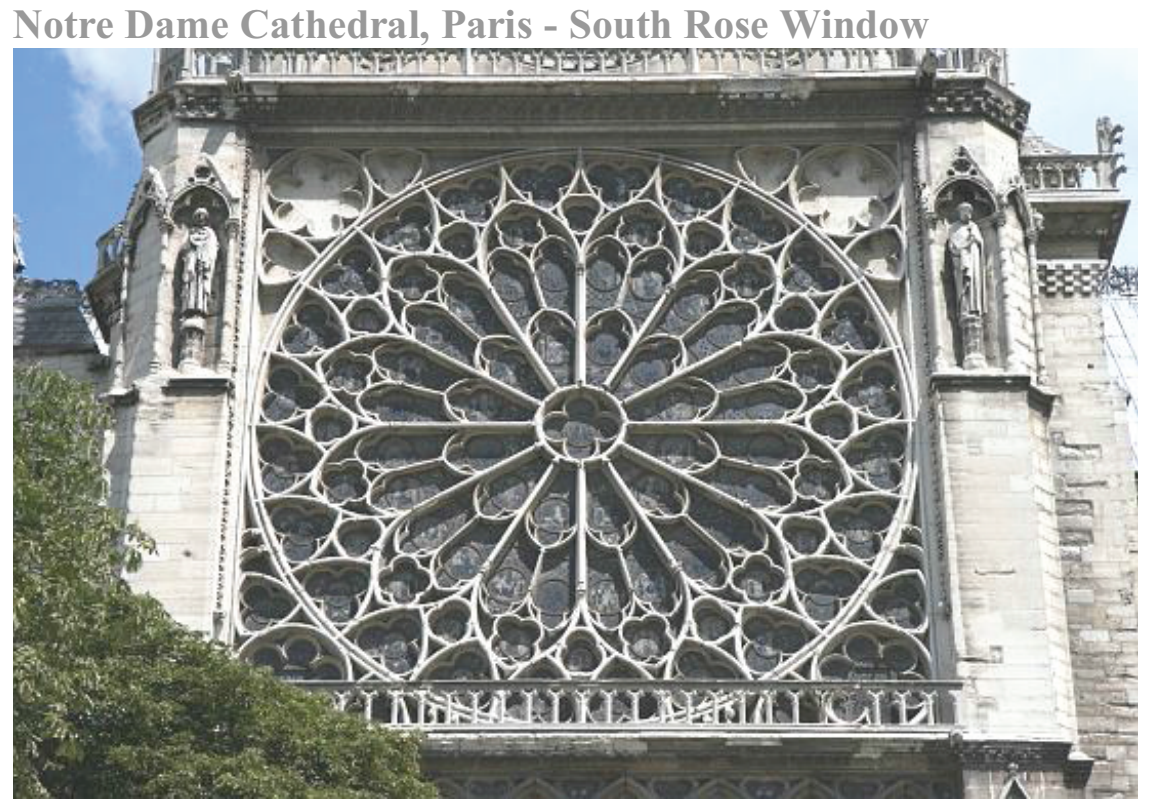

\section{Figure 6}

Another instance of elements both telling a story and being the story can be found in the stone elements on the walls that expressed the stories of Christian theology. Materials used in the

\footnotetext{
${ }^{18}$ Davies, Denny, Hofrichter, Jacobs, Roberts and Simon 2007: 401.
} 
sculptures illustrate the craftsmanship of the people working with them. Through intricate detailing, it is evident to the viewer that a human mind and body guided the work and that it took great care to create. Richard Sennett in The Craftsman (2008) discusses the human desire not just for skilled manual labour but for a good job based on values. The exterior of Notre Dame's west façade emphasizes proportion, geometric order and harmony. This formal emphasis is also evident in the placement of the sculptures and in how there is an assigned role for every element in the framework of the scenes (see fig. $7 \& 8$ ). ${ }^{19}$ One example of the Gothic architecture style of sculptures on the cathedral walls is evidenced by the Last Judgment Portal on the west side of Notre Dame (c.1230).

Notre Dame Cathedral, Paris-Last Judgment Portal: Christ in Majesty

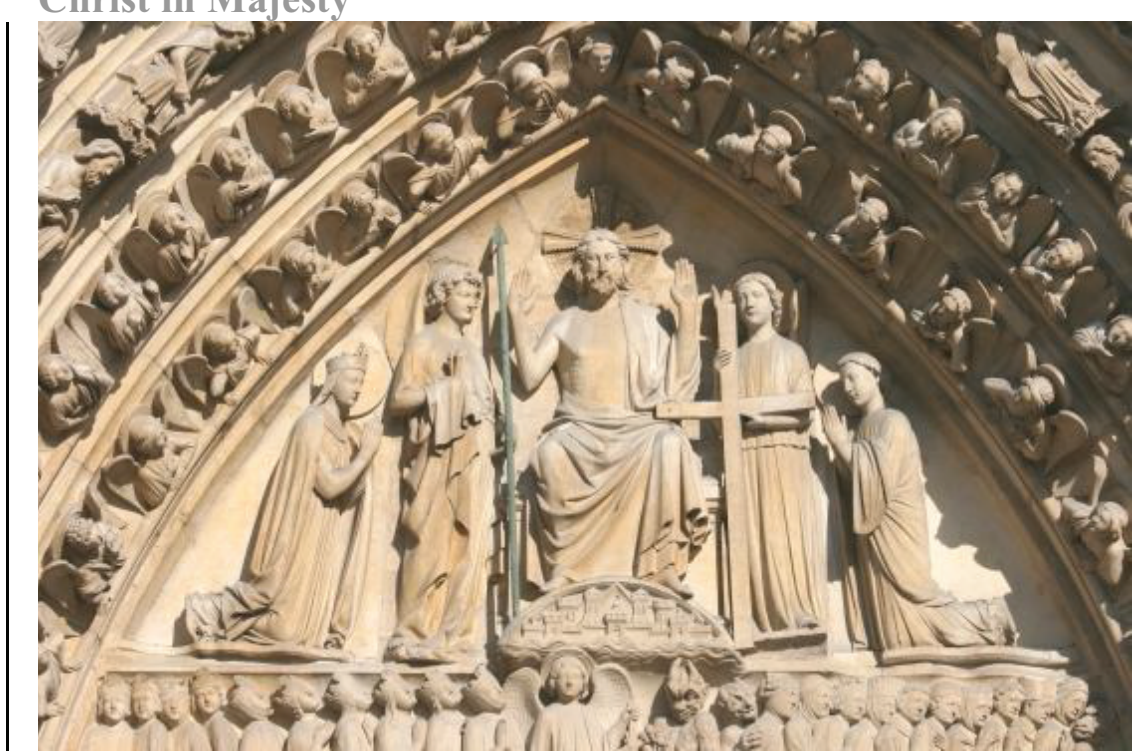

Figure 8

"Tympanum ---> Christ in Majesty with an emphasis on his sacrifice for humanity. Christ displays his wounds, flanked by angels with instruments of the Passion (spear and cross). On the left and right are kneeling figures of the Virgin Mary and St. John, who were present at the crucifixion. ${ }^{, 20}$

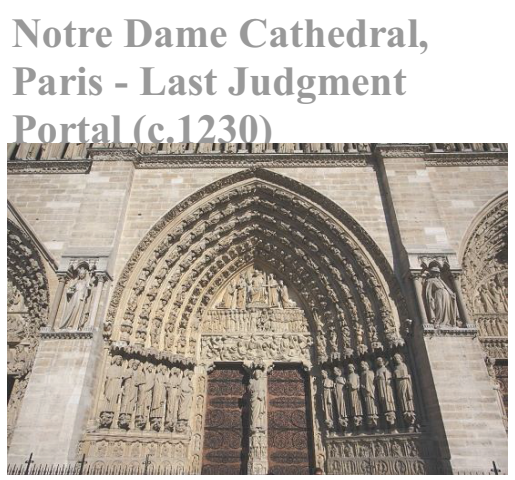

Figure 7

Last Judgment Portal (Center West Portal). The central west portal was sculpted last of the three, in the 1220s and 1230s, and its theme is the Last Judgment, with Christ emphasized less as judge and more as the suffering savior of humanity.

〈http://www.sacred$\frac{\text { destinations.com/france/paris-notre-dame- }}{\text { cathedral }) \text {. (Accessed on 26/03/2013). }}$

\footnotetext{
${ }^{19}$ Davies, Denny, Hofrichter, Jacobs, Roberts, and Simon 2007: 396.

${ }^{20}$ http://www.sacred-destinations.com/france/paris-notre-dame-last-judgment-portal.htm〉. (Accessed on 26/03/2013).
} 
Technology and construction materials change over time, and so do the skills and techniques used in knowledge transfer. There is an implicit ambiguity when thinking about technology. There is the technology involved in constructing buildings and the technology involved in inscribing knowledge. Richard Sennett in The Craftsman, explains that in the twelfth and thirteenth century the State and the Church in Paris celebrated together with the building trades that performed physical labour such as the glass blowers, carpenters and carvers. $^{21}$ However, the Industrial Revolution that took place in the eighteenth century created a tension between the machine and the craftsman because the machine can work ceaselessly, something impossible for the craftsman. $^{22}$

The current evolution of technology as an innovative medium allows more ideas and information to be recorded and produced faster, with greater precision and to be distributed to a greater segment of the population. Over time, the shift in the basic methods of transferring knowledge within Western culture has led to an altered experience and to altered physical interactions between people. The mass production of materials has the potential to alienate us from emotional involvement with them. This can be seen in building construction when building elements are put together in a seamless way, minimizing imperfections and joints. These can be created and controlled by computers, leaving little evidence of human work with its inherent irregularities and imperfections. For example Sennett explains in The Craftsman that machines are able to produce quantities of objects that are uniform; however he notes that favoring quantity over quality could potentially dull our senses. This is because the 'perfect' and

\footnotetext{
${ }^{21}$ Sennett 2008: 56

${ }^{22}$ Sennett 2008: 39.
} 
uniform product made by machine does not evoke a personal response. $^{23}$

Sennett explains that competition and a moral obligation to do good work in the modern world did not prove successful. The design of the buildings may have been good yet the quality of the work did not keep up with it. According to Sennett, this was evident in the construction of details. He uses the example of how prefabricated windows that were precisely designed off site in a manufacturing plant and later brought to the building site and placed into the rough opening of the poured concrete did not have a quality joint. The window and the concrete wall were not joined with great care and this could be seen in the seams of caulking joining the two elements. ${ }^{24}$

The experience of Notre Dame's monumentality and proportions is altered when viewing it virtually from anywhere in the world. The sculptures, for example, of the West façade can be appreciated in more detail by physically being there. Although the overall image can be seen from a distant location, the irregularities and individual elements are less noticeable from far way. For example, none of the three portals are the same size or shape, and the towers are not equal in width. The sculptural programs express Christian teachings, and when climbing the stairs people can get a | close view of individual details along the way. ${ }^{25}$

"Light has turned into quantitative matter and the window has lost its significance as a mediator between two worlds, between enclosed and open, interiority and exteriority, private and public, shadow and light having lost its ontological meaning, the window turned into a mere absence of the wall. Use of enormous plate windows deprives our buildings of intimacy, the effect of shadow and atmosphere. "26

\footnotetext{
${ }^{23}$ Sennett 2008: 109 .

${ }^{24}$ Sennett 2008: 28.

${ }^{25}$ Fazio, Moffett and Wodehouse 2009: 218 - 219.

${ }^{26}$ Pallasmaa 2005: 47.
} 
Large glazing panels, previously unavailable, produce an atmosphere different than that from traditional glazing. This is evident with the light and shadow produced by a smaller opening within a wall versus a larger opening in a wall that allows a large amount of light in, creating a more uniform experience of light and shadow within a place. The Church of the Light in Ibaraki by Tadao Ando is one example of this. It is a sacred space of small scale. The church has a cross opening in a wall situated behind the altar (see fig. 9). ${ }^{27}$ The small concrete space has great expression within it created by filtered light and unadorned materials (see fig. 11). The faithful come to pray, listen and sit on the wooden pews in the concrete container. The only light within the space enters, not from the ceiling, but through wall slits resembling a cross, creating peace and sanctity within its environment. The wood floors have rough textures that are painted black to offer a heightened optical effect within the space (see fig. 10). ${ }^{28}$

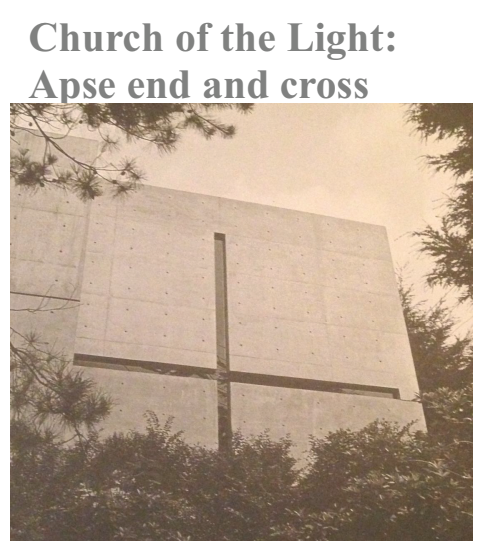

Figure 9

Church of the Light: detail of pews and wooden

flooring.

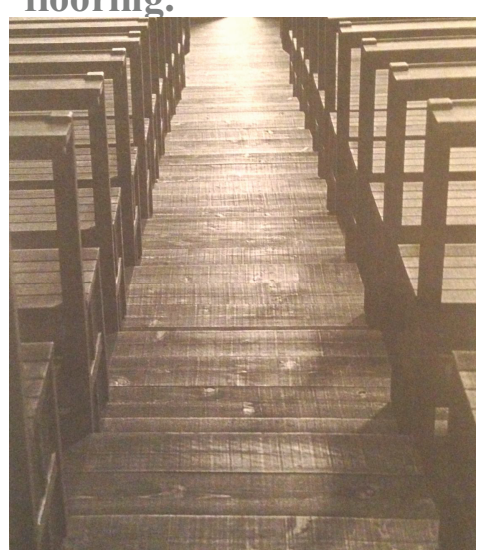

Figure 10

\footnotetext{
${ }^{27}$ Dal Co. 2010: 268.

${ }^{28}$ Kazukiyo 1998: 129-132.
} 
Church of the Light, Ibaraki (Osaka): sanctuary, looking toward chancel

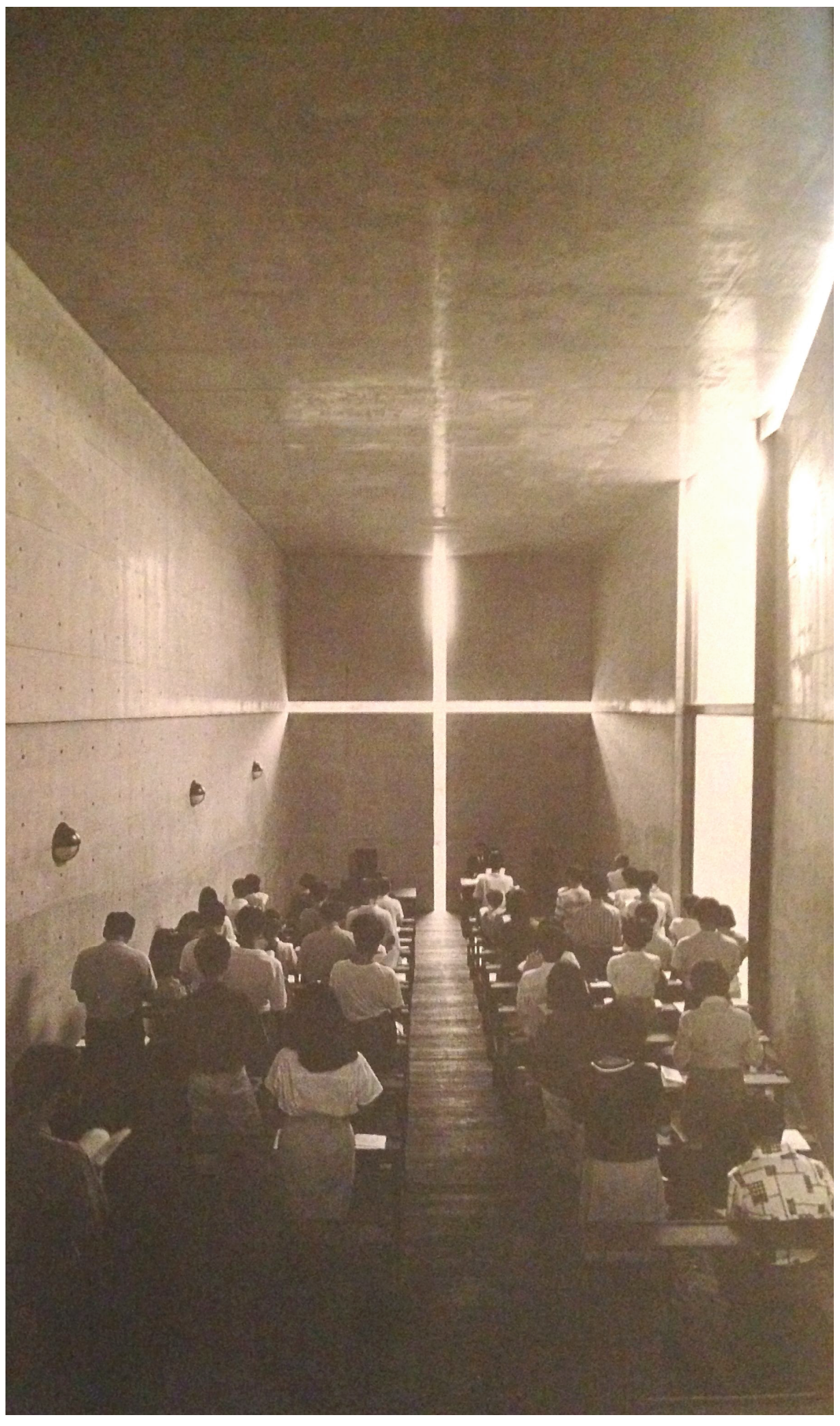

Figure 11 
It is not only the physical elements that are important to an experience. The senses play an important role as well. We not only visually see stories on stained glass and sculptures on walls, but we can measure the scale of a place in comparison to our own bodies. We can hear how the sounds resonate and we can touch the materials, which have textures and temperatures of their own. It is the engagement of all of our senses as we interact with the environment that produces an experience.

Architecture defines human physical presence in the world and creates memorable experiences. Architecture creates place by manipulating the way in which the physical world is experienced. By place I am referring to a physical location and physical materials, which define human existence within the physical world. In contrast, viewing a space from a virtual setting offers a diminished experience. Although a person can rotate a view in a virtual setting, senses other than sight are disconnected from the architectural experience. In this case the digital display is the medium through which interaction occurs rather than the body's own skin. Our physical interaction with architecture is closely linked to our ability to discern meaning. A digital representation, however detailed or realistic, cannot satisfy our basic core needs, those of our senses.

According to Juhani Pallasmaa's text Eyes of the Skin, all of our senses are extensions of the tactile sense and the tactile sense is important for our experience and understanding of the physical world we inhabit. ${ }^{29}$ The physical world has textures, smells, sounds, spatial dimensions. Pallasmaa discusses how all senses are engaged in a tactile way in providing us with lived

\footnotetext{
${ }^{29}$ Pallasmaa 2005: 10.
} 
experience. If this is true, it is important because skin acts as an interface that reads texture, weight and temperature allowing touch to integrate our experience of the exterior physical world with the interior world of the self. In this way we are not separated from the physical world but are in constant interaction with it.

Pallasmaa also talks about the constant movements of the physical body as it interacts with the environment it inhabits. As a result of this interaction the physical body becomes redefined with the world. The sensory experiences become integrated through the body and the body becomes the reader of the building. The body reads the building because physical place has, among other things, a measurability and a geometry. This is important because by experiencing a place through movement, memorable impressions are generated. For example in the cathedral, pews and kneelers have not been designed and made for the comfort of the body. The surfaces are hard and discomfiting to remind the faithful of human imperfection vs. the perfection of God who is represented on the altar that is raised a few steps above the floor of the 'earth'. In this case the religious message has been reinforced by manipulating of the way the body experiences the space.

"There is an inherent suggestion or action in images of architecture, the moment of' active encounter, or a 'promise of function' and purpose. Consequence of implied action a bodily reaction is an inseparable aspect of the experience of architecture." 30

\footnotetext{
${ }^{30}$ Pallasmaa 2005: 63.
} 
The ear is also important because it has the power to collect spatial cues related to the scale, form, and materiality of the place one is in. Different sound sources interact with spatial elements and surfaces, allowing for an interpretation of surface and space. ${ }^{31}$ This gives one the ability to create an image in one's mind that relates to the place and its characteristics even when the eyes are closed. The way architecture is arranged and the materials and combinations chosen in turn affects how we feel, hear and see spaces. Hearing and listening play a part in our experiences that stimulate emotion, communicate information and experience time. ${ }^{32}$ Spaces can influence and have an effect on associations and also on moods. Blesser and Salter discuss how a "grand Cathedral can create an exalted mood; those of a chapel can express the privacy of quiet contemplation." 33 Reverberation in a religious space can express a feeling of reverence and awe. The sounds one hears by physically going to a place, therefore, are important for measuring the boundaries of a place. ${ }^{34}$

"Every building or space has its characteristic sound of intimacy or monumentality, invitation or rejection, hospitality or hostility. A space is understood and appreciated through its echo as much as through its visual shape, but the acoustic percept usually remains as an unconscious background experience." 35

Since every place has a unique sound quality of its own and the sounds vary depending on where you stand within the space it is difficult to simulate this sensation. For instance sounds can be used within a place to heighten an experience. Whether purposefully designed or not, acoustics are an essential component in the design of the cathedral. A priest's voice that carries the word
"Physical sound is a pressure wave that transports both sonic events and the attributes of an acoustic space to the listener, thereby connecting the external world to the listener's ear."

Blesser and Salter 2007: 12.

\footnotetext{
${ }^{31}$ Blesser and Salter 2007: 2.

${ }^{32}$ Blesser and Salter 2007: 4

${ }^{33}$ Blesser and Salter 2007: 2 .

${ }^{34}$ Blasser and Salter 2007: 12.

${ }^{35}$ Pallasmaa 2005: 50.
} 
of God is made to reverberate within the structure so that even people far away from the priest can hear the voice. Here the eye and the ear work together to convey being in the deity's home. ${ }^{36}$ Blesser and Salter use England's Chester Cathedral as an example because it "contains six recesses where kneeling pilgrims inserted their heads while petitioning their saint. The geometry of these recesses, with their strong resonances and powerful amplification, created the feeling of an interment encounter with the saint., ${ }^{, 37}$

Another example of how sound affecting our experience is evidenced when one enters through the cathedral's grand portal. One enters through the portal then enters into the narthex, designed as a smaller volume compared to the larger exterior and interior volumes. It acts as a buffer to muffle sounds from the exterior and allows the ear to adjust to the nave's larger vertical volume inside. By creating these audio oppositions, the visitor is made aware of the transition from the chaos of the exterior to the solitude of the interior, symbolically leaving the chaos of earth and entering the solitude of God's kingdom. ${ }^{38}$

According to Pallasmaa "the most persistent memory of any space is often its smell",39 Smell is a very unique sense because every building has its own. For example, someone going to mass at Notre Dame for several years would have a very strong association with it through their sense of smell. During each religious ceremony or mass, incense is burned to sanctify the space. Due to the repetitive nature of this task, incense becomes one of the smells that we associate with Notre Dame. Scent can automatically trigger a memory of a place even if we do not

\footnotetext{
${ }^{36}$ Blesser and Salter 2007: 3 .

${ }^{37}$ Blesser and Salter 2007: 88 .

${ }^{38}$ Blesser and Salter 2007: 32.

${ }^{39}$ Pallasmaa 2005: 54.
} 
completely remember it visually. As a result, we can associate a distinct smell with the place we experienced it in.

Architecture highlights our experience with the world and our relationship to it. By physically going to a place like Notre Dame Cathedral our experience is shaped by all of our senses. This creates a memorable image of a place based on its materials, the way our muscles move through the different spaces, the various sounds that occur in different areas, smells and visual changes that occur throughout the day as light enters inside casting shadows. All of the senses are being used in the Gothic cathedral and are shaping our experience of this particular place.

The physical elements of the Gothic cathedral convey the story of its religion and the senses strengthen a person's physical presence in the world through the physical qualities of the place. Together elements and senses shape our experience. In physically visiting a location, impressions are gathered and encoded as knowledge that is based on our experience of that place. Each site has its own unique qualities and is multi-sensory as seen in the cathedral example. Many of these unique qualities cannot be perceived if the cathedral is experienced as isolated images on a computer.

"The authenticity of architectural experience is grounded in the tectonic language of building and the comprehensibility of the act of construction to the senses. We behold, touch, listen and measure the world with our entire bodily existence, and the experiential world becomes organized and articulated around the centre of the body.... We are in constant dialogue and interaction with the environment to the degree that it is impossible to detach the ${ }_{40}$ image of the Self from its spatial and situational existence."

\footnotetext{
${ }^{40}$ Pallasmaa 2005: 64.
}

1.1.3

Experience of physically going to a place 
The design and construction of the Gothic cathedrals conveyed the beliefs of those who conceived of it. The advances in construction and technology of the day were used to augment the experience. The brilliant engineering produced elements that seemed more delicate than their actual weight. ${ }^{41}$ The characteristic features in this cathedral that permitted the creation of the impression of ethereality and included the ribbed vaults (see fig. $12)^{42}$ and the flying buttresses (see fig. 13). The ribbed vaults in the cathedral used over the nave and aisles helped to transfer the loads onto the columns, walls, buttresses and piers. This transfer of weight to the exterior of the building reduces the appearance of heavy mass structure on the interior. ${ }^{43}$ This creates a sensation of weightlessness in a large stone mass. It allows an emphasis on verticality in our experience because it draws the eye to move up metaphorically towards heaven (see fig. 14).

${ }^{41}$ Davies, Denny, Hofrichter, Jacobs, Roberts and Simon 2007: 397.

${ }^{42}$ Trachtenberg and Hyman 2003: 225.

${ }^{43}$ Trachtenberg and Hyman 2003: 225. 


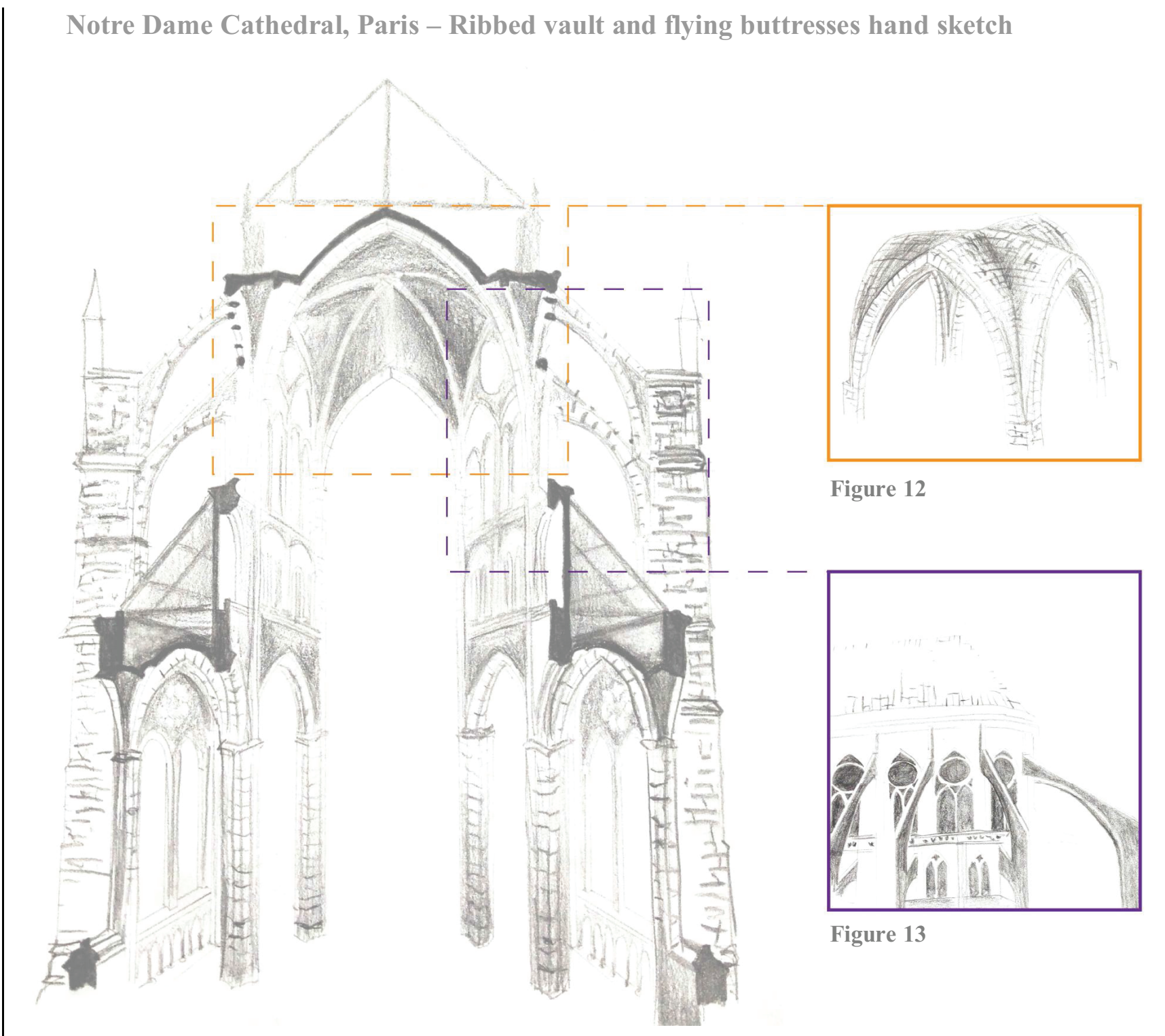

Figure 14 
Once inside the cathedral our eyes adjust to the lower light levels and the expressive structure allows stories of Christian theology to be told through the experience of the constructed atmosphere. The arrangement of the arcade and the invention of the flying buttresses has created a sense of lightness. These developments allowed the experience of verticality to be heightened due to the weight transfer of the heavy construction to the outside of the building, freeing the plan. The ability to move the heavy elements to the outside of the building further enhanced the effect. Glazing was inserted into the walls allowing more light to enter producing the experience of near weightlessness and verticality. The flying buttresses had a structural purpose, but were also an important aesthetic feature. ${ }^{44}$ The architecture served as a vehicle that allowed the people to connect to the experience of their Christian beliefs.

\subsection{Physical experience $\rightarrow$ Reading text. Implications of reading a book about a Cathedral versus going to the Cathedral}

Social interaction is essential in order to avoid the isolation that results from lack of communication. Forms of communication such as the Internet are efficient, but do not allow for the reading of body language that face to face communication affords. According to Walter Benjamin, the actual art of storytelling is to leave the story free of explanations so that the individuals can retell and interpret it in their own way. This gives the story has a narrative beyond its content. Based on the way we choose to gain information today, quickly and precisely instead of sharing more in-depth experiences and stories, we lose the ability to retain the stories, share them and repeat experiences; therefore we lose the

\subsection{1}

Physical experience of a place versus reading silently about it

44 Trachtenberg and Hyman 2003: 225-226. 
ability to learn from one another. ${ }^{45}$ Storytelling has become uncommon and the distribution of information not left to interpretation, has played a role in that regard. ${ }^{46}$

Reading about a cathedral through the information someone else gathered provides a different type of learning experience than that faced by physically going there. Looking at photographs taken by another person predetermines what one sees. The photographer is selective in choosing the angles, the areas and details to generate their vision of a multi-sensory experience for the viewer of the images. The interpretations and experiences of a place vary so when you read about someone else's experience, the place is narrowed to the lens of the author. We pay closer attention to experiences if we have the opportunity to have a personal encounter with the place. And this is based on our interactions and they can vary from culture to culture, from person to person, from time to time. ${ }^{47}$

When information is given to us, it is providing a focused vision of the author's interpretation of the physical world. If we look at facts alone, little is left to the imagination and to one's ability to dream of potential interpretations. Yes, some forms of writing, such as novels, allow us to use our own imaginations in constructing individual interpretations, but this differs from the physical experience of a concrete reality. For example the expression of light in Gothic cathedrals was used to blur the boundaries between the physical presence and the potential reality of the unknown. In books about cathedrals, we can read about the metaphorical evocation of filtered lights but we do not get the full

\footnotetext{
${ }^{45}$ Benjamine 2002:149.

${ }^{46}$ Benjamine 2002: 147 - 148 .

${ }^{47}$ Hall 1984: 108.
} 
experience of the light and shadow, the scale of the overall space in relation to our own body, and material textures.

\subsection{Physical experience $\rightarrow$ Digital transition. Viewing virtually from a distance through the digital medium. Virtual Notre Dame as an example}

With advancements in technology we can now visit a place such as Notre Dame Cathedral virtually by accessing a website (see fig. $15 \& 16){ }^{48}$
1.3.1

Invention of innovative medium thanks to technology allows viewing a place virtually possible

Notre Dame Cathedral, Paris - Virtual tour options to explore on a virtual tour
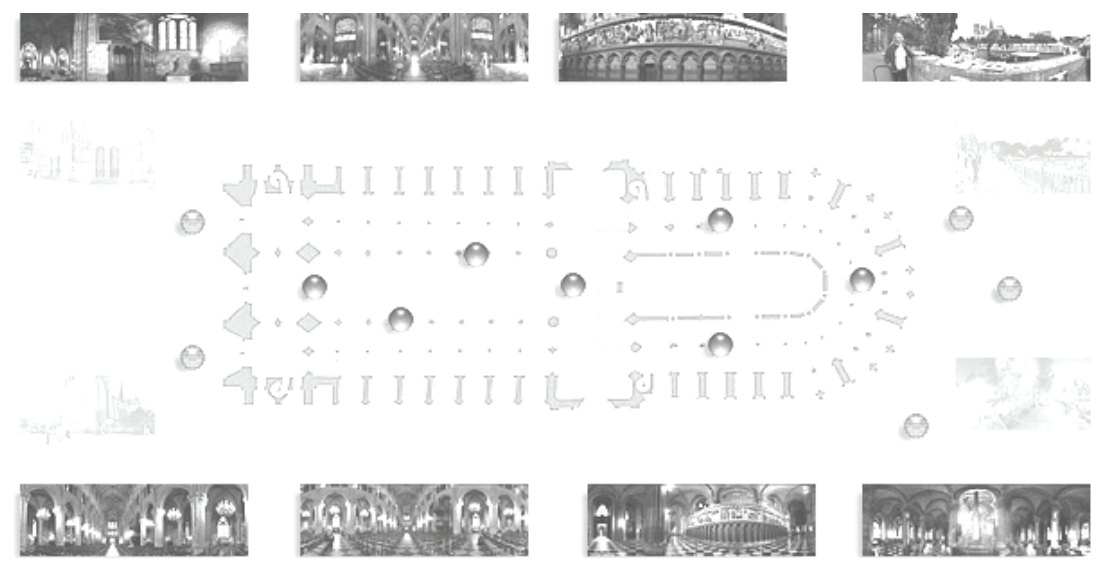

Figure 15

Notre Dame Cathedral, Paris - Virtual tour entrance

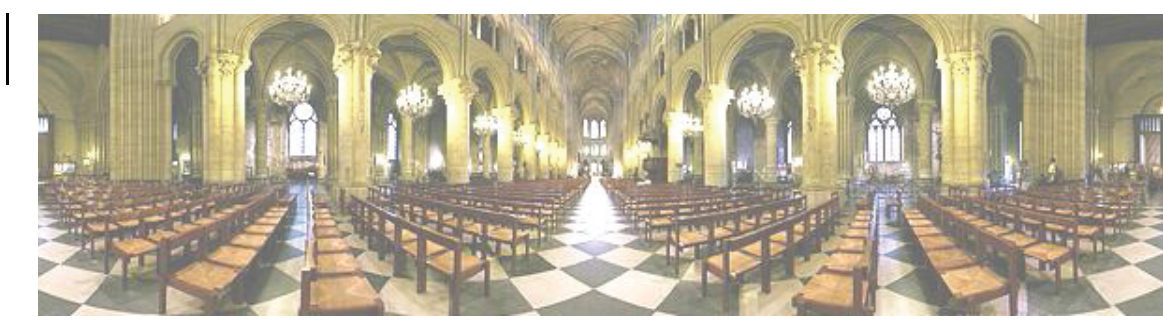

Figure 16

${ }^{48}\langle$ http://www. fromparis.com/virtual-tour-notre-dame/. . (Accessed on 26/10/2013). 
Virtual reality and the ability to engage in a simulated walk-through via computer generation have existed for some time. Spatial simulation relies not only on displayed images, but also tries to generate a perception of realism through field of view, lighting, sound and texture. Light is important for our perception of the space in a simulation. The virtual reality environment can change according to different conditions of light and can be manipulated to mimic the effects of different seasons and sun angles. ${ }^{49}$ In a simulation, sound volume can be increased or decreased as someone approaches a source, aiding in the perception of the space. However, similar acoustic qualities can mean different things depending on what social setting it is viewed in. ${ }^{50}$ Particular senses become privileged in different cultures. The way people respond to spatial acoustics depends on their biases, culture, and context. ${ }^{51}$ Blesser and Salter discuss how the architect has the ability to discourage or encourage the cohesion of people that inhabit a particular place. ${ }^{52}$ When people in one culture are exposed predominantly to particular sounds, the listeners could have a consistent perception ${ }^{53}$ yet, the auditory awareness of space encompasses more than perception, but also sensation and effect. ${ }^{54}$ Texture is also an important quality to look at in a simulation. To avoid a static quality of texture mapping, things like pressure sensation, smoothness or roughness could be added so that the skin experiences haptic sensations. A sense of full immersion within the virtual environment is crucial so that the viewer can manipulate the environment to allow for a natural range in how our bodies move in response to a variety of human actions. ${ }^{55}$
"VR systems usually provide at least monophonic sound, which can be complementary to the visual rendering but does not provide a realistic simulation of our sound perception. Stereoscopic sound with the system differentiates the components of a sound into left and right. In spatial sound sources of signals do not come only from left and right but from every spatial position. Spatial perceptions can be greatly enhanced if the location of a sound is detectable, especially if associated to the simulation of responses to acoustic signals according to the different materials."

Bertol and Foell 1997: 113.

${ }^{49}$ Bertol and Foell 1997: 96.

${ }^{50}$ Blesser and Salter 2007: 3 .

${ }^{51}$ Blesser and Salter 2007: 66.

${ }_{52}^{52}$ Blesser and Salter 2007: 5.

${ }^{53}$ Blesser and Salter 2007: 13.

${ }_{54}^{54}$ Blesser and Salter 2007: 14.

${ }^{55}$ Bertol and Foell 1997: 121. 
Virtual reality attempts to re-create a physical reality that would otherwise not be within our reach due to distances or opportunities. It tries to create an environment in which the computer and its devices become extensions of certain senses. Although virtual quasi-reality can be realistic, it still isolates people from the actual experience because we do not exist in a simulation. No place can be perfectly simulated to recreate a fully immersive experience satisfying all the senses. For example, Notre Dame Cathedral in Paris has a virtual tour, allowing a walkthrough of the interior showing the texture mapping by moving the camera at different angles and allowing the viewer to zoom in and out. Yet the tour cannot substitute for all the lighting conditions, the sounds associated with in the various volumes, the temperature, etc. in the space. The world and our experiences within it are comprised of many elements and the interaction of all our senses with these elements.

Although a simulation could be developed to try to replicate a particular place, it would not create the experience of a physical place and would be based on the replicators' assumptions of what that place would be. My experience of going to Notre Dame would be different from that of someone else. Having the opportunity to view a building virtually has provided a tool for people who might not be able to physically visit it, but viewing a place on a screen can be very misleading. When viewing virtually, we are missing the multi-sensory experience. This flattens our senses and creates a distance between us and the place. 
The way physical elements are organized creates boundaries offering a distinction between inside and outside. ${ }^{56}$ This is important because architecture hopes to create a sense of place which has physical materials subject to the laws of physics in contrast to digital architecture's cyberspace. Virtual architecture is made of representations which are visual simulations of reality, programmed as sets of numbers. ${ }^{57} \mathrm{We}$ view digital architecture on a computer monitor which has a physical characteristic. The same monitor has the ability to display a variety of different buildings and places from around the world. ${ }^{58}$ Although, cyberspace makes it easier to communicate with others this has a danger of altering how we experience or perceive places because we can accomplish many tasks online without physically visiting a building such as bookstore, or library. The computer brings the experience of the physical world and our senses inside cyberspace which we view on the computer screen. ${ }^{59}$

Physical place matters because only within it can we fulfill our multi-sensory, physical, psychological and emotional needs. This is evident in the Notre Dame example because physical materials are the architectural medium delivering messages to the senses and creating the experience for the viewers. Today, the architectural medium is being blurred because the active experience of a physical visitor has shifted to the passive role of a digital screen. Architecture is more than just a sculptural object. It has physical materials which engage with our senses. We are part of architecture in a figure/ground relationship and we inhabit space where social interactions can happen. ${ }^{60}$

\footnotetext{
${ }^{56}$ Bertol and Foell 1997: 56

${ }^{57}$ Bertol and Foell 1997: 57.

${ }^{58}$ Bertol and Foell 1997: 57.

${ }^{59}$ Bertol and Foell 1997: 60.

${ }^{60}$ Bertol and Foell 1997: 56.
} 


\subsubsection{Conclusion.}

The shift in the way we gather information has led to a change in the way we experience architecture. Recording information through this medium, as demonstrated by the Notre Dame example, illustrates that information was historically presented and embodied by the building itself. Today we have the ability to experience information through a virtual setting. While simultaneously allowing more people to view the cathedral, the absence of a physical interaction with the place including, its elements and other people produces a limited range of experience. Physical architecture is the primary instrument connecting us to a place. ${ }^{61}$ A simulation of a material might be highly rendered, but real materials have texture, temperature, weight, smell, etc. The light coming in to the building at different angles during various times of the day, the different sounds that might be heard from standing in different locations during unique events, the smells of the burning candles or old bibles, the coloured light coming through the stained glass - these all create unique material effects which provide us with a real sense of place.
"Both architecture and sculpture build solid forms with physical material; .... Sculpture can be thought of as a pure built form which follows an aesthetic approach, a building must be inhabited. One of the tasks of architecture is the creation of a manmade environment where specific functions are performed and social interaction happens. This task assigns a certain character to a built form transforming an architectural artifact into a place. The hollows created by solids provide us with .... a suitable physical container for actions of everyday living."

Bertol and Foell 1997: 56.

"Architecture is our primary instrument in relating us with space and time, and giving these dimensions a human measure. It domesticates limitless space and endless time to be tolerated, inhabited and understood by humankind."

Pallasmaa 2005: 17.

\footnotetext{
${ }^{61}$ Pallasmaa 2005: 17.
} 


\section{2}

\section{CHAPTER}

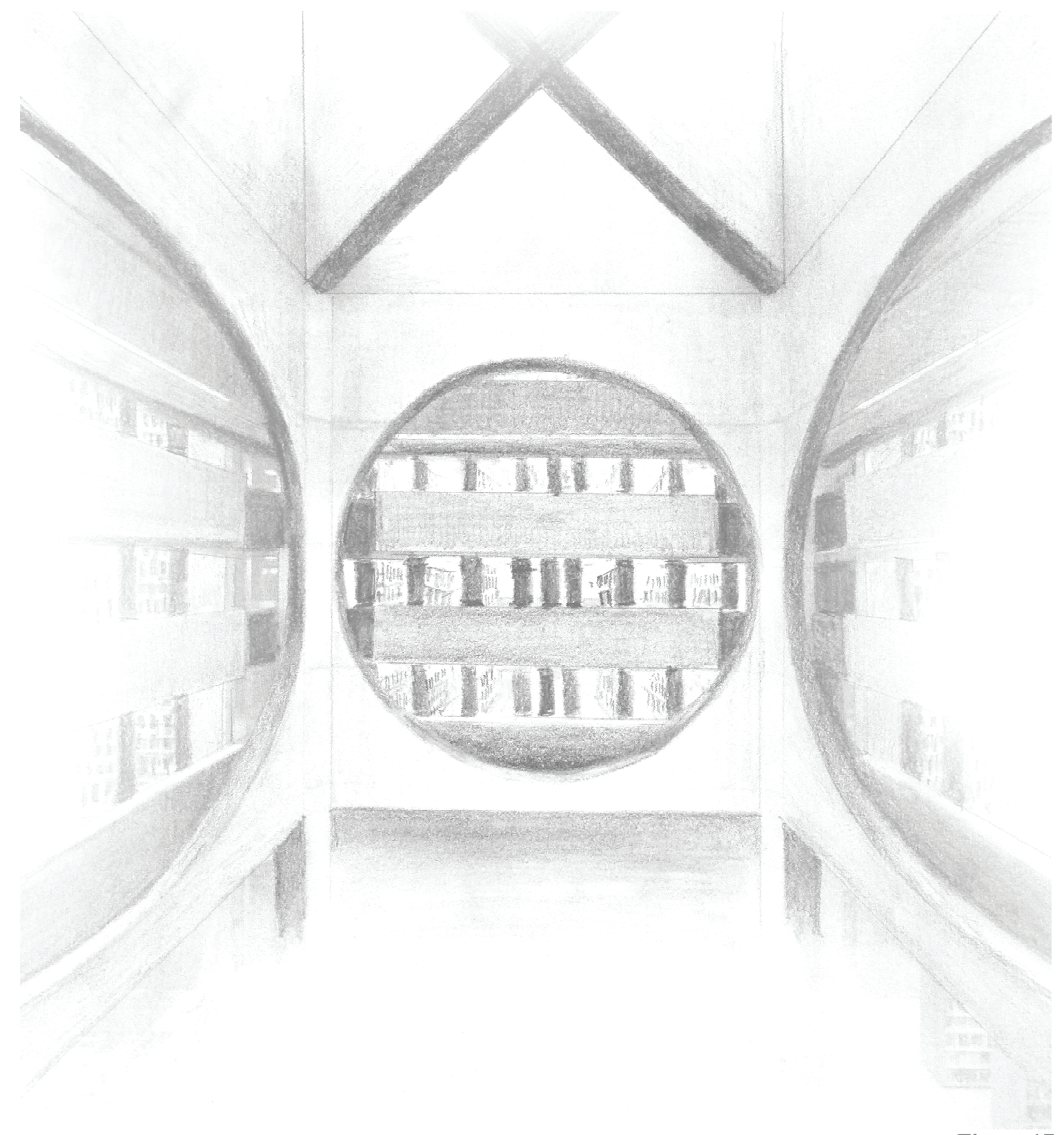

Figure 17 


\section{Chapter: Architecture that houses the message}

Physical libraries that house different forms of information have existed for some time. They began as a collection of information and knowledge. Some of these include the Ancient Library of Alexandria in Egypt (see fig. 18) that tried to contain the recorded knowledge available at the time. Monasteries in the Middle Ages included libraries run by monks that preserved and rewrote precious texts, while libraries in the Renaissance expanded the distribution knowledge to greater numbers of the literate classes. With the invention of the Gutenberg Press there was an increase in the size and number of libraries that stored texts. Now with the electronic medium there is digital access from anywhere and the library can be reduced to a 'vending machine' (see fig. 19), a convenience for the person on the go. Libraries may have come in different shapes and sizes, yet the mandate has more or less been the same throughout history - to preserve knowledge and make it more accessible to all. The housing of information within a library is not random and does have a system of filtering the chosen content that is made available. In some instances there are also

limits on who will have access to that information. The places that house the information have a great potential to create an atmosphere to express and communicate ideas, providing a place for various experiences. In this chapter several library examples such as the Ancient Library of Alexandria, Phillips Exeter Academy Library, Eberswalde Library, Ottawa Public Library and the virtual library or electronic medium will be analyzed. These examples will be used to discuss how the container, its structure, space, materials, content organization and display are utilized to heighten an experience of a place. Through the use of the container and the content, both the Cathedral in Chapter 1 and the libraries in 
Chapter 2 of this paper try to convey a message to the visitor regarding man and his existence in the world.

\subsection{Container: Ancient Library of Alexandria \& Phillips Exeter Academy, Library by Louis I. Kahn \& Eberswalde Library by Herzog \& de Meuron}

One early example of an attempt at collecting and containing textual records is the Ancient Library of Alexandria in Egypt, which was a significant library in its time. It was constructed in the 3rd century $\mathrm{BC}$ and it survived until $30 \mathrm{BC}{ }^{1}$ The library's location was on a seaport creating an opportunity for trading, and helped in making them the main producers of papyrus and shortly after that, books. The organization of books in the Library of Alexandria makes manifest the notion of a universal order. Its purpose went beyond preserving recorded mediums such as books and scrolls, and also satisfied human curiosity by providing a place for recordings to be stored and displayed. ${ }^{2}$

"belief that each of the books made up of these words was its own complex cosmos, each presuming in its singularity to address the whole of creation. ... Library of Alexandria rose when stories took on the shape of books, and strove to find a syntax that would lend each tablet, each scroll its illuminating and necessary place. "3

Ancient Library of

Alexandria

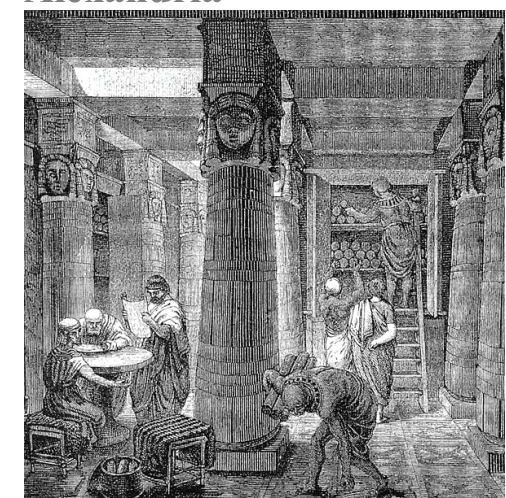

Figure 18
Book Vending

Machine

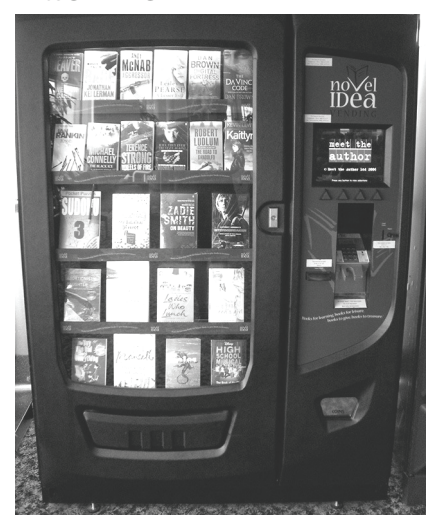

Figure 19
2.1.1

Transition from ascoustics of a space and experience to visual and written form

Manguel 2007: 20.

${ }^{2}$ Manguel 2007: 28 .

${ }^{3}$ Manguel 2007: 24. 
With the invention of the Gutenberg Press our experience of reading and the quantity of available books changed. In his book, Gutenberg Galaxy, Marshall McLuhan discusses how experience and expression have been changed by alphabet and printing. He expresses the idea of language as a metaphor in that it translates and stores experience from one form into another. This is because words in a written form transform experience into textual elements that are in turn transformed from an acoustic to a visual experience. ${ }^{4}$

|

"The mechanization of the scribal art was probably the first reduction of any handicraft to mechanical terms. That is, it was the first translation of movement into a series of static shots or frames... The reader moves the series of imprinted letters before him at a speed consistent with apprehending the motions of the author's mind. The reader of print, that is, stands in an utterly different relation to the writer from the reader of manuscript. Print gradually made reading aloud pointless...."

The term 'literature', which McLuhan refers to as "presupposing the use of letters", , allows verbal knowledge to be transmitted by writing and thereby changing experience because there was no longer a need to meet and listen to a dictation of a lecture when it could instead be recorded and put within a book. Listening by ear and transcribing what you are listening to by hand transitioned into reading alone and holding a book that was already written by someone else.

New knowledge can be gathered more easily because of the printed book. This is evident because the book became portable and could be read at any time, anywhere. Since the digital age, with its paperless reproduction of books and easier access to information online, books no longer need to be accessed in a

\footnotetext{
${ }^{4}$ McLuhan 1962: 124.

${ }^{5}$ McLuhan 1962: 124

${ }^{6}$ McLuhan 1962: 2.
} 
physical library. The experience of taking the time to physically go to a library and rummage through the stacks of books and verbally sharing the stories is becoming less and less frequent.

Yet the library could incorporate all of the cultural communication traditions - oral, written, digital and whatever else the future may bring. The shift from an oral to a written, visual communication had implications for all people. By retelling a story about an experience, people that are listening are able to reinterpret in their own way something useful and relate it to another experience. This is important because it allows for communication to take place by engaging others through a story. The danger in reading or gathering information silently and not sharing stories and experience can result in the decrease of social communication and the capability of learning from one another by means of oral communication and physical experience. The self does not develop on its own but through experience, communication and activities with others. ${ }^{7}$

"Every real story: it contains, openly or covertly, something useful. In one case, the usefulness may lie in a moral; in another, in some practical advice; and a third, any verbal or maxim. In every case the storyteller is a man who has counsel for his readers. But if today "having counsel" is beginning to have an old-fashioned ring, this is because the communicability of experience is decreasing. In consequence, we have no counsel either for ourselves or for others. " 8

According to McLuhan, in Western culture the emphasis placed on the importance of the invention of the alphabet has contributed to the separation of our involvement and the separation of the senses. Furthermore, he believes this happens because the alphabet leads to obstruction of visual elements or code from our
"Mead argues that the basic shape of our personalities is derived from the social groupings in which we live.... qualities that distinguish each of us from others emerge only within a social community."

Macionis, Benokraitis and Ravelli 2007: 81.

\subsection{2}

Reading physical book - book as container

${ }^{7}$ Macionis, Benokraitis and Ravelli: 28.

${ }^{8}$ Benjamine 2002: 45 - 46. 
physical sensory experiences by fragmenting functions, tasks and senses. ${ }^{9}$ As seen in the Gothic cathedral example in Chapter 1, its architecture had expression in the manner that light came into the spaces through the stained-glass window. This experience was utilized to heighten particular effects. In Western culture, the alphabet can transform our senses into an enclosed space of a visual code. The alphabet itself is a visual code of writing, translating an experience or speech. Since it is a written code each word has a fixed meaning. ${ }^{10}$ According to McLuhan, even though the written text has a fixed meaning and our overall sensorial participation is diminished, we do not necessarily lose all the experience that we can gain through our senses by reading texts within a physical library. He isn't necessarily saying we are losing the experience of our senses but that the written words remove us from the imaginative experience of someone else's story, leaving us with another layer to decipher.

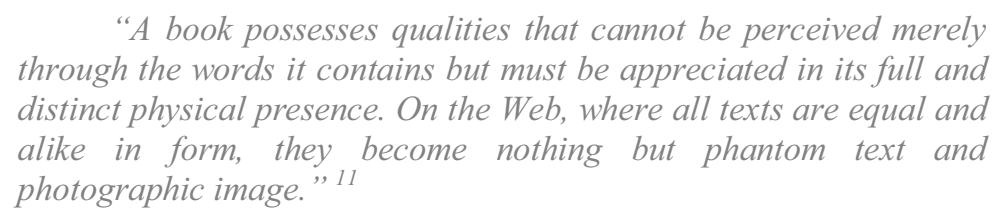

The book itself holds knowledge in a written form, but physical books themselves also have distinctive smells relating to their age or environment; they have a physical dimension and texture. Books display marks from people that have viewed them before us, whether pencil, pen, highlighter, torn pages.

\footnotetext{
${ }^{9}$ McLuhan 1962: 39.

${ }^{10}$ McLuhan 1962: 177

${ }^{11}$ Manguel 2007: 15.
} 
Louis Kahn believed there were several important fundamentals to consider within a library. An example that illustrates his concept of the library as a "house for books" is the Phillips Exeter Academy Library (see fig. 20). He knew that glare

2.1.3 Display on building building as container should be avoided, that wall space is needed and that little nooks for individuals are also important to afford an opportunity to be alone with the book. ${ }^{12}$ In this library one can see Kahn's desire to show honesty in construction. The exterior brick walls are thickened as they get closer to the ground and the piers become narrower as they get higher to express the different loads within the construction. ${ }^{13}$ To Kahn, the square form expresses symbolic universal connectivity. He uses the square in a different way, breaking apart all the closed corners with diagonal lines. The walls seem to be extending outwards and corners have slits to express the tension of this force to the world. ${ }^{14}$ The facades show the importance of the center. The forces push outward from the central space that is "the energy field of knowledge here that is bound into the ordering structure." 15 The manner that the building's windows were constructed also communicates that the building methods used can have, and express, a different character. This is seen in the masonry lintel construction of the windows with sills that have outward-thrust. ${ }^{16}$

\footnotetext{
${ }^{12}$ Buttiker 1994: 129.

${ }^{13}$ Brownlee and DeLong 1997: 207.

${ }^{14}$ Gast 1998: 82 .

${ }^{15}$ Gast 1998: 82 .

${ }^{16}$ Gast 1998: 82 .
} 


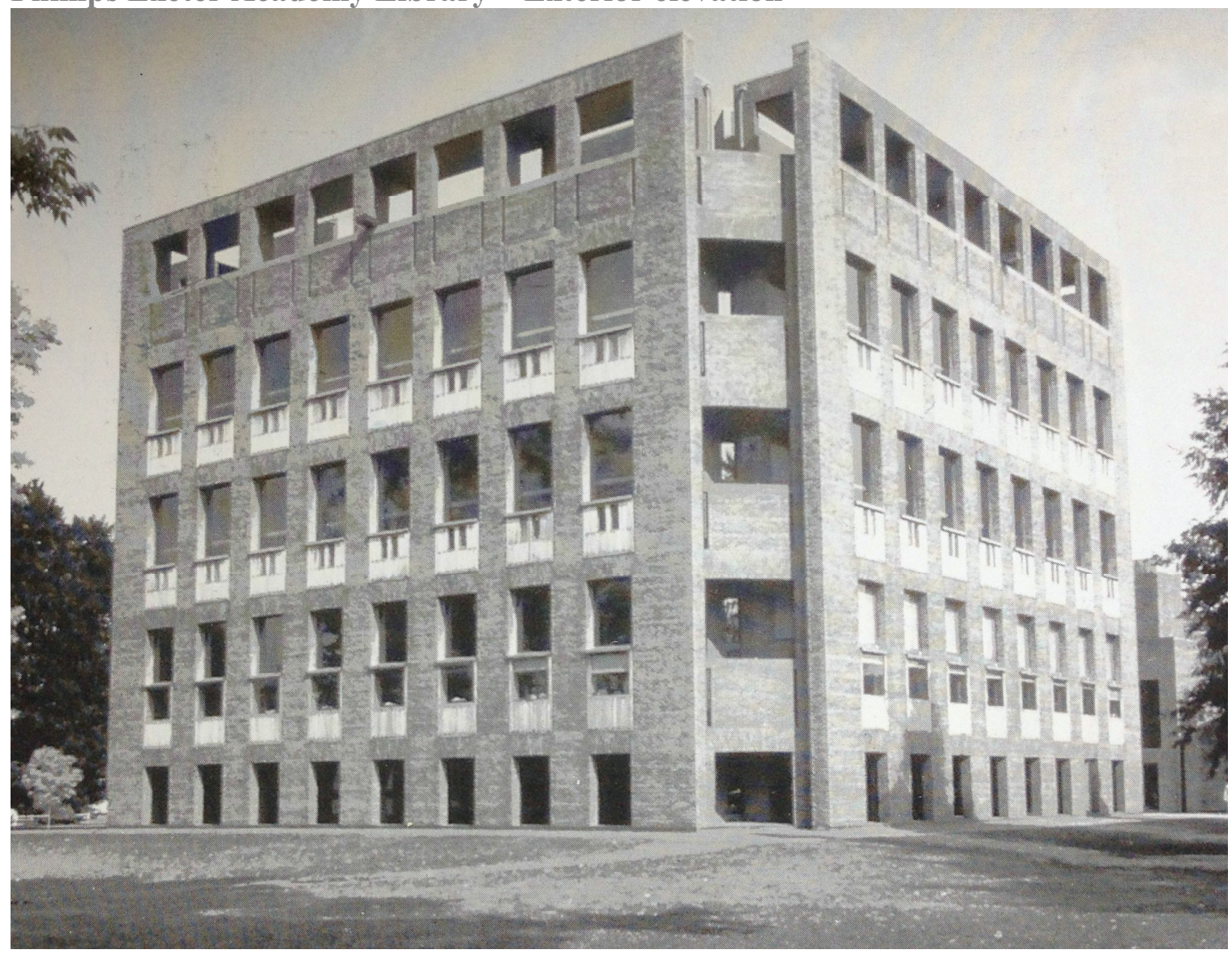

Figure 18

The building has identical facades expressing a classical architectural order. The piers taper on the exterior walls that display double height windows between them with lower parts showing wood paneling. ${ }^{17}$

While Kahn's design was inward facing and classical, its books are not visible from the outside. ${ }^{18}$ There are other libraries that not only house books but also display content on the container's surface. One such example of this is the Eberswalde Library by Herzog \& de Meuron. The building plays with different ways of reading. The lighting and viewing of the façade's historic narrative display can create the effect of motion or present a static image, similar to a cathedral's window. ${ }^{19}$

\footnotetext{
${ }^{17}$ Buttiker 1994: 129.

${ }^{18}$ Lobell 1979: 100.

${ }^{19}$ Mack and Liebermann 2000: 38.
} 
"Thomas Ruff has spoken of the façade as a 'poster wall' whose lack of structure contrasts with the structure within the ornament. He has referred to his baroque love of imagery and the pleasure he takes in juxtaposing seemingly incompatible images. Herzog \& de Meuron, on the other hand, tend to see the building more as an ornamental sign that punctuates the discourse of architectural history, restoring some of the possibilities prohibited by Adolf Loos's brilliant white modernism. "20

The building is a glass and concrete cube structure. The simple concrete core is wrapped with a tattooed skin displaying images of prefabricated concrete and glass panels (see fig. $21 \&$ 22). Images are displayed in horizontal bands and are repeated around the entire building. The idea of the displayed panels is to create a diffused appearance that becomes more distinct as one gets closer and the individual photographic images appreciated. ${ }^{21}$ The purpose of these images is not merely to provide a symbol or a meaning but to expose content on the facade.

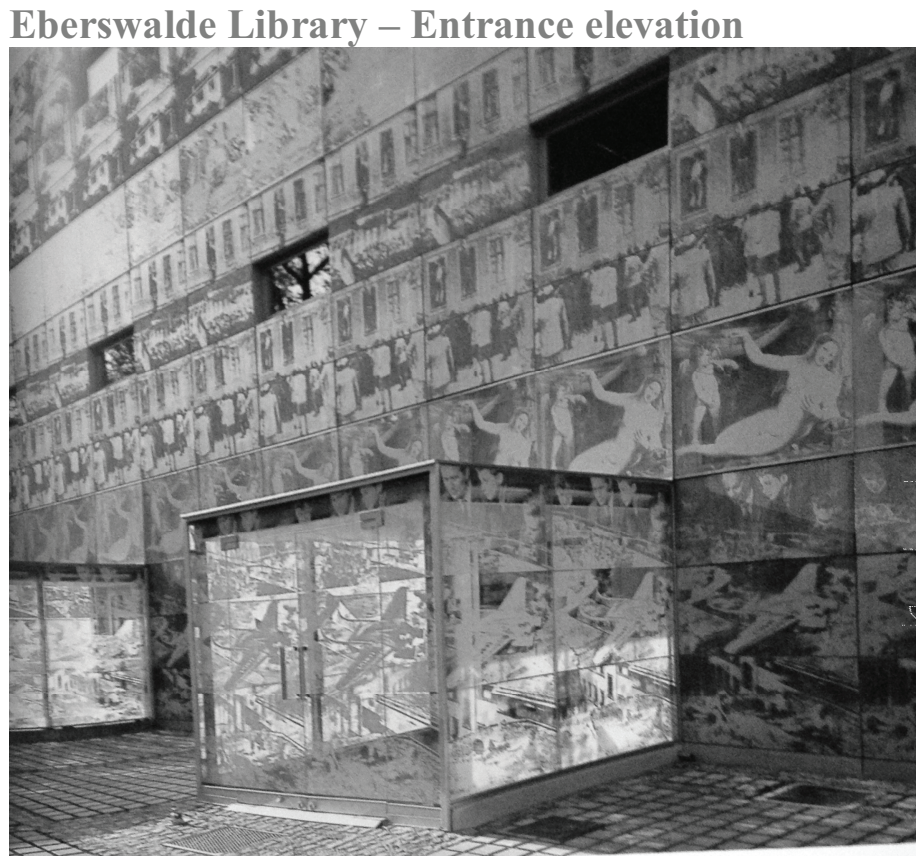

Figure 21

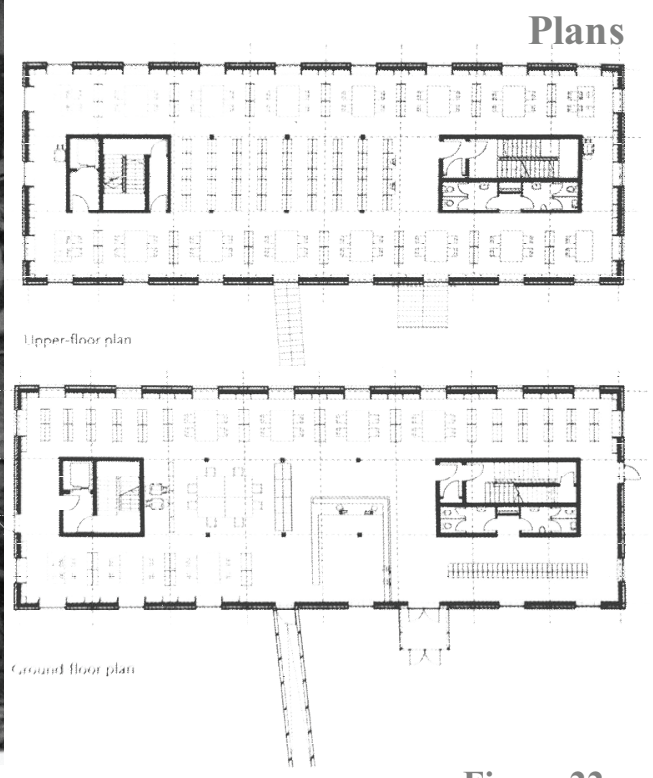

Figure 22

\footnotetext{
${ }^{20}$ Mack and Liebermann 2000: 38

${ }^{21}$ Mack and Liebermann 2000: 8.
} 
The skin combined with the structure creates an ambiguity of form. When viewing it at a distance it is difficult to distinguish the construction materials, number of floors, volumes and surfaces, perforations and enclosures, stillness and movement. This ambiguity plays with our perception of concrete and glass as solid and transparent. For example the printing on glass may seem solid during the day because of its similar print to the concrete panels, yet when the light is emitted from the inside at night the transparency of the glass is noticeable in contrast to the solid concrete panels. The distinction between the surface and façade seems to disappear. The building appearance changes with different site conditions such as weather and light. The tattooed skin acts as a membrane that is translucent during the day allowing natural light to penetrate through windows that seem opaque during the day and emit light at night, making the windows visible from the outside (see fig. 23). When the images are seen in the rain, they appear sharper, and when viewed on a bright or cold day they appear to have a sketched appearance to them. ${ }^{22}$

Several techniques had to be utilized to create the facade. Herzog \& de Meuron used an advanced technique for the concrete panels and used a silk-screen process to print on the glass itself. ${ }^{23}$ This technique uses the notion of tattooing. In this case the ideas are not expressed structurally but by engraving the building's surface to display the imagery (see fig. 24). This is important because they used modern materials together with an old technique, sgraffito. ${ }^{24}$

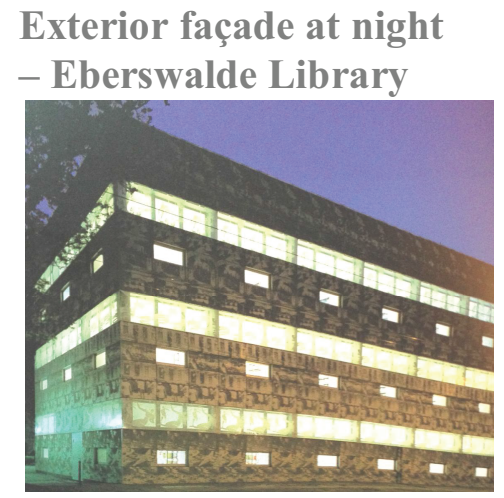

Figure 23
"The photographs are transferred onto a special plastic film by means of a silkscreen process, using a cure-retardant instead of ink. The printed film is then placed into the formwork (take care to avoid any slippage) and concrete poured over it. The amount of retardant used controls the degree to which the surface of the concrete sets. When the panel is taken out of the formwork, and carefully washed with water and brushes, the concrete that has lain in contact with the retardant remains liquid and is rinsed away, leaving darker, rougher areas of exposed gray aggregate. The difference between rough and smooth, dark and light, causes the pixilated pattern to emerge as images. The quality of definition depends on the brightness and clarity of the image, and on the contrast between the colours of the wet cement and the aggregate."

Mack and Liebermann 2000: 22.

\footnotetext{
${ }^{22}$ Mack and Liebermann 2000: 8.

${ }^{23}$ Mack and Liebermann 2000: 22.

${ }^{24}$ Mack and Liebermann 2000: 23.
} 
Eberswalde Library - Pictorial programme on the facade

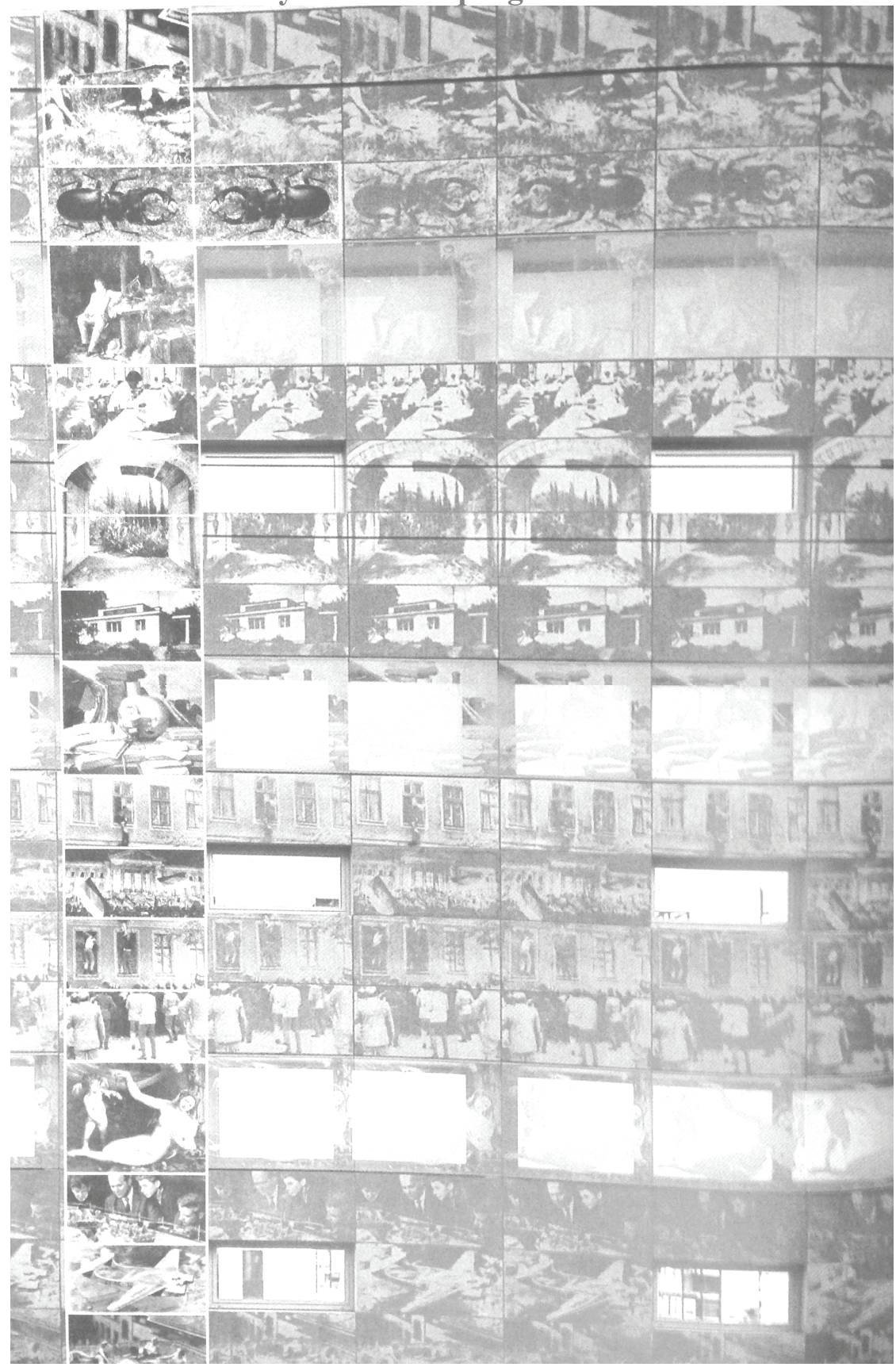

Figure 24
Palazzo at Colle Ameno, Bologna

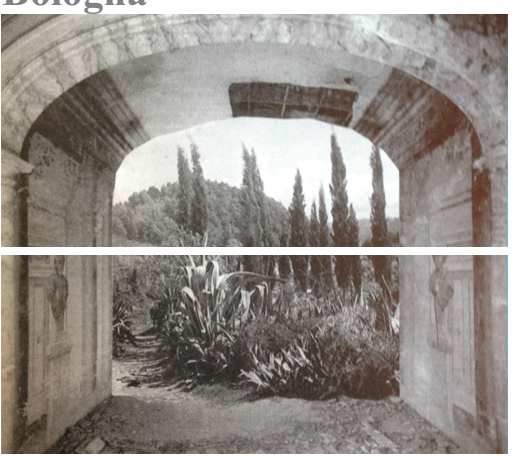

Figure 25

"Ruff has placed the dilapidated arch of a gateway from the Renaissance palace of Colle Ameno in Bologna. She shows us that, for all its firmitas, architecture is bound to go the way of everything of this earth. As though this reference to mortality were not enough, Ruff further disrupts the motif by cutting a hole in the archway and inserting into it an idyllic landscape in central perspective. In the context of Eberswalde Plytechnic, with its emphasis on forestry and timber technology, this may be regarded as a reference to the tension between architecture and nature." pg.33.

\section{Pietter Potter,}

\section{Vanitas}

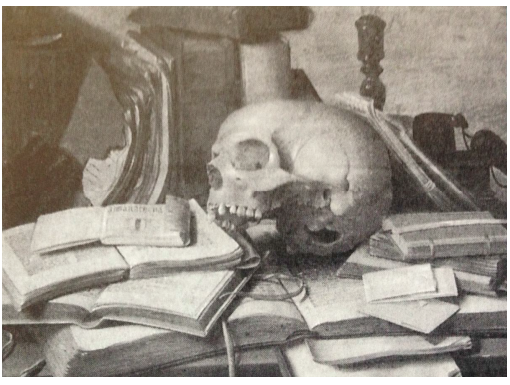

Figure 26

memento mori - on the second band of clerestory windows, where Ruff has selected a detail from a vanitas by Pieter Potter $-a$ still-life of a study table with books and skull. This melancholy landscape of classical learning is placed within the vertical sequence of images on the library façade, and related to the historical situation in such a way that it can be interpreted as a further exhortation to refer to the lessons of the past to shed light on nresent-dav nrohlems " no 3 ? 
Thomas Ruff envisioned the library as "a public building whose function is 'to store knowledge and make it accessible' and in doing so 'to develop historical and social awareness'." He chose scientific, historic and political images from photographs and newspapers to heighten awareness displaying them on the facade. ${ }^{25}$ Mark and Liebermann discuss how the chosen images express the banality of mass produced architecture while at the same time giving a "surreal touch" to the building. They try to challenge the way we are accustomed to seeing by juxtaposing functional objects with the opposite. ${ }^{26}$

\subsection{Content: Phillips Exeter Academy, Library by Louis I. Kahn}

In Western culture we tend to organize space based on activities. Places such as work/home and leisure activities are themselves divided into rooms such as office, meeting rooms, kitchen, bathroom, reading area, workshops etc and each has a public or private association depending on the function. This includes the requirements and needs of a particular place such as functional spaces, technical requirements and the amount of floor area needed to fulfill program requirements. The architectural program is used to help organize space. Although it is inevitable that we require and desire to have and contain particular spaces, the response to the program can be very different today due to technology. The stable routines or patterns within a space can be more diverse and flexible; these can be reconfigured based on various events of the space. $^{27}$
"At the foot of the building the image establishes an unusual contrast with the stone pavement whilst at the top it forms an apt transition to the grass-covered roof. Blurring the distinctions between roof and ground."

Mack and Liebermann 2000: 31.

2.2.1

Space communicatesshape, light, material

${ }^{25}$ Mack and Liebermann 2000: 31.

${ }^{26}$ Mack and Liebermann 2000: 30 .

${ }^{27}$ Mitchell 2003: 162-163 
According to Hall "culture controls behavior in deep ways, ${ }^{, 28}$ meaning that the way humans interact with each is dependent upon culture and our ideas about people, family, economics etc. We learn many spatial cues that provide their own particular meaning, based on their specific cultural context. This tells us that our physical experience sets up the notion that 'space communicates' ${ }^{29}$ In this case Hall says "Americans treat space as highly personalized". ${ }^{30}$ This is important because personal experience allows us to create relationships between different places. ${ }^{31}$ According to Hall the way people communicate is divided into words and behavior. Communication with words makes up $10 \%$ and behavior makes up the remaining $90 \%{ }^{32}$

\section{"There are readers who enjoy trapping a story within the confines of a tiny enclosure; others for whom a round, vast, public space better allows them to imagine the text stretching out towards far horizons; others still find pleasure in a maze of rooms through which they can wander, chapter after chapter. "'33}

Libraries and their spaces come in all forms, shapes and sizes. The physical shape of the library and the spaces within it encourage different book reading habits. Spaces have the ability to change the way we read books by creating a particular atmosphere. Someone reading a book may not necessarily read it in the same order or depth as another person. The location within a library that one might chose to read a text may also change from person to person. The space can act as a backdrop for a text that is being read. A large room might be much cooler and clinical acting as a pseudo office as opposed to a small niche whose warmth invites a cocooning type of response with the reader feeling compelled to curl up with a book and shut out the surrounding world to be alone

\footnotetext{
${ }^{28}$ Hall 1959: 48.

${ }^{29}$ Hall 1959: 190.

${ }^{30}$ Hall 1959: 193.

${ }^{31}$ Hall 1959: 190

${ }^{32}$ Hall 1984: 4.

${ }^{33}$ Manguel 2007: 133-134.
} 
with the text and images imagined. The rough texture of a floor might make someone leave the area, sit down on it or touch its surface. A small quantity of light that penetrates a space might encourage someone to be alone with their book or conversely a great amount of light might encourage people to gather together and interact by sharing their knowledge or push people to quickly skim through a book as opposed to lingering.

Alberto Manguel explains that we read and "lose ourselves" in books in different manners and dependent upon the library's physical space. This may vary depending on whether the shape of the room is a circle or square. A small personal space versus a large open room with high ceilings, the densities of books and content, and the shelving distance and size are variables that impact our reading experience. These spaces also suggest and create different lighting conditions and effects. ${ }^{34}$ All these characteristics can create unique atmospheres that affect our senses in different ways. For example, Kahn in the Phillips Exeter Library wanted to create an environment that encouraged reading. ${ }^{35} \mathrm{He}$ believed that the structure should be evident in a space and that cast shadows highlight the presence of light. ${ }^{36}$ To him mass was a structural and rational part of the building while the space within the building was something of a mystical nature as "the energy that brought space to life." 37 This space defined the relationship between the book and the reader:

"I see the library as a place where the librarian can lay out the books, open especially to selected pages to seduce the reader. There should be a place with great tables on which the librarian can put the books, and the reader should be able to take the book and go to the light"'38

\footnotetext{
${ }^{34}$ Manguel 2007: 132-133.

${ }^{35}$ Brownlee and DeLong 1997: 206.

${ }^{36}$ Brownlee and DeLong 1997: 203.

${ }^{37}$ Brownlee and DeLong1997: 202.

${ }^{38}$ Luois Kahn cited in John Lobell 1979: 100.
} 
Despite the fact that Kahn wanted the books to be on display, the books were not in direct light. The light came in from above the central space (see fig. $27 \& 28$ ) and the double-height areas around the building's perimeter where individuals can read, allow users to close the windows with shutters or to work in different areas such as on the mezzanine beside the bookshelves. ${ }^{39}$

\section{Exeter Academy Library - Diversion of light}

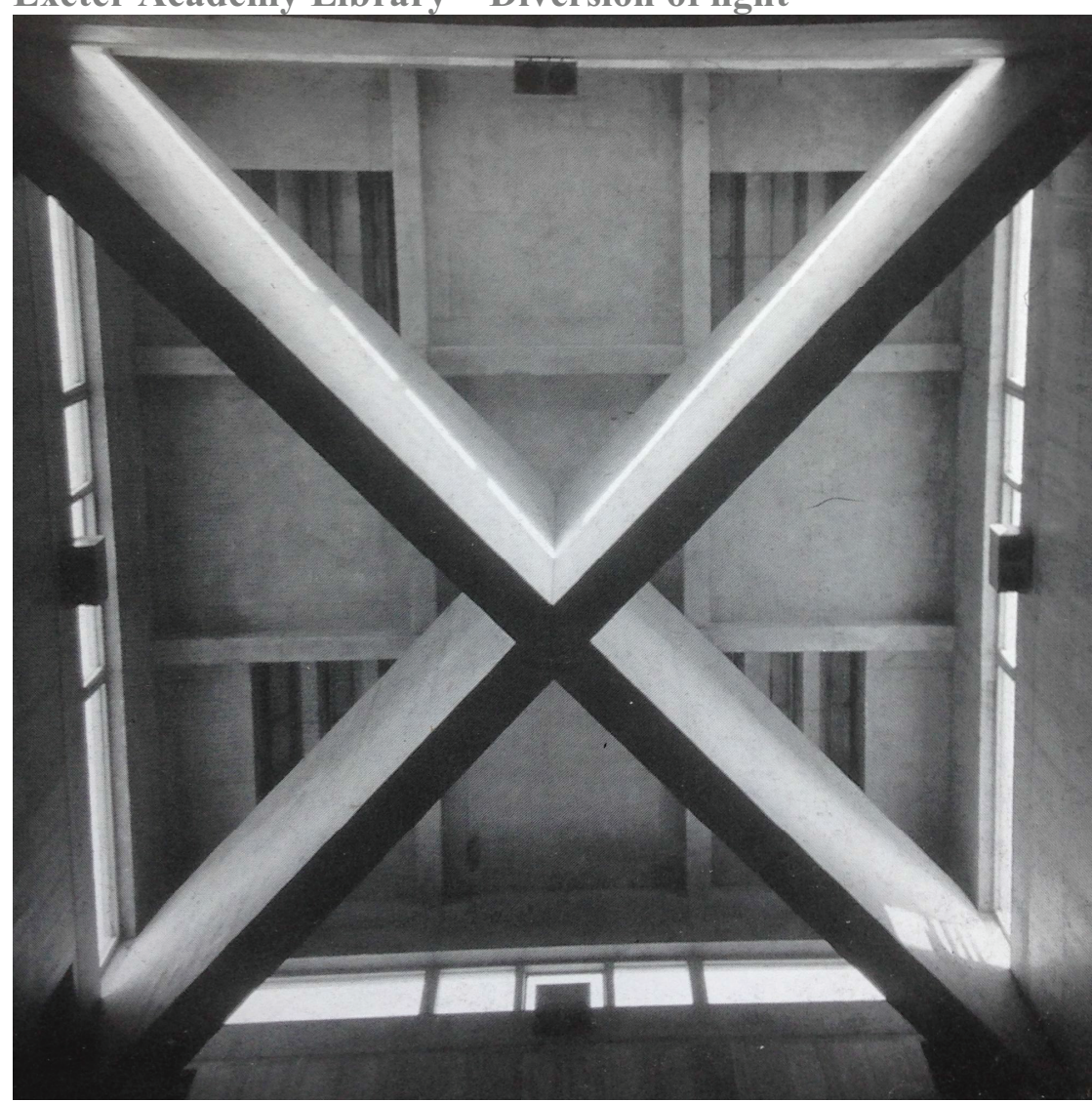

Figure 27

The central atrium structure that is acting as a shield to prevent light from coming down into the space. Therefore is not only for structural function but also the structure deflects the light down. ${ }^{40}$

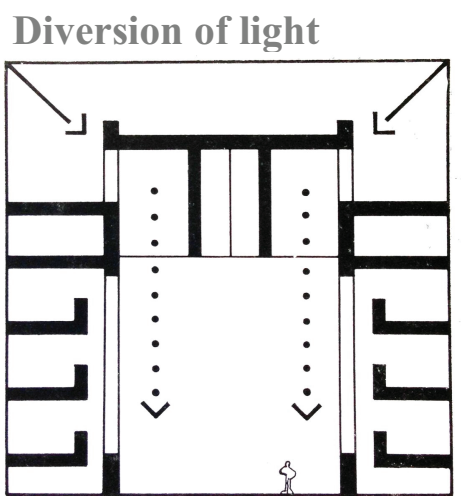

Figure 28

${ }_{40}^{39}$ Brownlee and DeLong 1997: 207.

${ }^{40}$ Buttiker 1994: 131. 
As seen in both the Notre Dame Cathedral and in Kahn's library, a window can communicate different ideas. Windows and light offer an excellent opportunity to heighten an experience. The amount and type of light needed for the preservation of artifacts must be controlled. Protecting precious books from excessive light and preserving them need not conflict with the use of the expressive qualities of light. Kahn saw the window as something that could be an interface between the inside and outside in different variations. ${ }^{41}$ The window as a surface that acts as an interface between us and the world can allow natural light to come in during the day and emit artificial light at night. Light can help communicate and heighten by opposition; an awareness of a dark space can be conveyed by allowing minimal light in. ${ }^{42}$

Kahn's use of materials reflects areas where people will be in contact with the physical building. He uses wood for the carrel areas and allows people to open and close the window to the study area, physically interacting with the building (see fig. 29 \& 30). Another example includes the grand staircase going into the central space from the entrance where the concrete banister's surface is covered with travertine. ${ }^{43}$ Kahn did not design the building to relate to the neighboring area. Aside from the use of dark brick material, even the integration of wood products into the façade is an anomaly within the surrounding context. Untreated wood was used for windows on the exterior. The surfaces of the interior central space are finished in smooth concrete. ${ }^{44}$

\footnotetext{
${ }^{41}$ Buttiker 1994: 22.

${ }^{42}$ Gast 1998: 82.

${ }^{43}$ Lobell 1979: 102-104.

${ }^{44}$ Gast 1998: 81.
} 


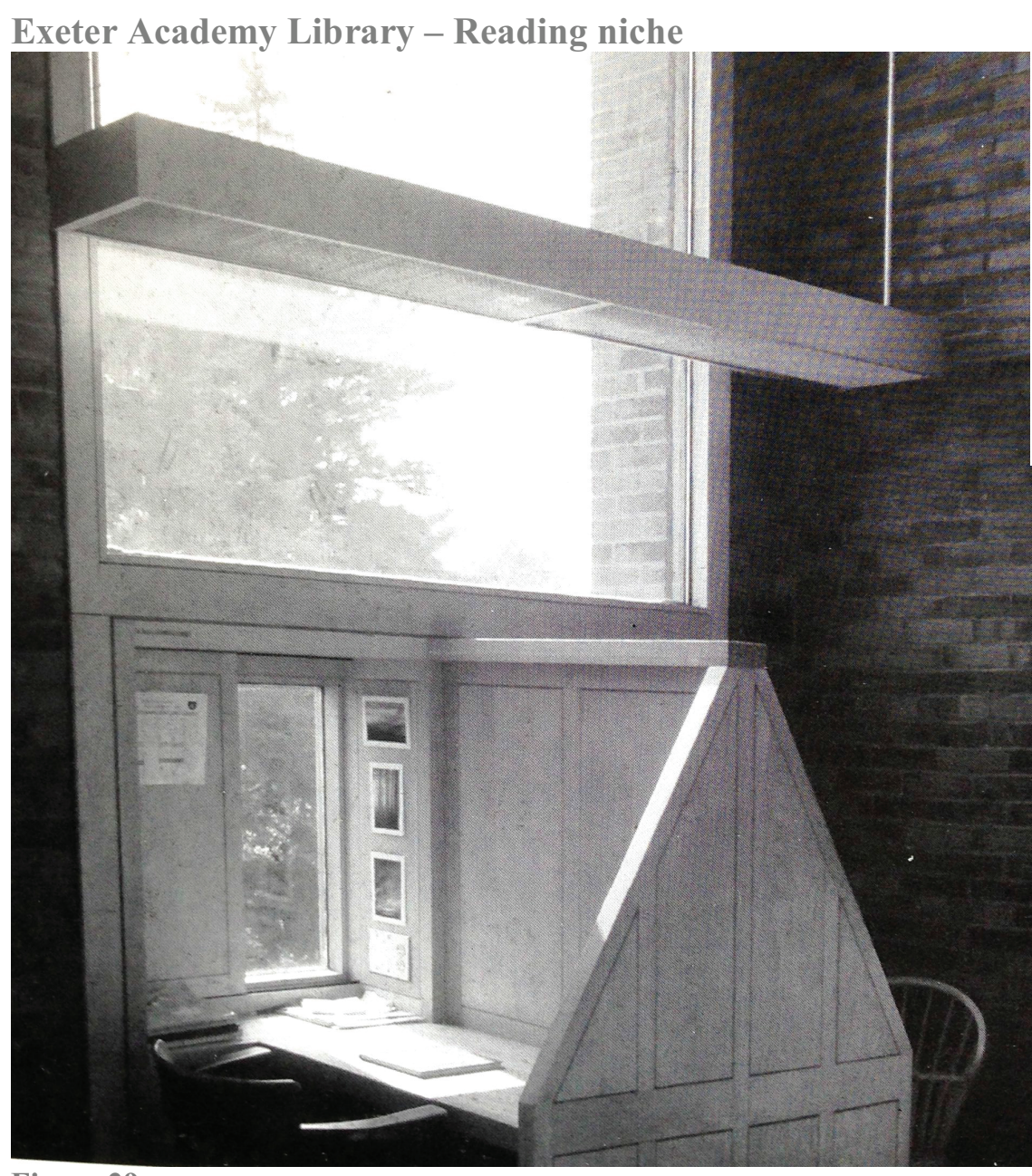

Figure 29

Every library is a work in progress, each one houses content that is the result of choice, evolving over time. No matter which library it is, the collections of information and stories eventually require a system of organization to allow space to be used efficiently. Keeping up with current and future book production as well as the continual accumulation of artifacts forces libraries to change, adapt and update.

Most people have a personal library, of some sort that displaying a private collection of books and objects gathered throughout their lives. Pieces come together from school, leisure,

\section{Light penetration}

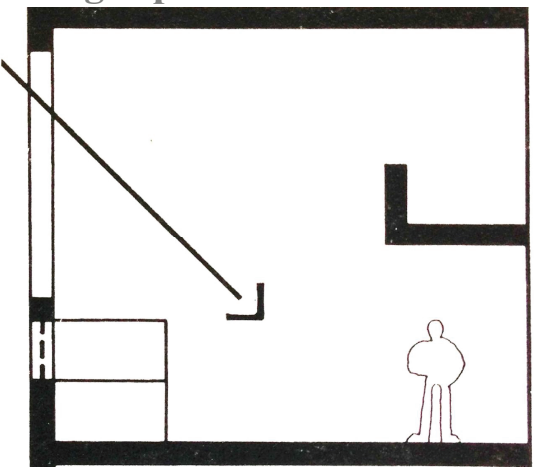

Figure 30

"A row of wooden carrels, each with its own shuttered, desk-level window, lined the exterior wall. This environment responded to what Kahn considered the instinctive behavior of the reader: "A man with a book goes to the light. A library begins that way." The Carrels, which gave students the ability to let in the view or close it out, also afforded them an essential autonomy. Kahn said about schools in general. "The windows should be made particular to suit a student who wants to be alone even when he is with others."

Brownlee and DeLong 1997: 207.

2.2.2

Organization 
work, family etc. Objects in our personal collection can show others the issues and topics that have been important or interesting to us as readers, based upon the objects we chose to keep. The way we organize our private collections can give a glimpse of the issues and ideas that have shaped our identity. It is interesting to note that public libraries need a classification system that can be understood by all whereas the private libraries do not necessarily need one. ${ }^{45}$

In the physical library, content is constantly being added up and evolving, like a work in progress. The content increases overtime reflecting the interests of collectors, the community values, current political issues and funding considerations. ${ }^{46}$ In order to keep up with the ever-growing content, the library, as Dewey discovered, needs an ordering system - a logical structure to help organize collections. The Dewey decimal system of classification works in a way that creates an opportunity for further divisions and subdivisions. ${ }^{47}$ Although his method was revised over time, Dewey's idea and basic cataloguing technique, that emphasized our need to contain and classify, was generally adopted as an organization and classification system. Everything in the system can be assigned a number "so that the infinity of the universe can be contained within the infinite combination of ten digits. ${ }^{~} 48$ Organization of collections in a practical, common, logical or universal way helps visitors in a library find the materials they are looking for with related items placed near each other. Since the physical space in the library that containing the collection has boundaries, even with a logical organization of collections, the library will eventually run out of space ${ }^{49}$ as empty
"Libraries, he thought, had to be instruments of easy use for every soul. He argued that the cornerstone of education was not just the ability to read the knowledge of how to get the meaning from the printed page. It was in order to facilitate access to that page that he dreamt up the system for which he is remembered."

Manguel 2007: 60.

${ }^{45}$ Manguel 2007: 294-305

${ }^{46}$ Manguel 2007: 56-57.

${ }^{47}$ Manguel 2007: 58-59

${ }^{48}$ Manguel 2007: 60.

${ }^{49}$ Manguel 2007: 41. 
shelves become filled with books. Combining the Dewey system with the electronic cataloging system can help the visitor find the proper location of particular collections within the library. The cataloging system allows all users to view a list of available materials. This helps protect the collections from unnecessary handling and damage and, it facilitates cataloging without rearranging the books. ${ }^{50}$ Roaming freely within the library still allows for chance encounters with catalogued artifacts.

\begin{abstract}
"A library is not only a place of both order and chaos; it is also the realm of chance. Books, even after they have been given a shelf and a number, retain a mobility of their own. Left to their own devices, they assemble in unexpected information; they follow secret rules of similarity, unchronicled genealogies, common interests and themes." 51
\end{abstract}

The Warburg Institute Library for the Science of Culture in London, England has a unique system of classification. The system deviated from traditional classifications such as the Dewey Decimal system or general subject classifications. ${ }^{52}$ Warburg did not want to use the practical or systematic approaches in organization because of one "limited serendipitous discovery via shelf browsing" 53 . He believed the method was a "static model of the universe of knowledge to be contained by external fixed structures. ${ }^{54}$ Warburg was interested in creating an unconventional, dynamic and interdiciplinary approach of exploration providing for discovery of materials in a non-familiar way. His design expressed the evolution of iconology by placing importance on new ideas and content and not only on form. ${ }^{55}$ Here the organization with interdisiplinary connections is achieved by
The Warburg Library Diagram of organization scheme

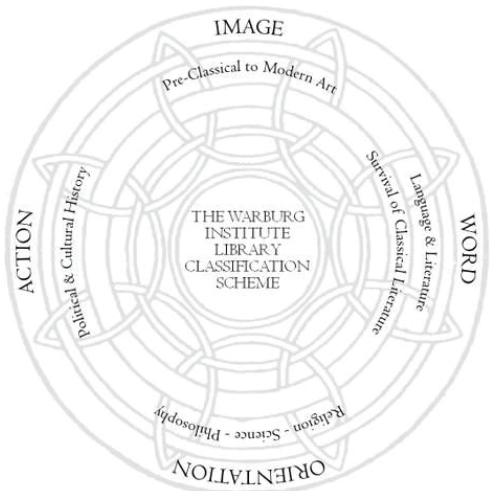

Figure 31

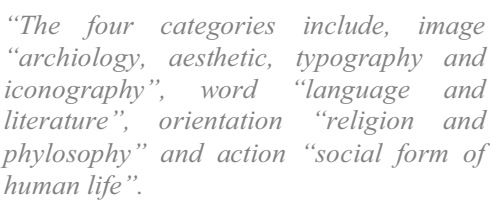

Pattuelli 2011: 8-9.

\footnotetext{
${ }^{50}$ Manguel 2007: 41.

${ }^{51}$ Manguel 2007 : 163 .

${ }^{52}$ Pattuelli 2011: 3 .

${ }^{53}$ Pattuelli 2011: 4.

${ }^{54}$ Pattuelli 2011: 4

${ }^{55}$ Pattuelli 2011: 4.
} 
what he calls "the law of the good neighbor" ${ }^{56}$ This helps to create dynamic associations of thinking and broader context of ideas because of the elimination of disciplinary boundaries. ${ }^{57}$ To utilize these ideas of flexibility and a cross-disciplinary approach, the design displays the categories on the building's four floors (see fig. $31)$.

In the Exeter Library, Kahn not only planned the location of the books in the library but also the experience and journey for obtaining knowledge from them. He created the central space for social engagement keeping other functions at the edge. ${ }^{58}$ The first floor has an arcade running along the perimeter that acts as a 'transition zone' into the interior (see fig. 32). By doing this he eliminated a defined entrance. This also helps to bring in people that arrive from different directions into the library. Visitors climb a grand staircase before entering the book area. The symbolic movement upwards refers to an "Olympus of Knowledge" according to Kahn. ${ }^{59}$ The library has a simple plan layout with a large space in the center that is filled with sunlight coming in from above. The second floor (see fig. 33) provides the visitor with a square atrium space that is defined by the light penetration and being diffusion of it between the structure's concrete diagonal elements. The interior elevations (see fig. 34) of the large square space have circular cutouts reducing the mass of the concrete walls that frame and display the book stacks around its perimeter. ${ }^{60}$ This way "stability and frailty enter a border zone of unity." The visitors to the library can see books selected by the librarians on display in the central space. This allows the reader to encounter

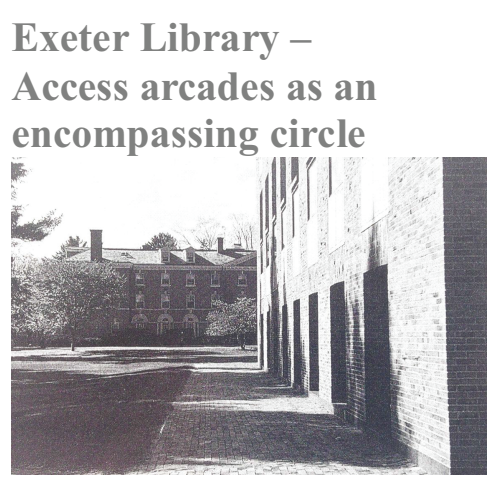

Figure 32

\footnotetext{
${ }^{56}$ Pattuelli 2011: 5

${ }^{57}$ Pattuelli 2011: 5 .

${ }^{58}$ Lobell 1979: 100.

${ }^{59}$ Gast 1998: 81.

${ }^{60}$ Brownlee and DeLong 1997: 207.

${ }^{61}$ Gast 1998: 82-83.
} 
these 'selected materials' and if interested take them to an individual carrel located at the perimeter of the library for study ${ }^{62}$ The plan is arranged in a concentric manner to provide visual clarity for the visitors. Symmetry echoed Kahn's search for order.

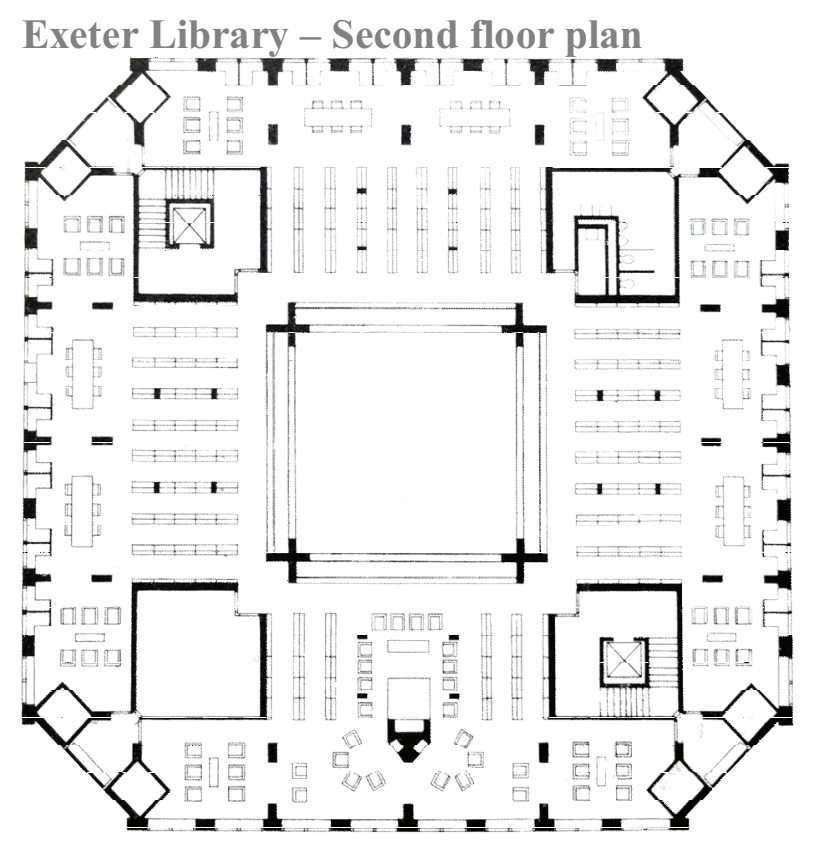

Figure 33

${ }^{62}$ Lobell 1979: 100. 


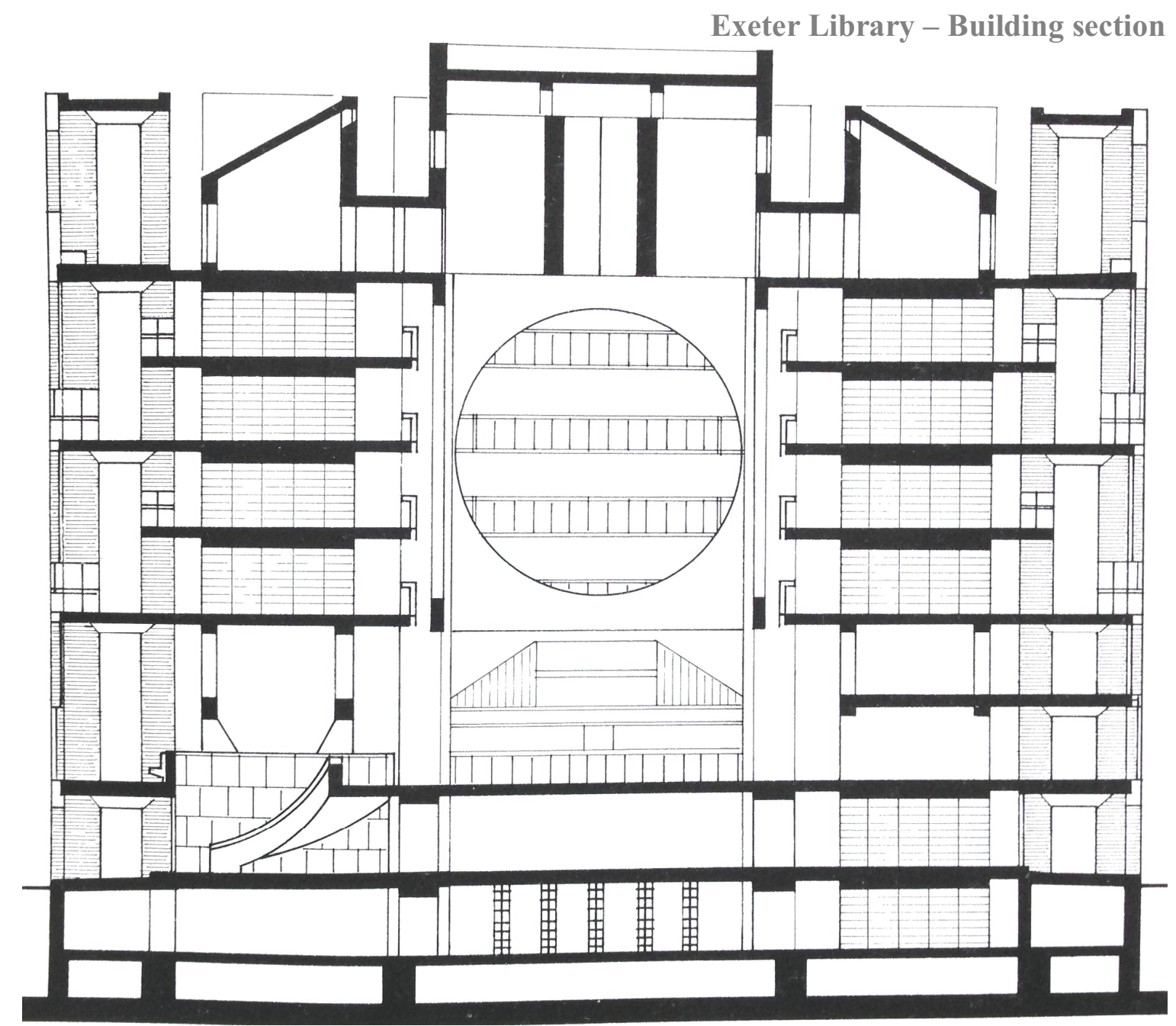

Figure 34

"On the outside, the double-story edge zone of the reading area in brick, then the area of the stacks in concrete, and last the concrete core configured as an atrium provided with four huge circular cutouts in the walls. . The four large circles cut out of the concrete slabs are best interpreted as windows not onto landscape, but into the world of books. Kahn's design therefore proves inviting to readers to select their book and take it into a reading niche or to the library fireplace to read.",63

${ }^{63}$ Buttiker 1994: 131. 
People typically feel they have the freedom to choose their reading material within a library, and this is true. Yet, the material chosen for the library are filtered by the manner in which the 2.2.3 Collections and Display sections are catalogued, the types of collections that are housed, the physical size of the space and the budget of the library. This is important because the collections we are exposed to in the library are not a random gathering. Spatial constraints also affect which physical objects can be stored to be viewed. The materials we display, the manner in which we display it and the materials we choose to keep offers a glimpse into the message being conveyed and the medium being used to convey it.

Libraries provide us with the ability to house and retrieve information from past generations and relay them to the present and future generations of people who will view them. ${ }^{64}$ This process of continually renewing, adding and editing content is a selective one. Libraries choose items to reject and materials to house so that the ${ }^{65}$ content is communicating the issues that a culture places importance upon. The materials we choose to display are important because different cultures tend to teach us to pay closer attention to some topics while disregarding others. ${ }^{66}$ It is important to think about the manner in which we access information because this reveals our communication habits and the issues we find important to our culture.

\footnotetext{
"We dream of a library of literature created by everyone and belonging to no one, a library that is immortal and will mysteriously lend order to the universe, and yet we know that every orderly choice, every catalogued realm of the imagination, set up a tyrannical hierarchy of exclusion. Every library is exclusionary, since its selection, however vast, leaves outside its walls endless shelves of writing that, for reasons of taste, knowledge, space and time, have not been included. Every library conjures up its own dark
}

\footnotetext{
${ }^{64}$ Manguel 2007: 123.

${ }^{65}$ Manguel 2007: 107-108.

${ }^{66}$ Hall 1984: 108.
} 
A physical library is more than a container of collections. Books and artifacts collected are objects that remain as traces from different historic periods and cultures that hold specific meaning in written form. Books are displayed within the library that contains them. ${ }^{68}$ The library acts as an exhibition area for important thoughts from an historic time period and displays them in the current container. This is evident in Stephen Bann's discussion of the notion of curiosity. He discusses curiosity and explains that it can refer to a specific historic and cultural attitude and subsequently, to the display and collection of objects. Objects are an important part of curiosity as is the manner in which they are displayed. ${ }^{69}$ Ways to use the physical space within a container and its organization vary from era to era and according to culture in terms of the size of collections, scale of container, and content. The order, type of collections, their display and relationships set up a narrative/frames of reference that are presented to visitors.

In the chapter "Shrines, curiosities, and the rhetorical of display" of his book, Stephen Bann discusses the idea of a museum and pilgrimage to the idea of display. ${ }^{70}$ He uses the remains of a cathedral as an example of a secular shrine of curiosity. He discusses the concept that the viewer experiences these curiosities as distant objects in a museum. He then relates it to pilgrimages and explains that the collections are viewed as remains from another place and as a notion of curiosity that captivates the viewer. The shift from the shrine to the cabinet and from the cabinet to the museum follows along a line of rhetoric that

\footnotetext{
${ }^{67}$ Manguel 2007: 107.

${ }^{68}$ Bann 1995: 19.

${ }^{69}$ Bann 1995: $24-25$.

${ }^{70}$ Bann 1995: 14-29.
} 
illustrates change in different historic times and places. For example in the Gothic period the cathedral displayed the notion of the sacred. The display depended not only on the object, but also on the form and manner in which it was presented. ${ }^{71}$

"Regime of curiosity itself was tributary to certain established
ways of disposing objects and communicating through them. They
were the amazingly elaborate and costly arrangements for showing
the relics of saints, and other cultic objects to the faithful pilgrims
who traveled hundreds and sometimes thousands of miles to gain
sight of them-a custom that began in the early Middle Ages",72

The container not only holds the object, but it also becomes part of the storytelling. Even though the viewer cannot experience the object in its historic time period and physical context, it can still be viewed and accessed through a re-reading in the present context. This is important to note since it means that the relic can be transformed endlessly through history. Bann uses the triptych as an example of display that is not only containing the cross as a relic but also its story. The sacred object is built into a prototype and is transformed endlessly in the sacred religious narrative. ${ }^{73} \mathrm{In}$ this way the container offers a site of access to the story of the object. Although Bann is referring mostly to the idea of museums, the library can also relate to the notion of display and curiosity because it houses objects in the form of books and artifacts. These objects contain their own individual stories and different authors' voices and beliefs from different times.

The Ancient Library of Alexandria may be used to discuss collections and display. Even though the exact layout is unknown, it is said to have housed gardens, hall, lecture halls, a reading room, and a dining room. ${ }^{74}$ The library was thought to have had a

\footnotetext{
${ }^{71}$ Bann 1995: 10.

${ }^{72}$ Bann 1995: 15.

73 "Narrative that incorporates all of the time the death of Adam to the Christian Empire of Constantine." Bann $1995: 16$.

${ }^{74}$ Manguel $2007: 26$.
} 
long and high hall, designed for scroll shelving. ${ }^{75}$ Some of the subjects on the scrolls included astronomy, natural sciences, physics and mathematics. The division of the areas by categories, alphabet and themes positioned the library essentially as a "house" containing multiple different libraries addressing different varieties of the worlds that extended further than Egyptian borders. ${ }^{76}$ These collections were intended for scholars to demonstrate Egypt's wealth. Manguel discusses the notion that it was important for these collections to be viewed as a glimpse into Egyptian's longing for immortality. This demonstrates that scholars in Alexandria believed in the past as the source of knowledge renewed in new readers through the process of reading the old books. This gave knowledge a sort of immortality. ${ }^{77}$

\subsection{Physical versus Digital in the Digital Age: Ottawa Public Library}

Modern society, in its quest for ever greater efficiency and capacity has created material extensions for parts and uses of the human body. "Technology is an inevitable result of mankind's propensity to evolve outside his body." ${ }^{, 78}$ It is natural for us to want to evolve and create extensions, yet, when the evolution of such extensions speeds up, the extension has a danger of taking over. ${ }^{79}$ Among these extensions of our senses are eyeglasses, telescopes, telephones, power tools, books and computers that allow us to perform tasks and acquire knowledge more efficiently and quickly. ${ }^{80}$ The advantages are evident with eyeglasses, for example. They can correct vision and enhance ocular precision

\subsection{1}

Technology as tool extensionsspeed, senses

"Our private senses are not closed systems but are endlessly translated into each other and that experience which we call consciousness. Our extended senses, tools, technologies, to the ages, have been closed systems thinking bold interplay or collective awareness. .... Our extended faculty and senses now constitute a single field of experience which demands that they become collectively conscious."

\footnotetext{
${ }^{75}$ Manguel $2007: 26$.

${ }^{76}$ Manguel 2007: 24.

${ }^{77}$ Manguel $2007: 28$.

${ }^{78}$ Hall 1984: pg 9.

${ }^{79}$ Hall 1966: 178.

${ }^{80}$ McLuhan 1962: 5.
} 
when it starts to decline. The telephone, as another example, creates an opportunity to have a discussion with someone who is physically located too far away for a face-to-face discussion. Power tools enable machines to complete tiresome and laborious work with potentially more precision than our body may be able to produce. Books provide a medium for recording thoughts and ideas that others can view at a later date passing on knowledge from generation to generation and person to person. Computers enable people to perform various functions for knowledge gathering including communication through email, online chats/discussions, shopping, reading, etc.

Although technological advancements can help us with progression, allowing a faster and more efficient way of performing particular tasks, this progress may lead to an alteration of sense perception. 81 "Man's sense of space is a synthesis of many sensory impacts: visual, auditory, kinesthetic, olfactory and thermal." 82 Experiences that people share within a society create references for other events. Hall discusses the concept that people have different sensory screenings that admit and filter different sensorial sensations. ${ }^{83}$

Today we are able to gather information at a quick pace from anywhere in the world because of the importance we place on time. ${ }^{84}$ Even though accessing information online expediently can assist with time constraints, we forfeit the experiences that take place by physically going to a library.
"All including English, treat time as continuum divided into past, present, and future. We have managed to objectify or externalize our imagery of passage of time, which makes us feel we can manage time, control it, spend it, save it, or waste it."

\footnotetext{
${ }^{81}$ McLuhan 1962: 24.

${ }^{82}$ Hall 1966: 60.

${ }^{83}$ Hall 1966: 2.

${ }^{84}$ Hall 1984: 36.
} 


\begin{abstract}
"Somehow we have managed to objectify or externalize our imagery of the passage of time, which makes it possible for us to feel we can manage time, control it, spend it, save it, or waste it."
\end{abstract}

According to Hall "people are tied together and isolated from each other by invisible threads of time. Time is treated as a language, an organizer for activities, handling priorities and categorizing experience." ${ }^{86}$ In Western contemporary culture, time is used to organize our everyday activities that are based on schedules. This is because people are tied together in a larger cultural rhythm, one of which is time. ${ }^{87}$

Western society has become extremely reliant on computers and electronic devices. These devices are not immortal but are instead rather ephemeral, which has interesting implications from the viewpoint of knowledge conservation. One of the key problems is that software designs prepared for the present day may not be available tomorrow, and may be replaced in a few years with new software solutions. ${ }^{88}$ For example it is difficult to retrieve information from a floppy disk for the typical user when current technology does not provide a portal for it. To retrieve the information one would need to keep all the outdated hardware or alternatively to continually update and regenerate the archives. This is an issue because storing digital materials is easy, yet digital preservation is difficult since the technology used to retrieve this information may be replaced by a newer and different technology.

\subsection{2}

Boundaries space without place
"Anybody who has used a computer knows how easy it is to lose a text on the screen, to come upon a faulty disk or $\mathrm{CD}$, to have the hard drive crashed beyond all appeal. The tools of the electronic media are not immortal. The life of the disk is about seven years; a CD-ROM lasts about ten." Manguel 2007: 75.

${ }^{85}$ Hall 1984: 36 .

${ }^{86}$ Hall 1984: 3.

87 "Primary Level Culture has core components which pattern our thinking and give us sets of underlying assumptions." Hall 1984: 3.

${ }^{88}$ Manguel 2007: 75. 
"In our time, bereft of epic dreams - which we've replaced with dreams of pillage - the illusion of immortality is created by technology. The Web, and its promise of a voice and a site for all, is our equivalent of the mare incognitum, the unknown sea that lured ancient travelers with the temptation of discovery. Immaterial as water, too vast for any mortal apprehension, the Web's outstanding qualities allow us to confuse the unprofitable with the eternal." 89

Even though wireless access provides an ability for the increasing amounts of information to be read anywhere, unbound by the physical boundaries of a library, we lose the different links of association that can happen by chance within the library. There are certain virtual libraries that suggest other readings. Yet, we lose the physical experience, the shape of the object and its material, the atmosphere and our own chance encounters because we are dealing with a flattened object in our controlled environment on the computer screen.

Order and scale have become less important because of the transient way we gather information today by logging into the virtual library of collections. An ordinary architecture has appeared from our social habits and a reliance on technology has replaced a desire for monumentality. This is because our perception of architectural space is based on being outside or inside a building and acts as a mediating plane/element that contains space where activities take place or objects can be stored. ${ }^{90}$ Today it can be seen that the structure has become synonymous with the program and this is causing a loss in the relationship of the inside and outside. The physical mediating architecture boundary of an actual physical encounter holds us back to the world and, it becomes blurred.

\footnotetext{
${ }^{89}$ Manguel 2007: 27-28.

${ }^{90}$ Bertol and Foell 1997: 55-56
} 
"If a visitor from the past arrived today in our civilized cities, one of the aspects that might surprise this ancient Gulliver would certainly be our reading habits. What would he see? He would see huge commercial temples in which books are sold in their thousands, immense edifices in which the published word is divided and arranged in tidy categories for the guided consumption of the faithful. He would see libraries with readers milling about in the stacks as they had done for centuries. He would see them exploring the virtual collections into which some of the books have been mutated, leading the fragile existence of electronic ghosts. Outside, too, the time-traveler would find a host of readers: on park benches, in the subway, on buses, and trams and trains, in apartments and houses, everywhere." 91

The issue with the vast amounts of information we are accumulating is that this information needs to be stored and all the information that is being generated requires servers as storage vehicles. Although some people and businesses own and maintain their own servers, many look to hosted environments. These servers are housed in physical buildings and provide us with our "cloud" environment. These facilities have costs associated with them and consume large amounts of energy. They are, and must, always on. The result is that, "data centers can waste 90 percent or more of the electricity they pull off the grid. They further rely on backsup generators. A backup diesel generator at a large computer data center is capable of providing enough power for a community of 7,000 homes." 92 The wasteful use of power is driven by users that demand an instantaneous response to their immediate desire for information through the click of their mouse.

The access points to cyberspace through the digital medium are well-defined. The space between these access points however, becomes blurred and less defined. Bertol and Foell explains that due to Web/cyberspace, users' ability to be everywhere at the same time and simultaneously with their network of connections, alters

\footnotetext{
${ }^{91}$ Manguel 2007: 223.

${ }^{92}$ Glanz 2012: http://www.nytimes.com/2012/09/23/technology/data-centers-waste-vast-amounts-of-energy-belying-industryimage.html?_r=1\&partner=rss\&emc=rss. . Accessed on 22/10/2012).
} 
our traditional concept of time and space. They argue that buildings such as bookstores, libraries, schools and museums have a potential of being replaced by cyberspace. The sense of a physical place that we identify with starts to disappear because we don't associate with them. ${ }^{93}$ This space without place does not have the constraints of a physical place, making it seem limitless. Manguel explains that users of the Web are not concerned with the past because they place importance on the information displayed on their computer screen. A book has physical age and volume but the Web doesn't have a history as a physical object, is all surface and has no shared time but does encourage speed. ${ }^{94}$

Although the Web does not contain everything, it certainly tries to emulate the ambition of the traditional library to contain all that is recorded. The Ancient Library of Alexandria exhibited society's desire to contain all of the knowledge in the world and yet it was lost. It was burned down resulting in many books and scrolls being destroyed. It can be seen as a symbol of the fact that all conceivable/recorded knowledge in a medium can still be destroyed.

\footnotetext{
${ }^{93}$ Bertol and Foell 1997: 60-61.

${ }^{94}$ Manguel 2007: 225.
} 
Some of the earliest Canadian libraries were private collections belonging to European immigrants. In the eighteenth and nineteenth centuries these libraries were maintained in military posts, settlements and fur trading posts. ${ }^{95}$ One example of a contemporary Canadian library is the Ottawa Public Library (see fig. $35 \& 36)$. The building was constructed in 1974 in the 'Brutalist' style. It is constructed primarily of concrete, has corners and not much light. It was meant to replace the smaller Carnegie libraries. The only part of the Carnegie library left in our central home of the Ottawa Public Library today is the stained glass window (see fig. 37)..$^{96}$

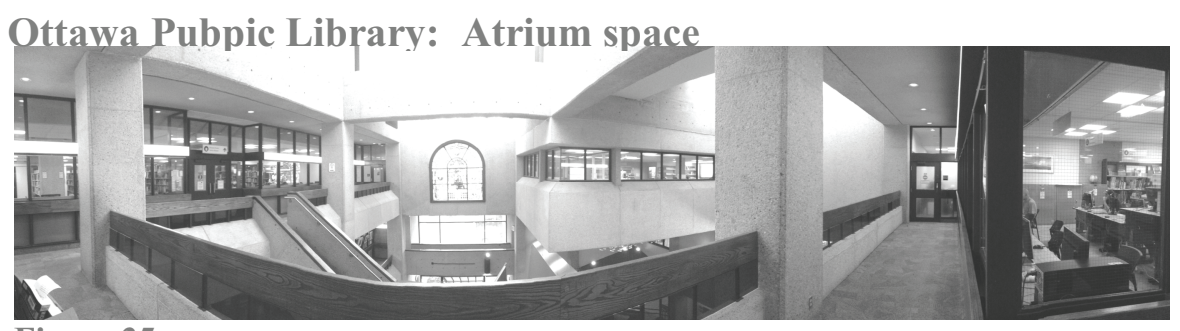

Figure 35

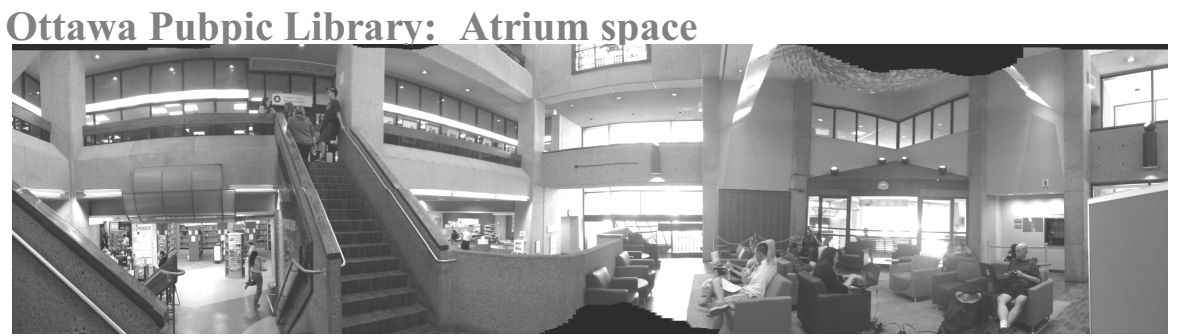

Figure 36

\subsection{3}

\section{Current Ottawa}

\section{Public Library}

“.... construction of 125 Canadian libraries between 1901 and 1923. Influenced by the beaux-arts design common in public buildings of that period, classical columns and other elaborate ornamentation...... 1960 s and 1970 s, with emphasis on internal rather than external monumentalism.... 1980 s and 1990s focused attention on renovations and additions rather than new construction..... Technological developments such as electronic compact shelving became the basis for accommodation of collection growth without additional construction.... neighbouring universities integrated their catalogues and a shared storage facility for less used materials, reducing the space required for the individual collections but increasing the resources accessible to all members."

Beckman 2013: 〈http://www.encyclopediecanadienne.ca/arti cles/libraries $>$.(Accessed on 12/02/2012).

${ }^{95}$ Beckman 2013: 〈http://www.encyclopediecanadienne.ca/articles/libraries $\rangle$.(Accessed on 12/02/2012).

${ }^{96}$ Brule 2013: Personal interview. 20/06/2013. 
Ottawa Public Library: Carnegie window

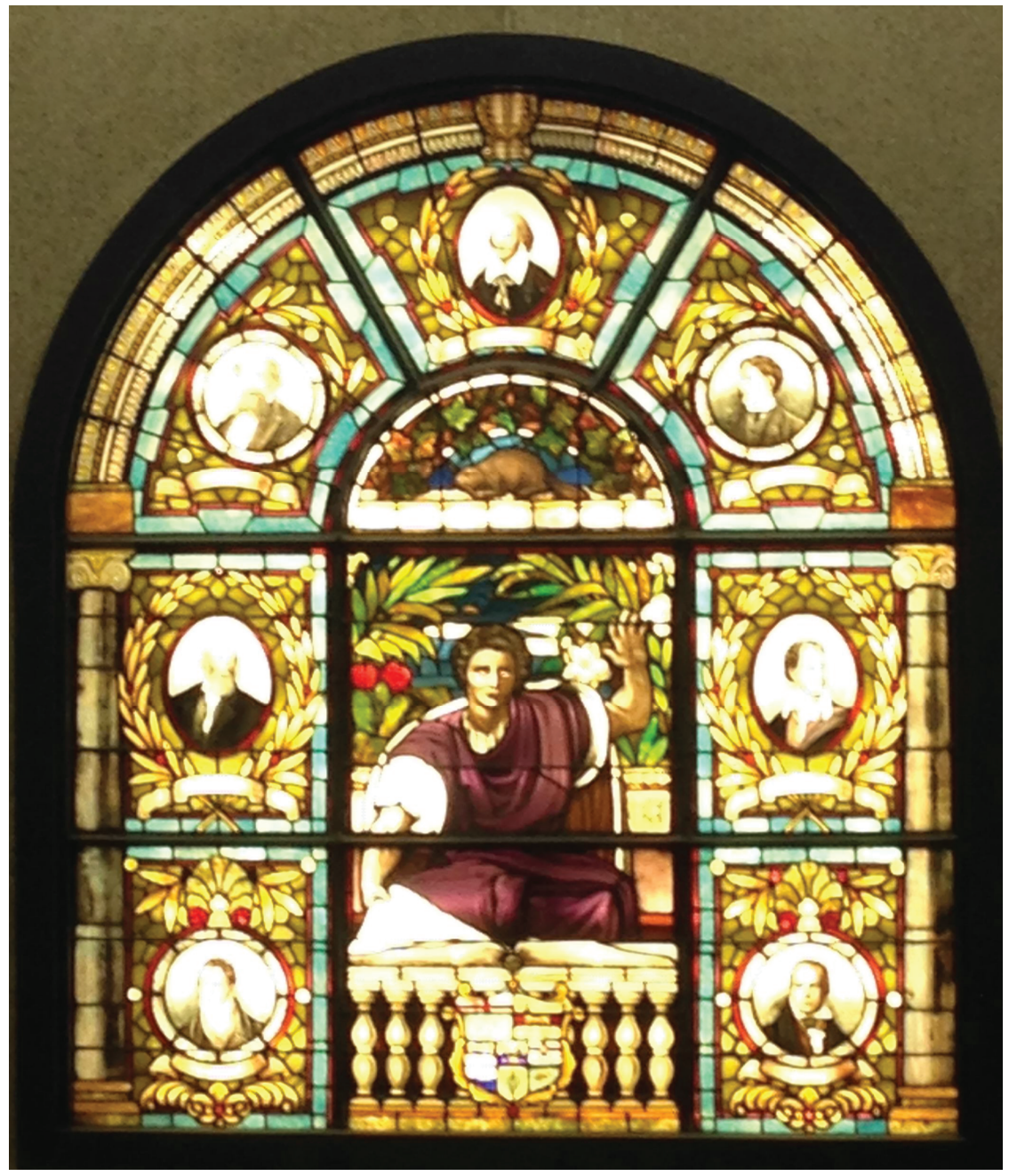

Figure 37

Monique Brule, a collections manager with the Ottawa Public Library stated in an interview that the library, once mainly a book repository, is now a collaborative community and individual space. Every branch of the Ottawa Public Library looks at space differently with each design based upon the community and the people within the community. The use of space is varied with people wanting both physical and digital books. As a result, all available space is used and there is a seemingly constant struggle to find more space. These space constraints make it more attractive for the library to store information online. Ms. Brule commented 
that the library is more than a repository because people can go to read and not purchase anything there, making it one of the only places that loitering and not purchasing anything is encouraged. As a result, the Ottawa Public Library is adapting the library environment with a focus on casual visitors instead of simply providing individualized desks. ${ }^{97}$

The collection development department, with input from the public, chooses the materials to keep and those to disregard. The collections are very diverse but still filtered (see fig. 38). Items long in disuse are culled. The Ottawa Library houses material in eleven languages inlcuding English and French and has books and electronic devices such as CD-ROMs and DVDs. They also lend out museum and ski passes. Ms. Brule stated that digitizing certain items is a slow process but they have approximately $5 \%$ of their material digitized and will continue the process. The budget is a priority issue since it remains constant even as demand grows for electronic devices and their applications. Furthermore electronic devices are more expensive than physical books and more money is spent for the same amount of content. There are different barriers to overcome with electronics; yet, the library recognizes that although costs may be higher, they still want to provide this capability. An issue that is currently being discussed is the ownership of physical and digital books. When a library purchases a physical book, it is theirs to keep forever. However, when leasing an electronic copy, the book has a limited ownership period with the library. If the contract is completed or a vendor withdraws its support or access, the collection can suddenly disappear. Not all publishers make electronic books available to the library making the electronic versions unavailable to the public. Storage has

\footnotetext{
${ }^{97}$ Brule 2013: Personal interview. 20/06/2013.
} 
improved with more options for shelving, vendors, colours, compact shelving etc. available today. Organization systems include the Dewey system for non-fiction, an alphabetical system by author for fiction and subject headings but no particular classification system for online items. They market new materials by displaying them face up on sides of the shelving to make it easier for people to notice the library's selections. Accessibility for their patrons is very important and they are working to adapt. Approximately $30 \%$ of circulation is directed from Internet inquiries. People can reserve and select books online and come in quickly to pick them up. The most popular books are located closest to the entrance and on displayed for people to access them quickly without having to do a long search within the library (see fig. 39). ${ }^{98}$

Ottawa Public Library: Book collection on the second floor

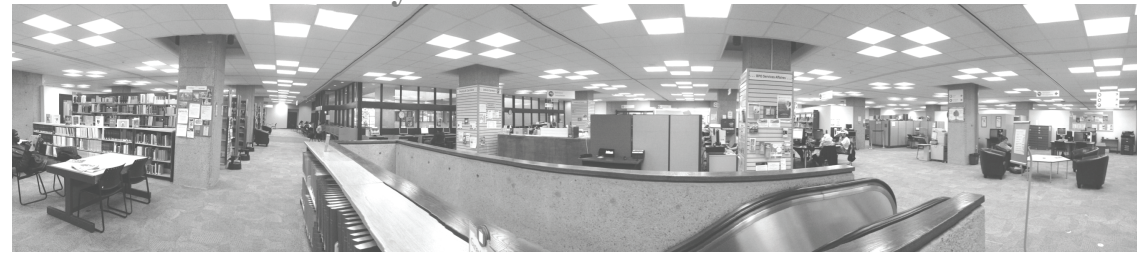

Figure 38

Ottawa Public Library: Express checkout terminals and express books

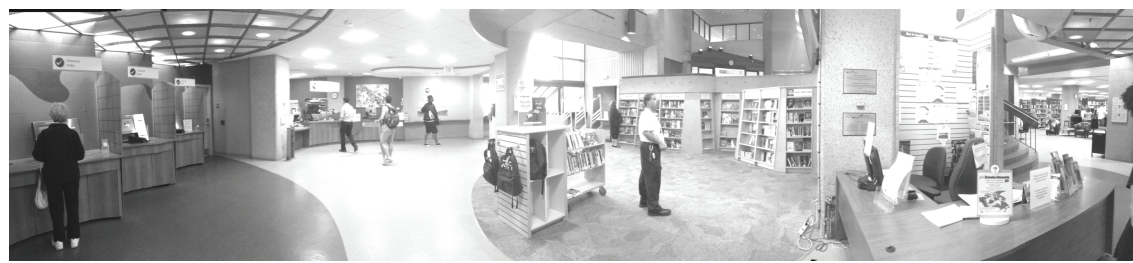

Figure 39

\footnotetext{
${ }^{98}$ Brule 2013: Personal interview. 20/06/2013.
} 
According to an article in the Ottawa Sun and an interview with the collections manager at the Ottawa Public Library, the use of one medium, such as technology, is not necessarily replacing other forms. Visitors are still using the library despite their ability to access information digitally. "In 2012, downloaded eBooks/Audio books/music was $6 \%$ of the $11,172,085$ items borrowed." 99 The library itself is trying to embrace technology. They teach visitors the proper methods for using these electronics so they are able to read their content. They offer free Wi-Fi and computers for public use. They also provide services beyond electronics and books including social spaces for seminars or meetings and writing workshops. Kelly Roche, when asked if the information that can be accessed from anywhere will make the library not as appealing for visitors said it "will be more enticing because we can get information from home.",100

\section{Conclusion:}

Whether libraries made of physical materials or flickering screens, the advancements in technology have changed rapidly over the years, changing how people interact, our relationships and our social gathering habits. We are now witnessing a major shift in methods for gathering, containing and experiencing knowledge and information. The effects of information technology on our everyday life are causing parts of our cities to disperse, making physical boundaries obsolete. The advancements in technology allow us to use wireless devices to communicate and access information. This loosens the physical need to connect to a particular place within a city. This is an issue because we can now essentially be in two or more places at the same time since some of

\footnotetext{
${ }^{99}$ Roche 2013: Ottawa Sun newspaper article. 26/05/2013.

${ }^{100}$ Roche 2013: Personal interview. 13/06/2013.
} 
our tasks can be done wirelessly and without being necessitating our physical presence. Furthermore, the library is not the only place to get information anymore.

"Quantity, speed, precision, on-demand availability are
obviously important to the researching scholar. And the birth of new
technology need not mean the death of an earlier one: the invention
of photography did not eliminate painting, it renewed it, and the
screen and the Codex can feed off each other and coexist amicably
on the same reader's desk....the craft of reading cannot be entirely
replaced by scrolling down the screen, any more than real travel can
be replaced by travelogues and 3-D gadgets.",101

Technology however, will not necessarily make the library disappear. Although there are libraries that do not have all their content online it is essentially the place that matters. Place matters because physical architecture allows us to relate to a physical world. We live in the physical world and are not isolated from it.

\footnotetext{
${ }^{101}$ Manguel 2007: 78-79.
} 


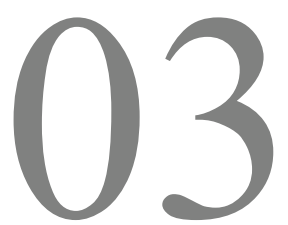

CHAPTER

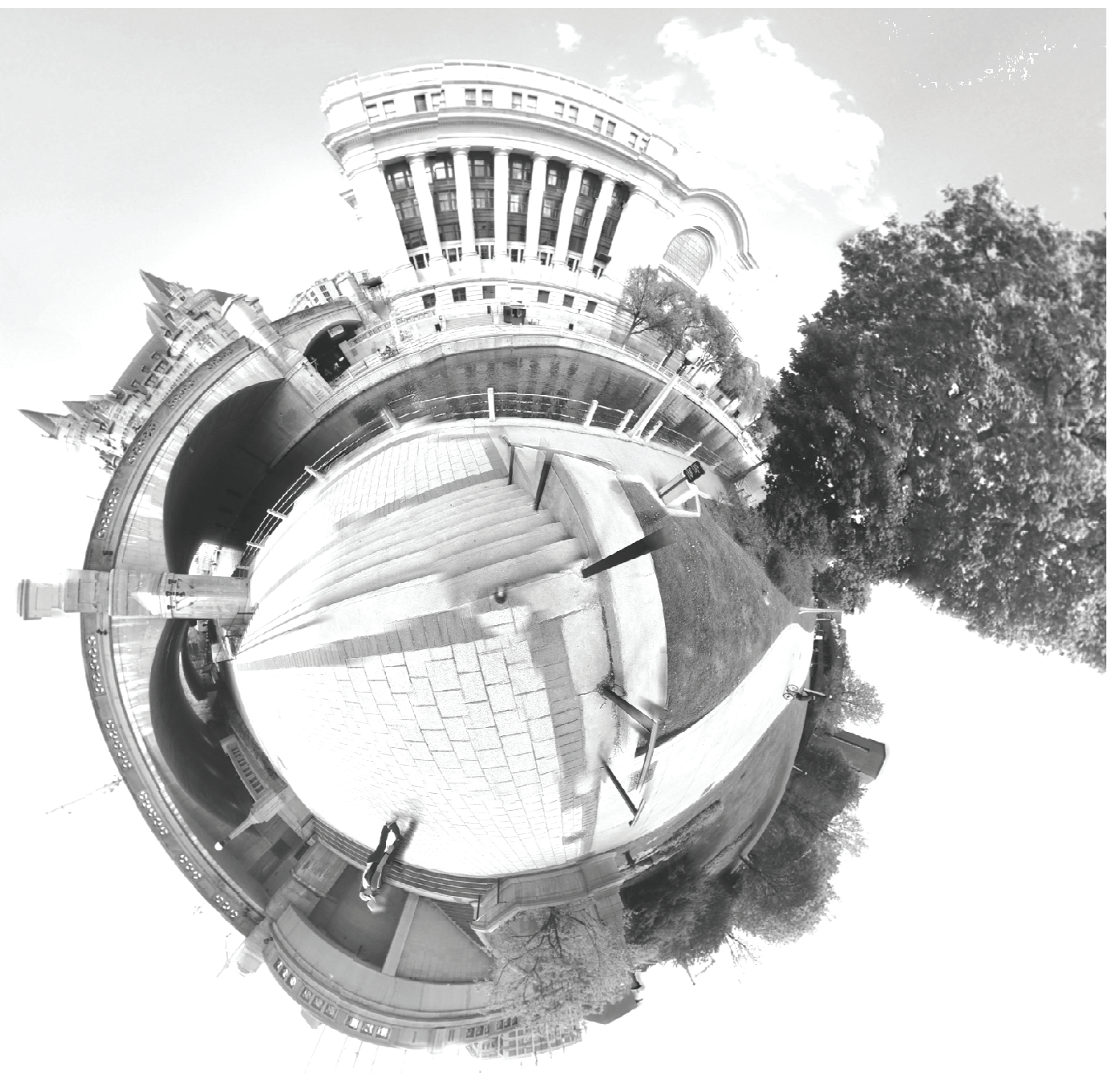

Figure 40 


\title{
3 Chapter: The Contemporary Library
}

\author{
"Architecture enables us to perceive and \\ understand the dialectics or permanence \\ and change, to settle ourselves in the world, \\ and to place ourselves in the continuum of \\ culture and time.... All experience implies \\ the acts of recollecting, remembering and \\ comparing., "I
}

Advancements in information technology are challenging the role of the traditional library as a central communal information resource. Access to information from homes, Internet cafés and mobile phones means we are no longer bound to the traditional library. The technological revolution has changed the way people interact with each other and their relationships in social gatherings. The weight of endless volumes of books is now reduced to a single computer, which one can access wirelessly, through Internet social applications and through mobile devices. While technology provides us with easier and faster ways to access information, our use of this technology can result in distancing ourselves from one another. This can be attributed to dispersed nodes dissolving the social interactions and physical connections that a physical library encourages. Since we cannot avoid the evolution and development of technology and we cannot ignore the importance of social interaction and physical connection with one another, it is critical to find a way to incorporate both into the physical place. The design of a primary Hub that ties all the nodes together in a central location is proposed for this project. The nodes include private libraries, museums, art galleries and social | media elements that are dispersed throughout the City of Ottawa.

\footnotetext{
${ }^{1}$ Pallasmaa 2005: 71-72.
} 


\subsection{Intent of the proposed project as a forum and nodes}

The contemporary library manifests itself as dispersed nodes throughout the city. It is in need of a central hub to tie them all together (see fig. 41). This is important for sustaining social interactions and providing a physical connection for the transfer of knowledge while still embracing advancements in technology. This physical connection links us to a defined place that incorporates all of our senses and connects us to other people.

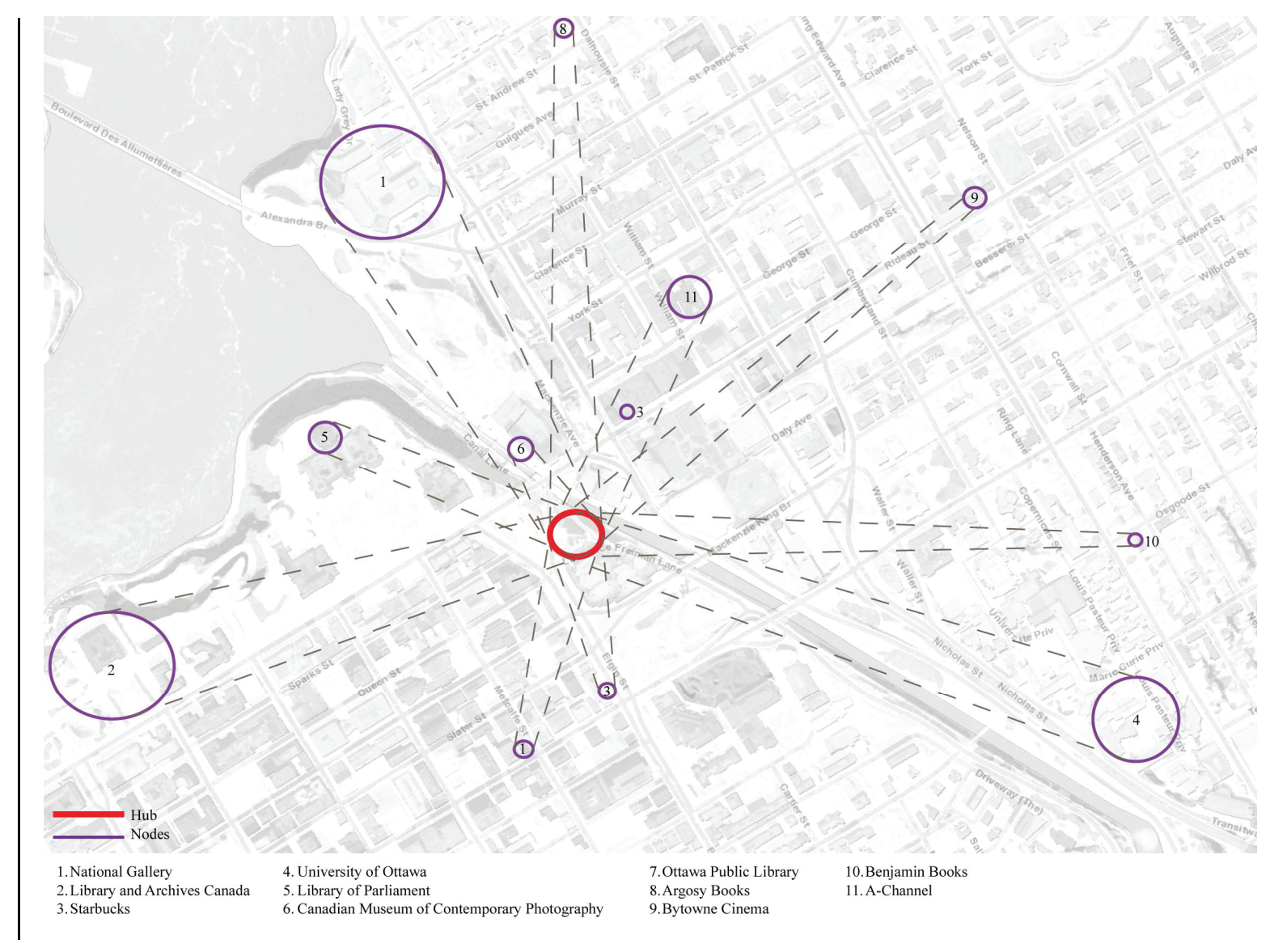

Figure 41 
The nodes can be located anywhere and can contain different collections. They can be tied to private library collections, museums, and galleries. These nodes become narrative spaces telling the stories of the individual collections. Each node can have its own expression and yet be an integral part of the larger changing picture of the city and of the Hub since each of the collections will be digitally networked to the hub.

The project proposes in my project that the site for the hub be situated in Ottawa, Canada's capital (see fig. 42). The hub is designed as a multi purpose entity with many multi media connections to additional places within the city. It will operate 24 hours per day and act as a gathering place that brings people together, with digital documents and physical books coexisting and supporting each other. The library space needs to be flexible and adaptable to unknown future uses. This ensures that more links can be created for transferring knowledge in different ways, providing a diverse group of people with a place where they can meet and share their ideas and stories. Here people can connect with and learn from each other, helping to define our greater culture. 
The 'Hub library' acts as a shifting point between the world of texts and the digital world, merging them together to create a balance between a physical library and a digital library. The physical books act as references to the digital information and the two different information mediums work together. In this way the hub can enhance awareness of the methods in which we choose to gather information and expresses the importance of having various information mediums co-exist. The goal of the hub is to bring people together, to share and record knowledge. There are also areas devoted to promoting

\subsection{Site location, conditions and organization}

It is important for the Hub to respond to its site location and to the surrounding urban fabric. Since the Hub's goal is to educate users and combine personal development, cultural enhancement and entertainment, it is important for the Hub to be accessible to everyone.

The building identity comes from its context. This is important in order to pick up on the different activities and patterns of use that the site is currently attracting. The Hub creates interactions between people and urban spaces. It brings us awareness and roots us back to the complexity of the city and its networks. The desire is to avoid the rigid hierarchies seen within many libraries or monumental compositions such as those of Gothic cathedrals. Instead it must offer both a response to the urban environment and to the question of "what is a contemporary library?' 
The site proposed for the Hub is in a central spot located along Confederation Boulevard (see fig. 44). This is known as the Grand route and runs through the centre of Ottawa. Its path has been historically used for important national ceremonies and parades. $^{2}$ This route contains key attractions and historic sites, ${ }^{3}$ monuments and public art, green spaces and waterways. ${ }^{4}$ Vibrant colors often predominate with the Christmas Lights Across Canada show, banners celebrating Canada's provinces and territories and important events in Canadian history, and the Tulip Festival. ${ }^{5}$ Although there are many significant buildings around the site, the hub does not try to visually compete with them (see fig. 43). The library is modest in size, visually paying homage to its existing historic neighbors.

\footnotetext{
${ }^{2}$ Route that foreign dignitaries and Royal Family use during visits. People watch changing of guard and Remembrance Day ceremony. ${ }^{3}$ Include: Parliament Hill, Rideau Hall, 24 Sussex, the Supreme Court of Canada, the Canadian Museum of Civilization, the National Gallery of Canada, the National Arts Centre, National Archives, National War Memorial, Ottawa Convention Centre, Chateau Laurier, ByWard Market, Rideau Centre, etc

${ }^{4}$ Include Nepean Point, Confederation Park, Jacques-Cartier Park, Major’s Hill Park, Ottawa River and Rideau Canal.

$\langle$ http://www.canadascapital.gc.ca/places-to-visit/confederation-boulevard $\rangle$. (Accessed on 24/09/2012).

${ }^{5}$ http://www.canadascapital.gc.ca/places-to-visit/confederation-boulevard . (Accessed on 24/09/2012)
} 


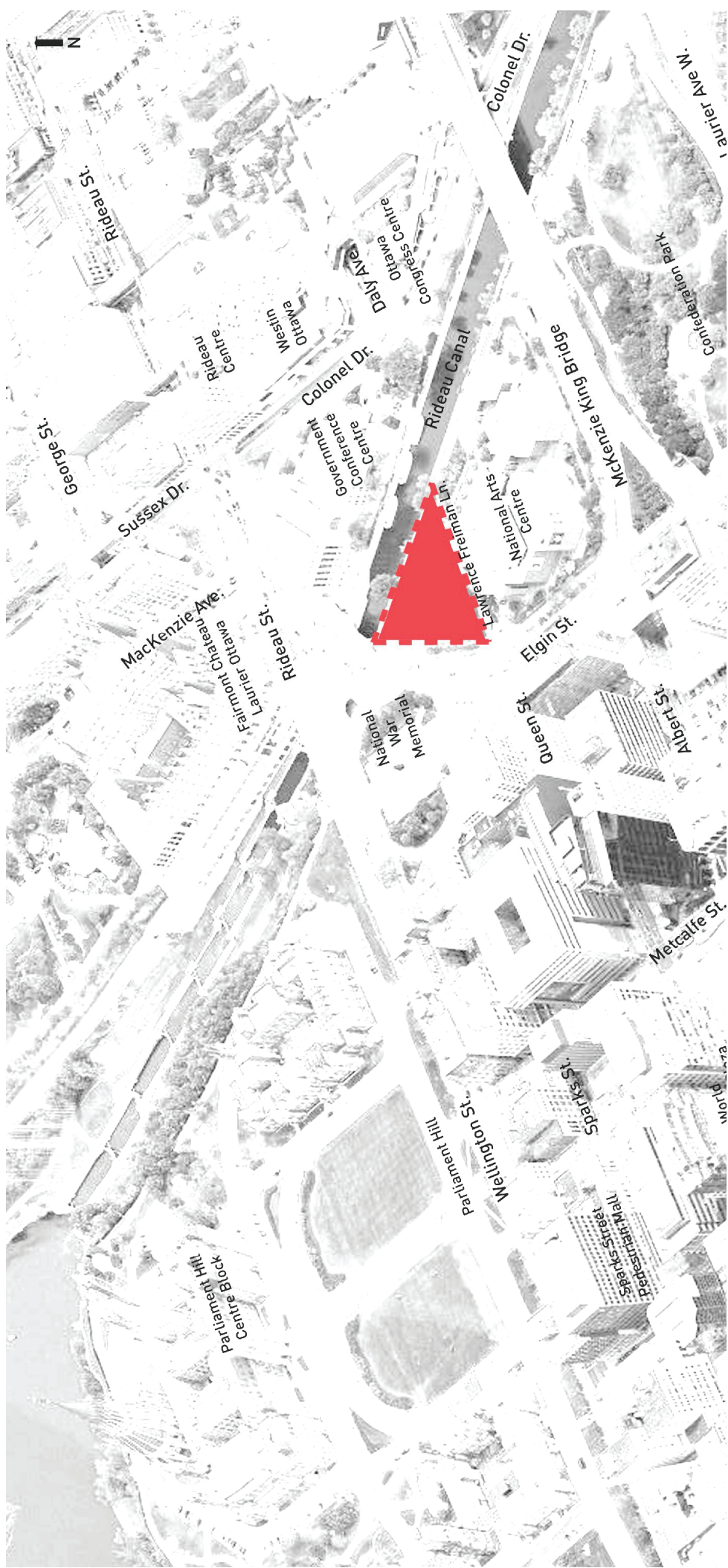

Figure 42

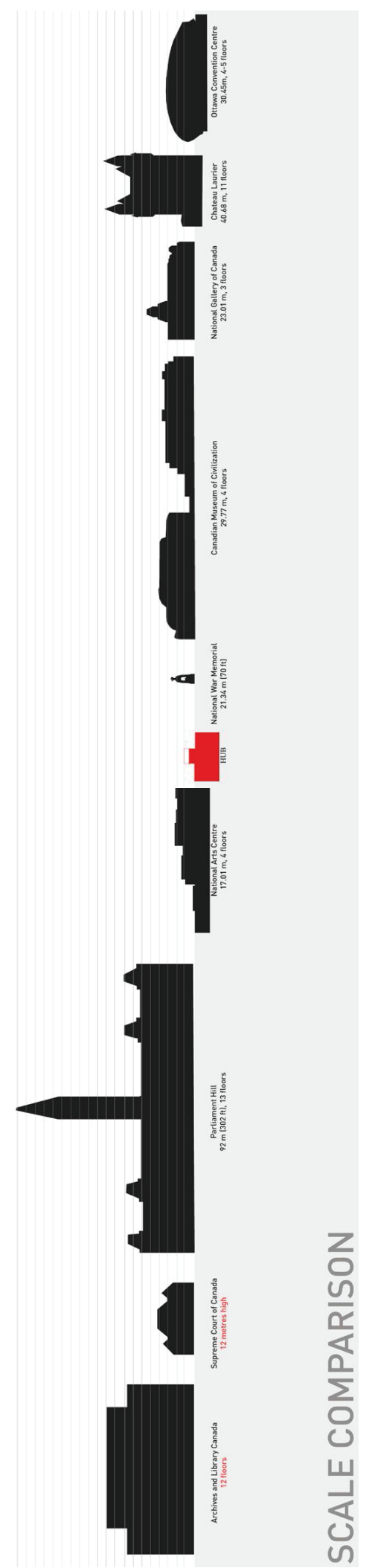

Figure 43 


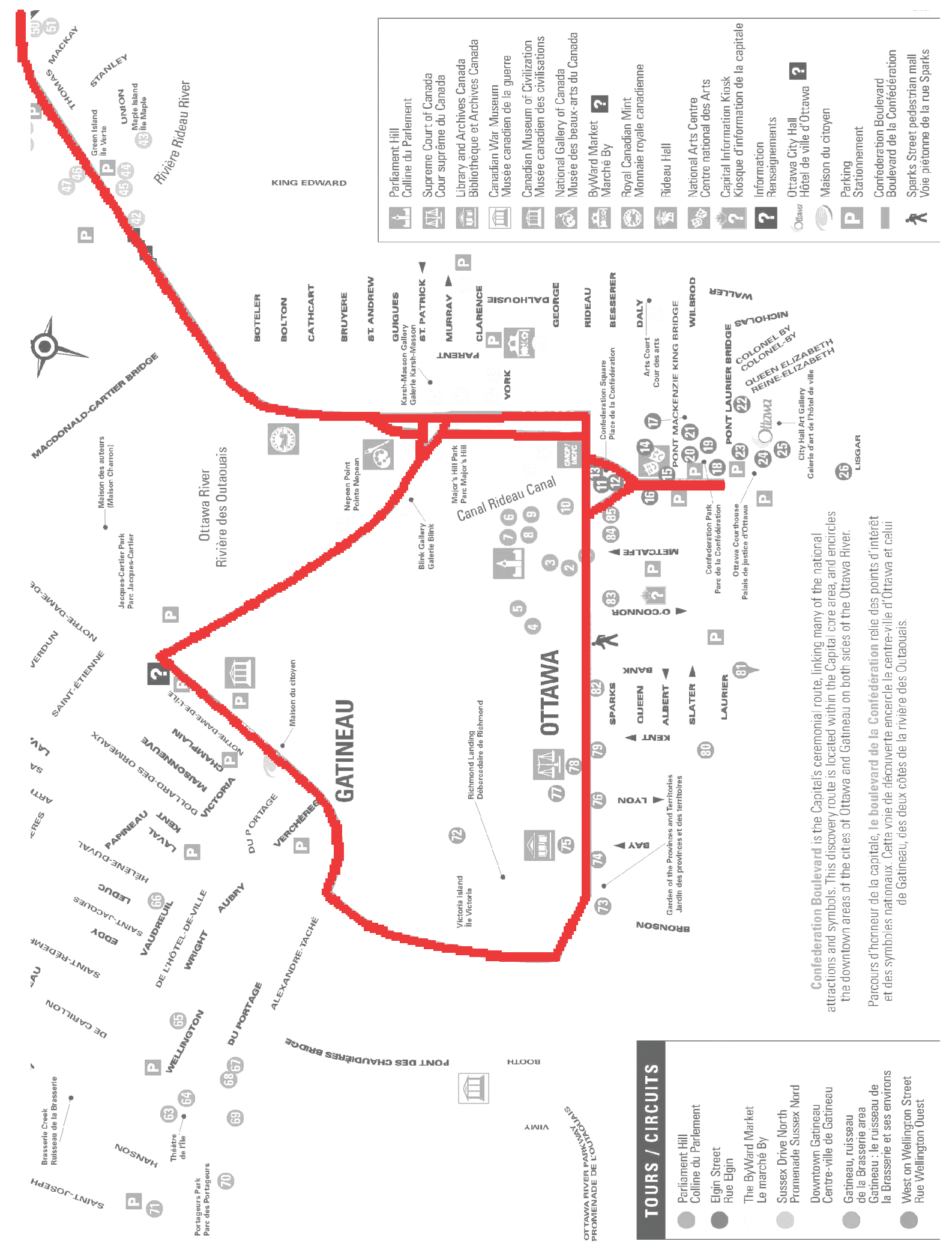

Figure 44 
The site can be accessed from Elgin Street, Rideau Street, Lawrence Freiman Lane, and the Rideau Canal (see figs. 45, 46, 47 $\& 48)$. People will also be able to access it from the Rideau Canal ${ }^{6}$ if traveling by boat in the summer or by skates in the winter. Another access point is from the Confederation Line, the new light rail $^{7}$ tunnel that will run beneath the Complex. The new Light Rail Transit system is proposed to run beneath the Library and will connect many of Ottawa's popular attractions. An additional mode of access is via bicycle. There will be well-lit rack locations that are close to entrances and protected from the weather. This conforms with the Ottawa Cycling Plan which tries to improve cycling conditions and encourages people to walk. ${ }^{8}$ The site can also be accessed from many bus routes throughout the city that converge at nearby schools, offices, pedestrian areas and tourist sites within the downtown core (see fig. 49).

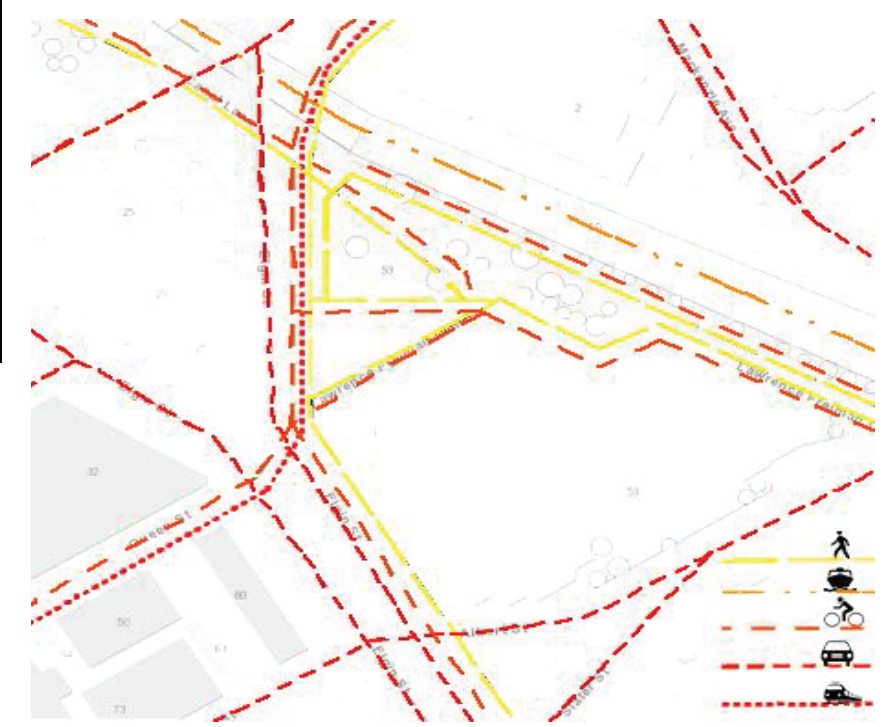

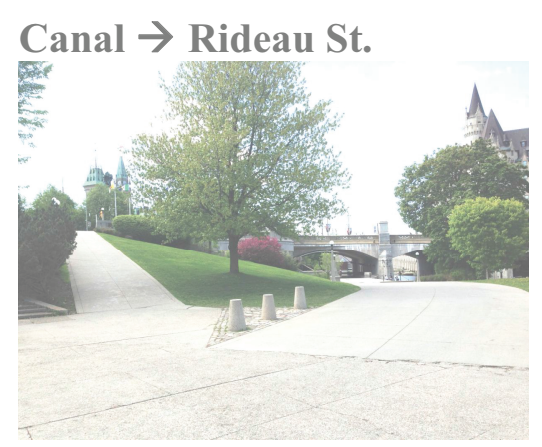

Figure 45

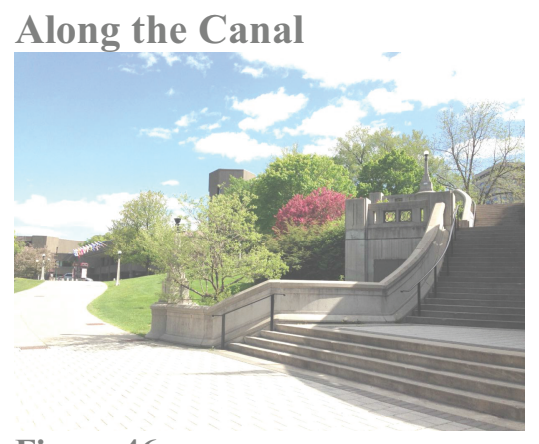

Figure 46

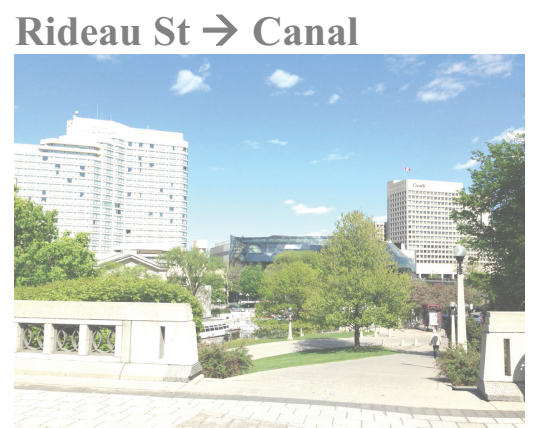

Figure 47

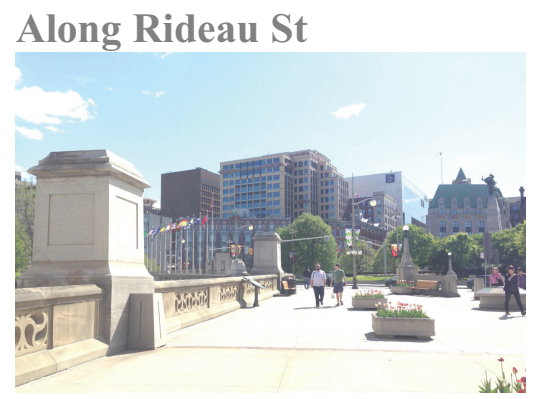

Figure 48

| ${ }^{6}$ It was originally a commercial waterway and eventually became used for recreation. 〈http://www.canadashistory.ca/Magazine/Online-Extension/Articles/Canal-Rideau.aspx〉. (Accessed on 03/02/2013).

"“Confederation Line is symbolic of the power of rail to join us, and of the importance of light rail in building a sustainable future for | the nation's capital."

〈http://ottawa.ca/en/residents/transportation-and-parking/cycling/ottawa-cycling-plan〉. (Accessed on 25/10/2012).

${ }^{8}$ Objectives: "Require walking-, transit- and cycling-oriented communities and employment centers."

〈http://ottawa.ca/en/residents/transportation-and-parking/cycling/ottawa-cycling-plan〉. (Accessed on 25/10/2012). 


\subsection{Organization of the Building and its Content}

In the following sections, the manner that the mixed-use Hub is organized and its materials will be discussed what it consists of. These include multiple access points, the circulation spine, both natural and 'digital landscape/digital screens' (ie. screens with digital content), exhibition of collections from the nodes, three libraries that include an underground archive, a physical book collection and a broadcasting screen (see fig. 50), as well as discussion areas that include individual speakers' corners, and interior and exterior forums. The spaces are diverse and can be adapted to both the physical library and the digital library. As needed they can be flexible or fixed, peaceful or lively. They consist of interconnected elements that reflect the society we live in, no longer hierarchically ordered but an adaptable network of connections, resulting in dynamic spaces that can be looked at from different speeds of viewing and interaction.

The multiple access points to the building reflect the differing speeds at which the various activities and tasks bordering the site are conducted, whether the experience is at great speed by car or lightrail, or leisurely, by bicycle or on foot (see figs. 51, 52, $53 \& 54)$. The library also welcomes virtual visitors sitting at a café or in classrooms, logged into its network. Visitors can access the library from many different points using a variety of transportation alternatives. In this way the Hub promotes urban continuity by connecting different public places, opening it to all the activities and events taking place around it. It does this by continuous and open arrangement and through transparent and flexible areas. By monitoring the external forces that relate to context, these forces can be a part of the determining factor of the
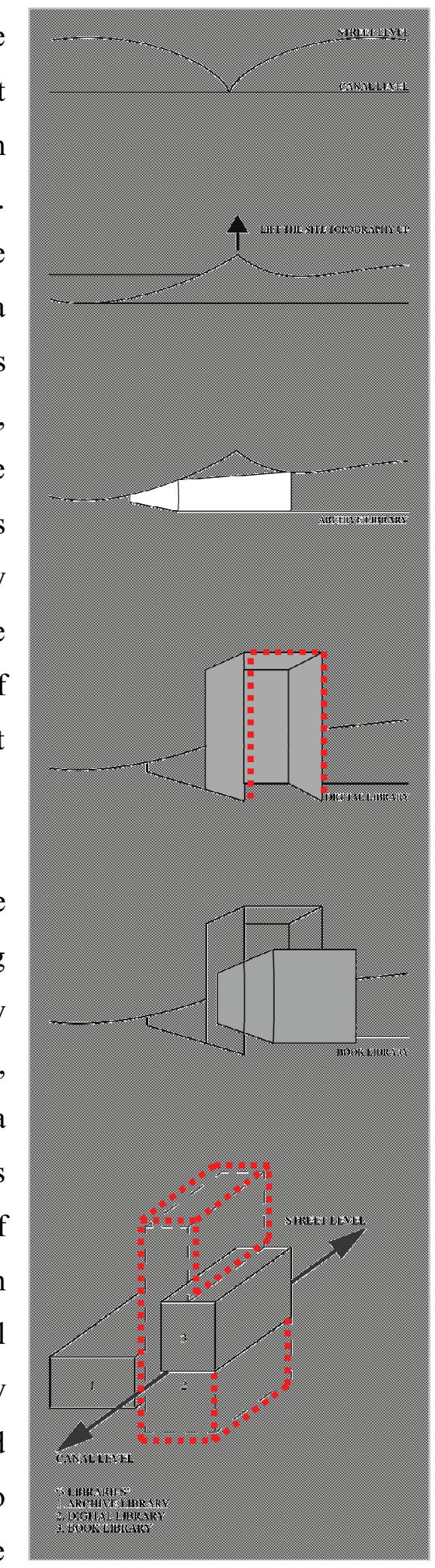

Figure 50 
building. In this way the Hub will help actualize the public space and contribute to the cultural life of the area.

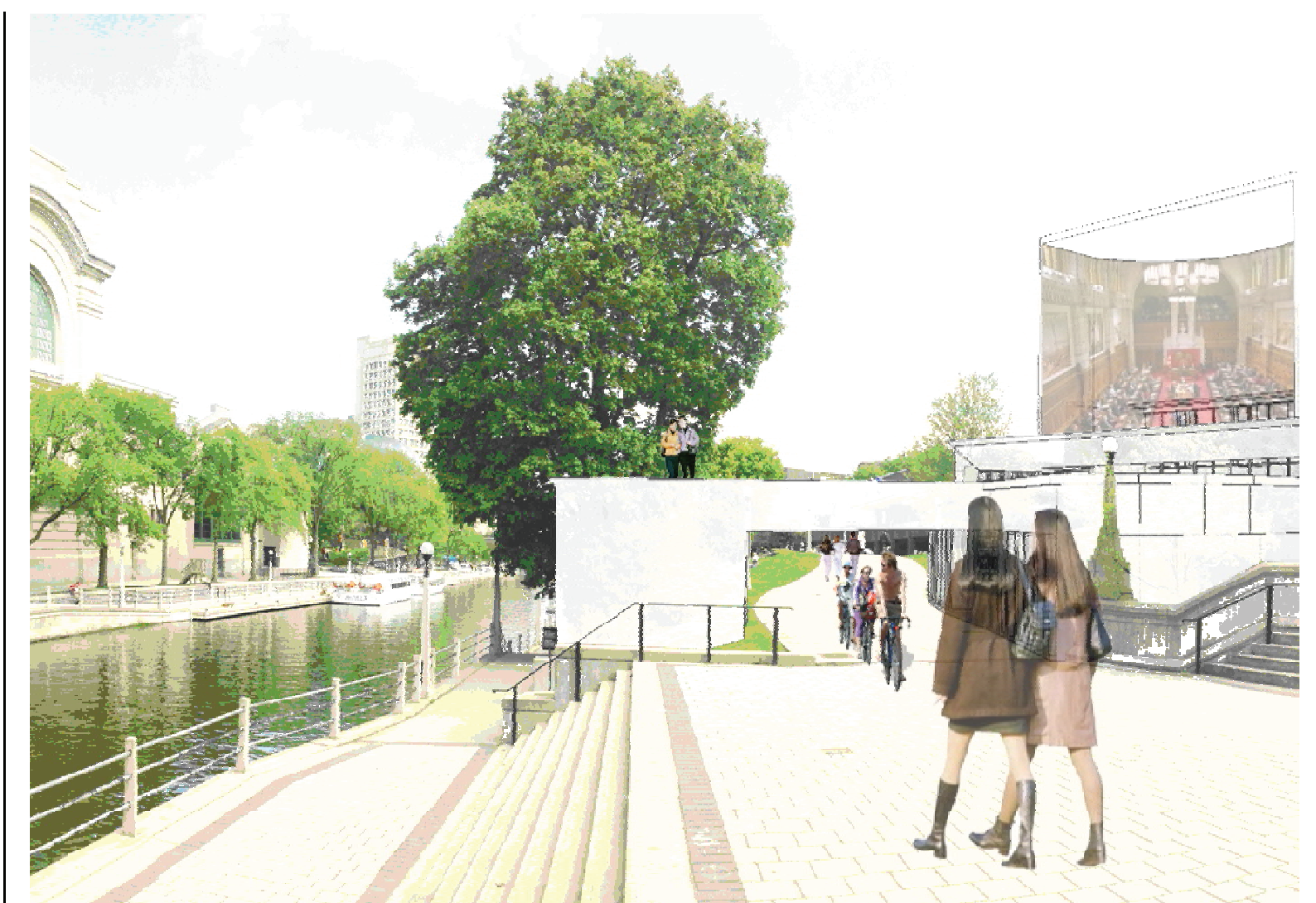

Figure 51

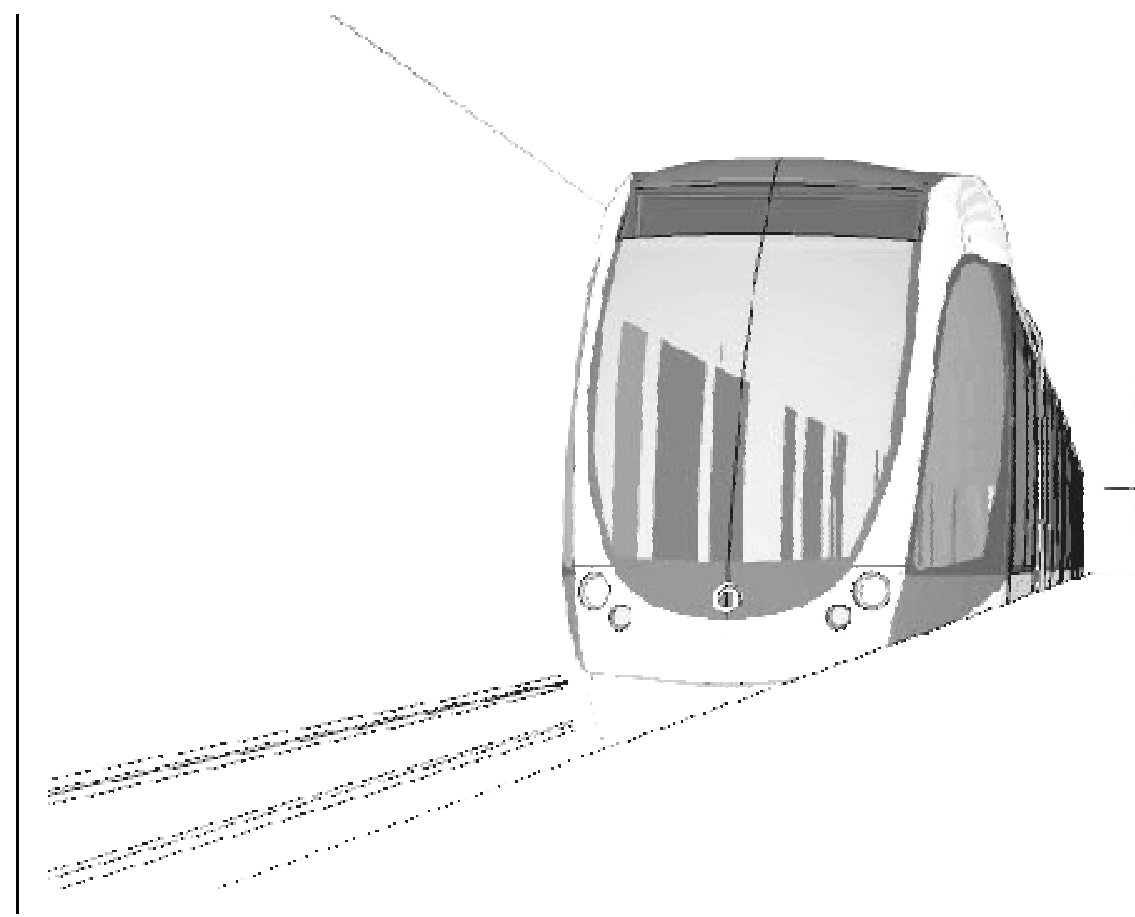

Figure 52 


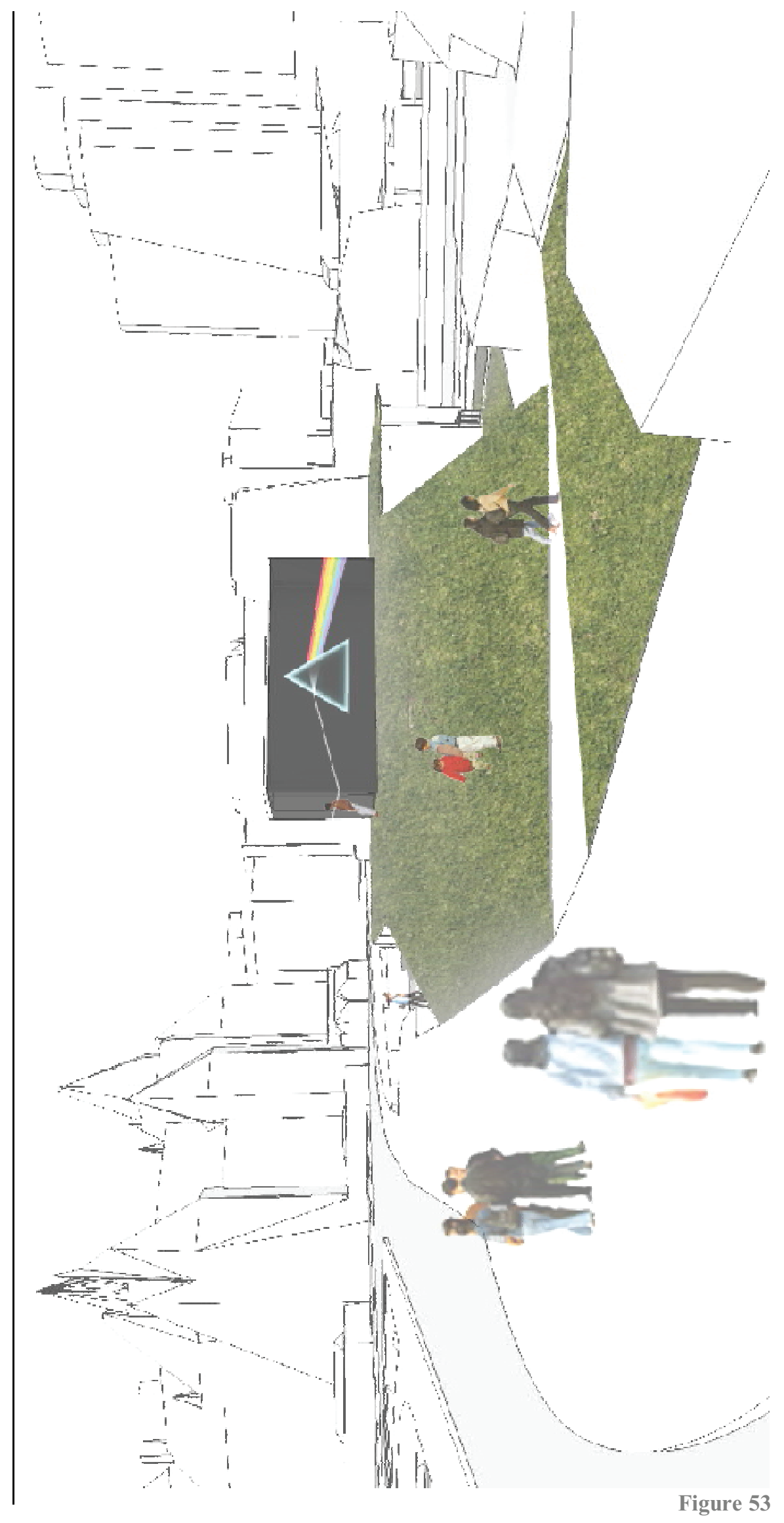




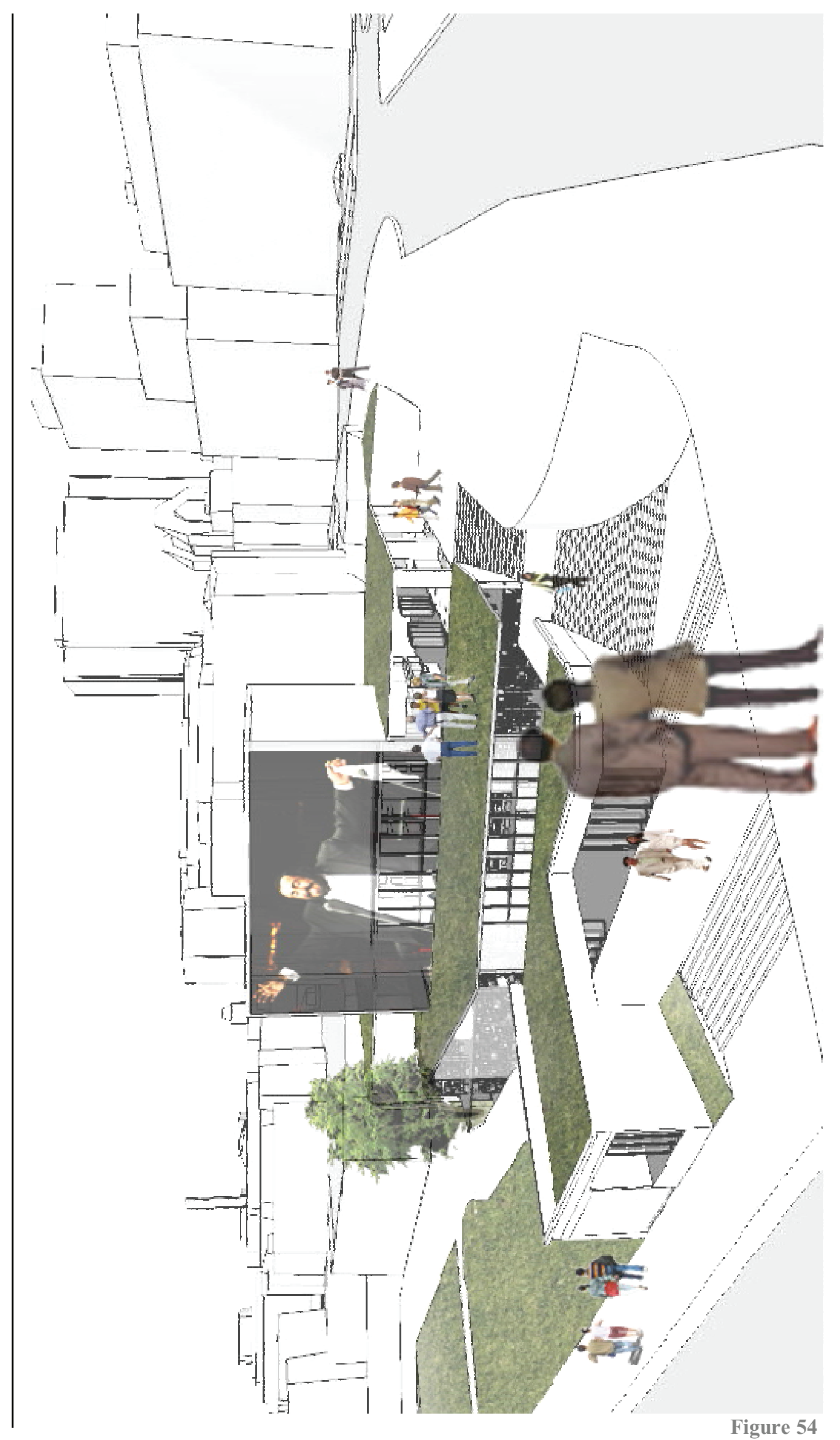


Once visitors enter the Hub they travel along the circulation spine where the ramp allows visitors to move at their own pace and access most of the programs. Along the ramp a grande allee is created by displaying books as one moves up and down the ramp. This is a reference to the National Gallery by Moshe Safdie and links art together with knowledge thereby making the visitor climb the long ramp slowly upwards until the person comes into contact with the art. ${ }^{9}$ The circulation spine in the Hub is located between the underground archive that stores historic information, books and artifacts and between books and digital media in current use. The side that merges books and digital screens has a fragmented and looser design to enable people to inhabit the space more freely. This corresponds to the idea of being wirelessly connected to everything and everywhere in a free-flowing manner. On the other side of the circulation spine where the archives are stored, the architecture is symmetrical in organization. This reflects the selective nature of containing a defined set of physical items within physical boundaries and is a reference to libraries of the past. The circulation spine connects the 'three libraries' together. These libraries are: the underground archive, physical library, and digital library. The combination of archives, books and digital mediums co-exist and support each other. This will help strengthen awareness of the different informational mediums and their coexistence (see figs. 55, 56, 57, 58, 59, $60 \& 61$ ).

\footnotetext{
${ }^{9}$ Ord 2003: 17.
} 

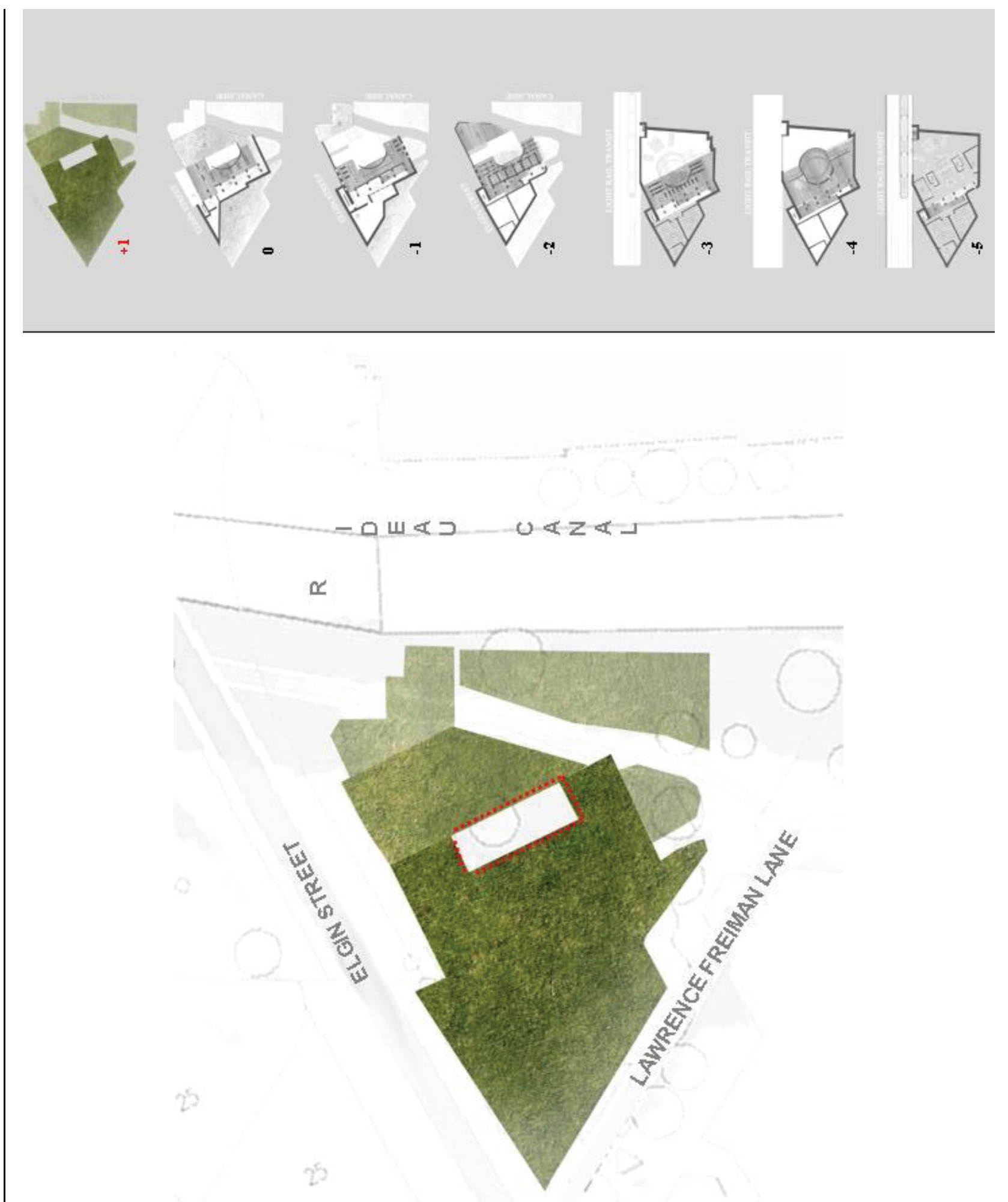

Figure 55 


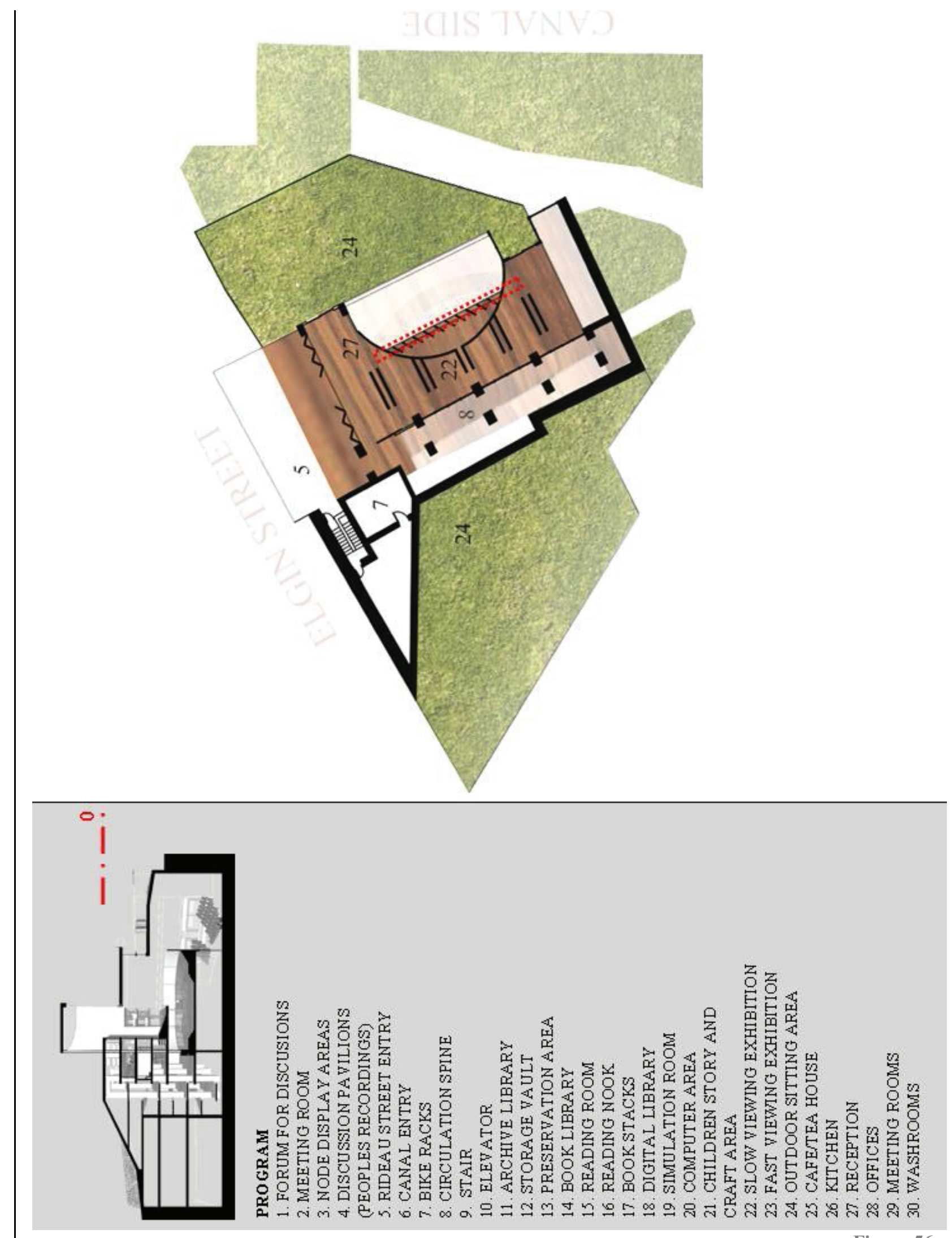

Figure 56 

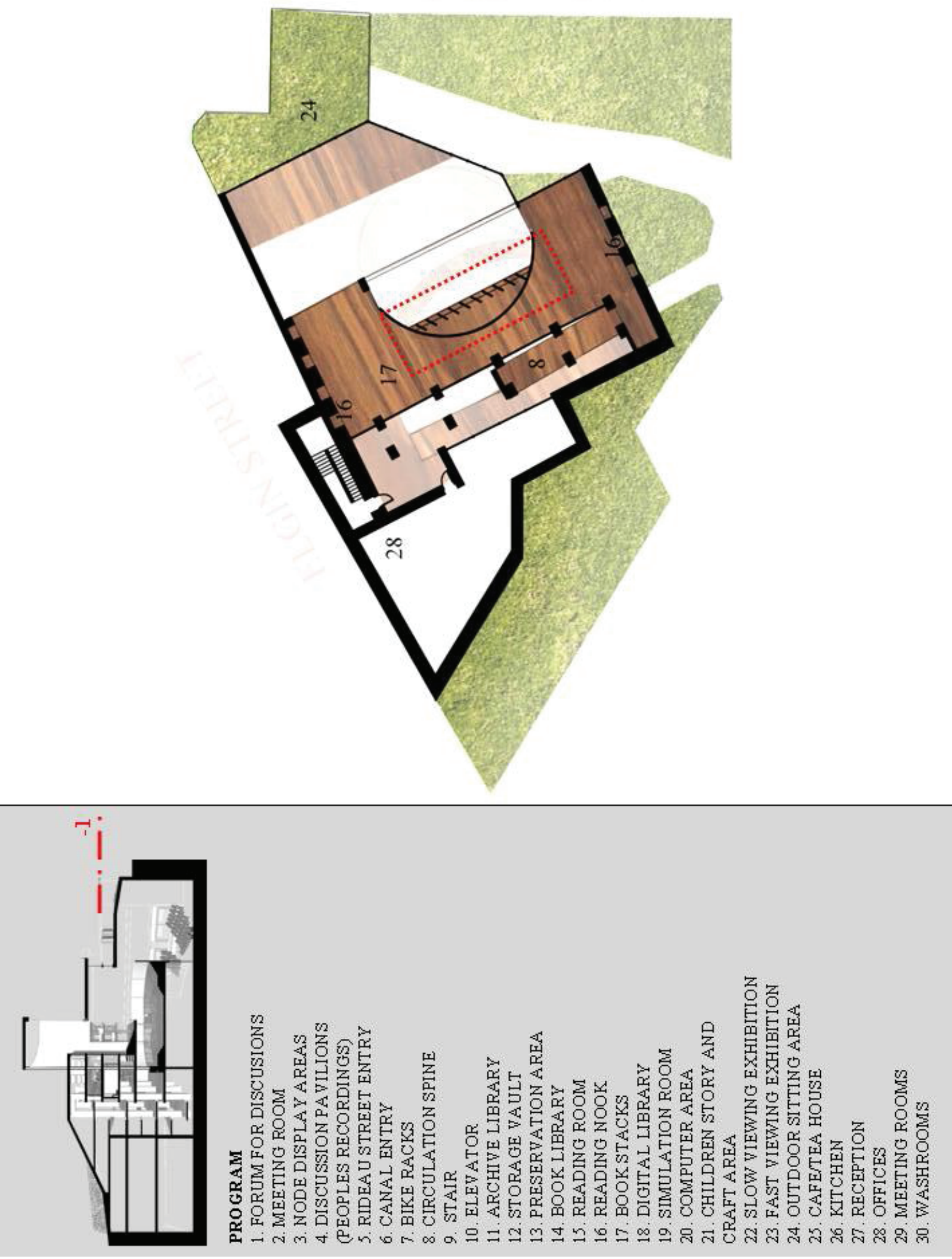

Figure 57 

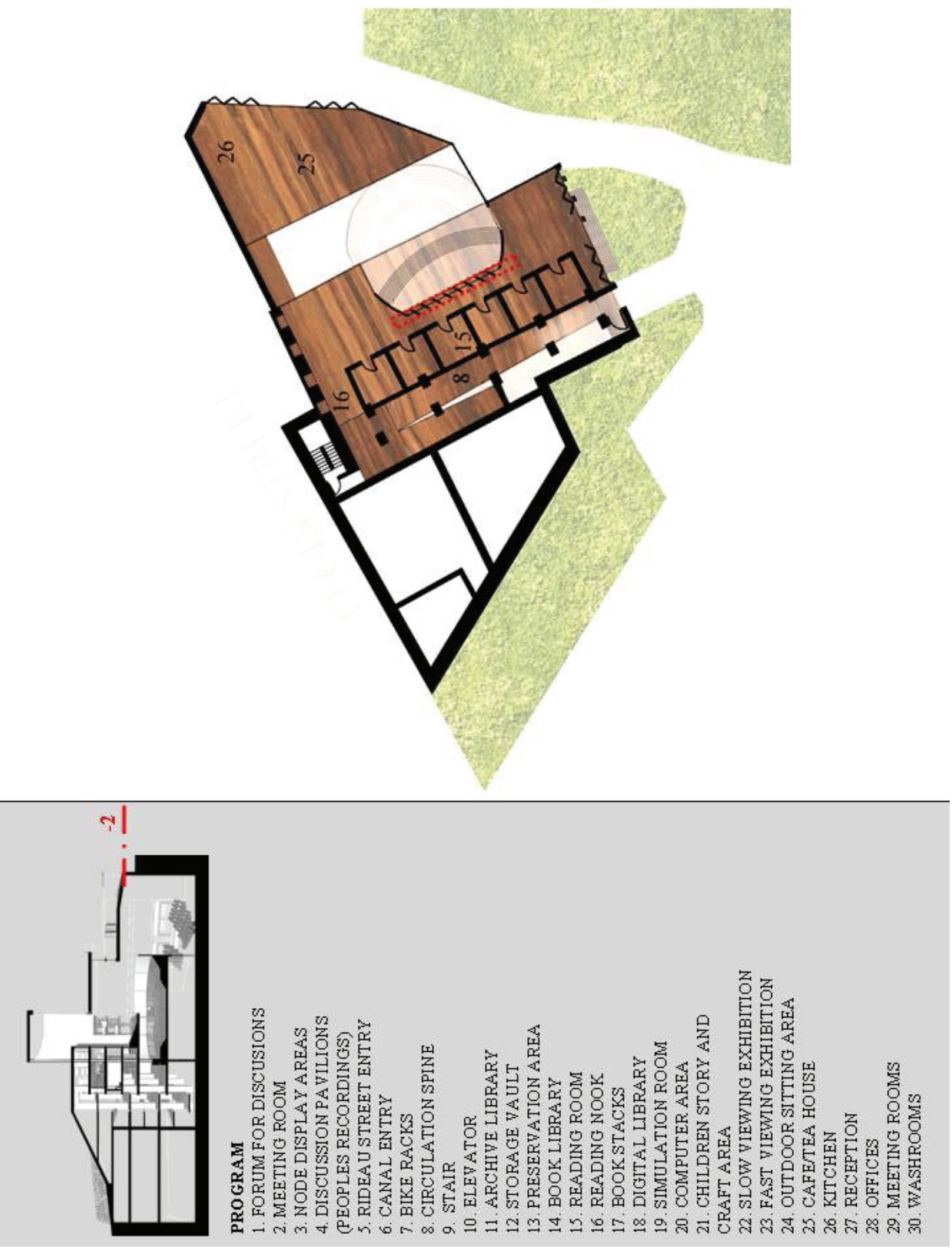

Figure 58 


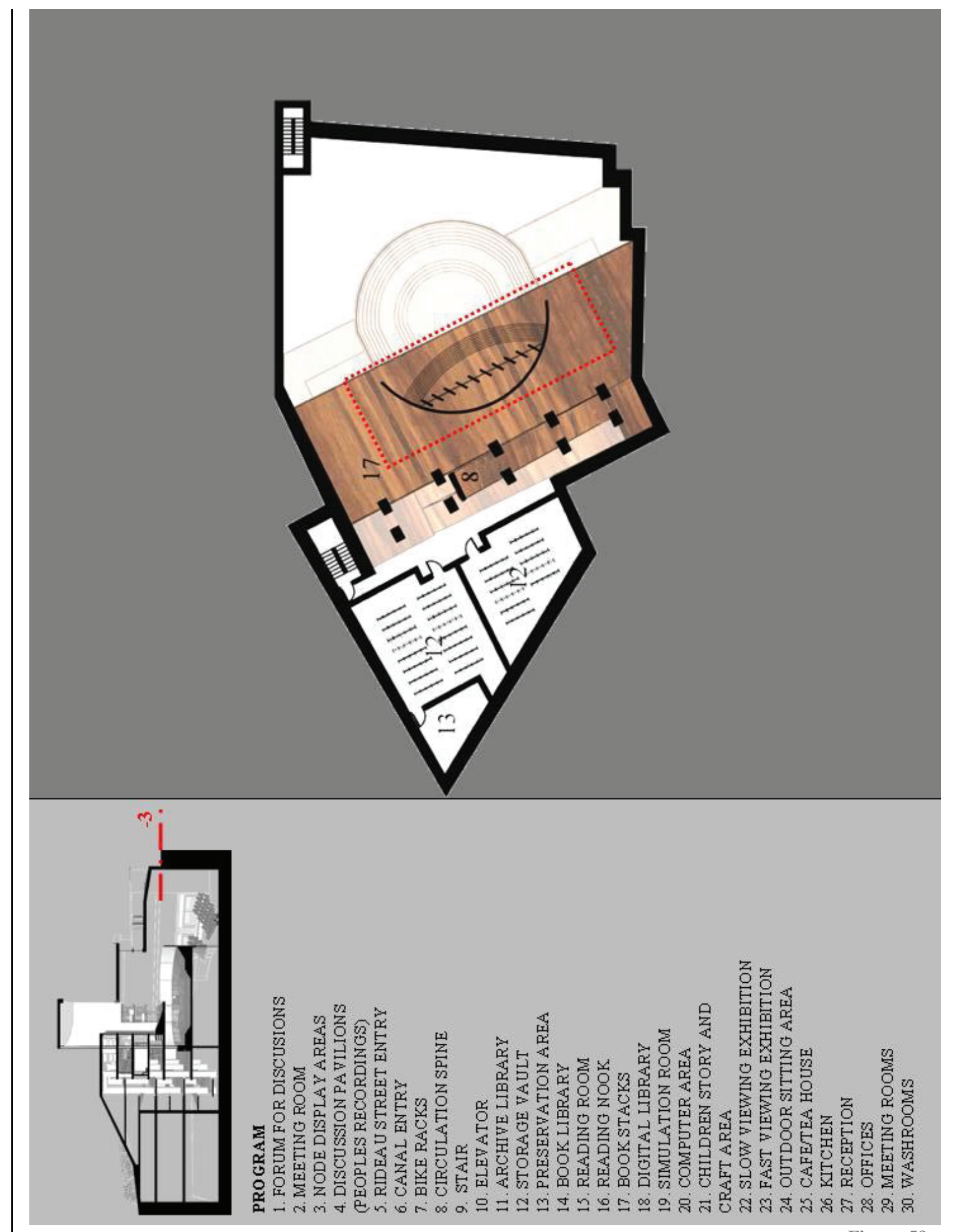

Figure 59 


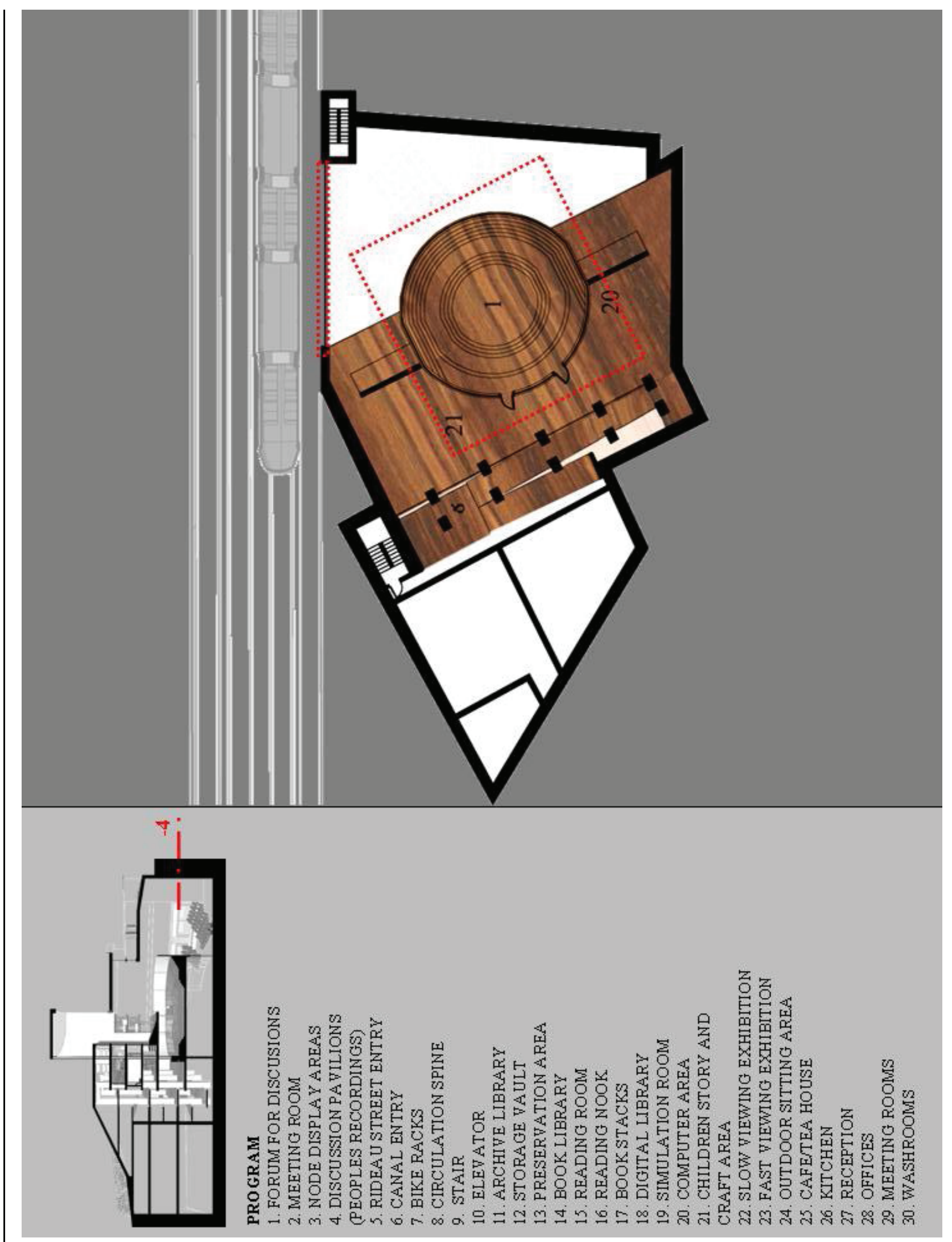

Figure 60 


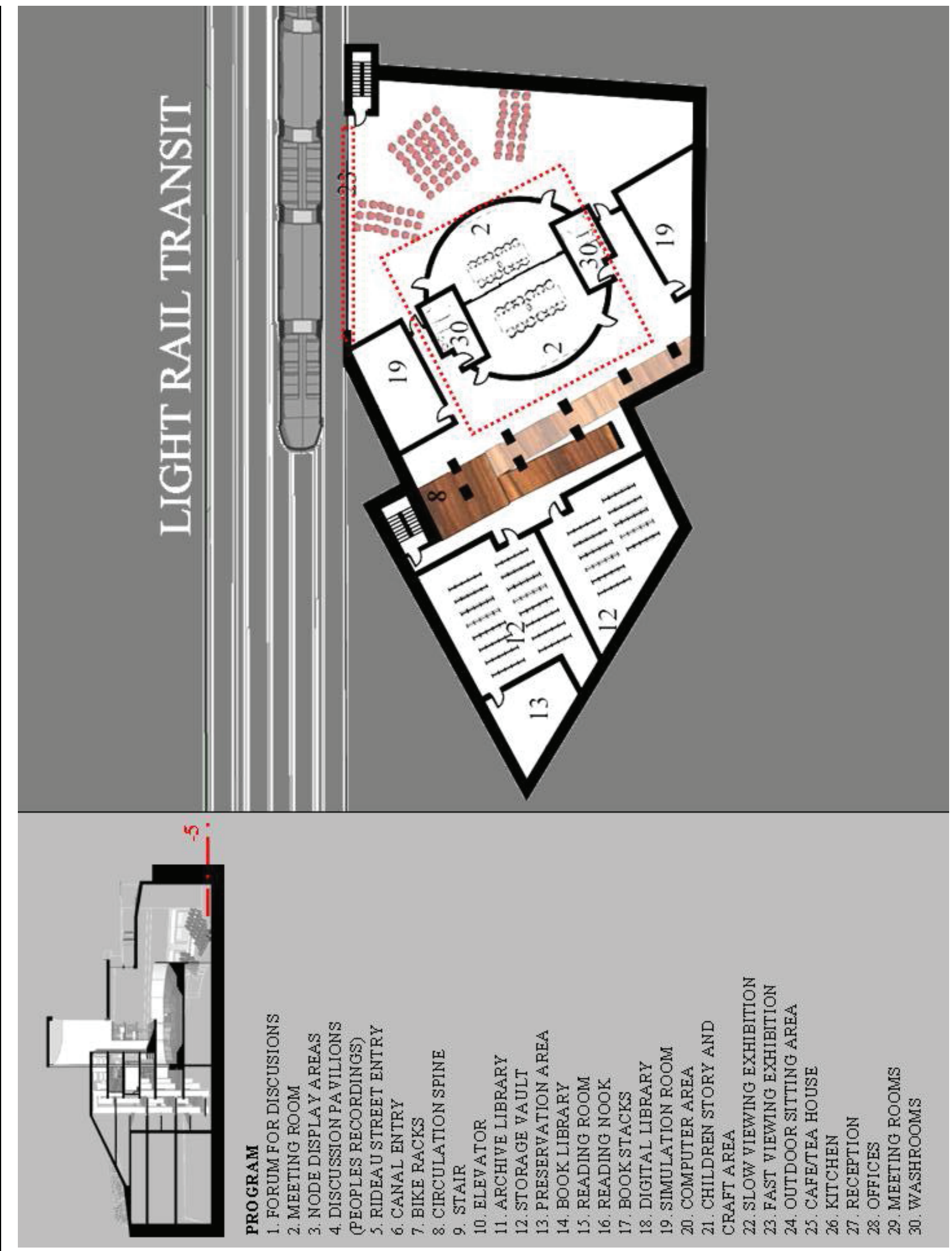

Figure 61 
The library as a physical building is still necessary, having a tectonic quality that roots us to the physical reality of place. It allows forgotten knowledge to be rediscovered while adding new knowledge through the interconnected activities of the program. In the Hub, the 'three Libraries' express the unity, different scales and structure of the medium, with archives becoming a sort of palimpsest demonstrating the old and the new co-existing and imposing themselves on each other. Complete experiences necessitate the use of all our senses and are impoverished when reduced to a purely visual input. We still exist in a physical world. Whether used in conjunction or side by side, the different mediums help inform and express each other by opposition bringing awareness to their importance as conveyors of knowledge and to the benefits of social interaction. A material has weight and texture and necessarily interacts with surrounding conditions - climate, light etc. By creating a hybrid library, mediums weave together contrasting elements of spatial development such as lightness/heaviness, transparency/opacity, slow/fast, open/closed, simplicity/complexity, abstract/concrete, virtual/real. The design highlights and challenges our perceptions of the relationship between architecture and our bodies (figs. 62 63, 64, 65, 66 \& 67).

The Archive library acts as a conservatory for the written texts and artifacts that are choosen to keep as recordings of the past for future viewing. This part of the library is important because society is continually evolving and therefore constantly making, recycling and storing objects that represent its history. Even obsolete and out-of-date devices once used to store information are stored here. These stored, unusable or rarely used devices become objects in an archive that is a monument to the past, recording the evolution of these recording devices. As physical objects and the 
mediums they are recorded on are often sensitive to light and require very specific storing conditions, the archival portion of the library is located underground.

The Book library collection is dispersed throughout the multi-level space creating a large reservoir of books in the main area that opens up to the city. As one moves down through the building, the spaces become more intimate and more precisely tailored to individual needs. The entire program is connected through a central area, allowing users in the various spaces to reference the main area where physical media and digital media co-exist. Based on the changing number of books in the stacks throughout the day, the character of the central space fluctuates. This space is directly linked to the reading spaces, reading rooms, and bookshelves. Beyond the main space, views open towards the city and canal. Working areas are oriented to the north side for natural daylight and are acoustically protected from noisy urban spaces.

The Digital library screens follow the contour of the central space weaving into the archive library and the book library. It Library showcases changing digital content and projecting real time news, events, or library recordings with rows of books and collections as references. The paneling permits various media on its surface and allows for playing, projecting and interacting with the screens. The paneling is capable of accommodating different content to be played on the screen and on various parts of its surface throughout multiple ocations different parts of the Hub. This can occur at different times, becoming more transparent or opaque depending on its display/events. With the variety of displays in spaces offering interaction and a variety of uses the screens can separate 
and come together in order to create spaces. They sometimes become an interface, a tectonic membrane or an independent space, making us question the boundaries of the exterior and interior spaces. Screens can become transparent giving up a solid materiality devoid of its own content in order to offer a glimpse at the surroundings of the canal, buildings, city, and people. At other times it appears as a solid material for displaying ever changing content. This flexibility in use is important to reinstate the solidvoid articulation that generates enclosure and boundaries. Since architecture is constantly dealing with boundaries and territorial dimensions the lines of separation in the space or boundaries become blurred, so the surrounding context can start weaving in and out(see fig 68, 69, 70, 71, 72, $73 \& 74$ ). 


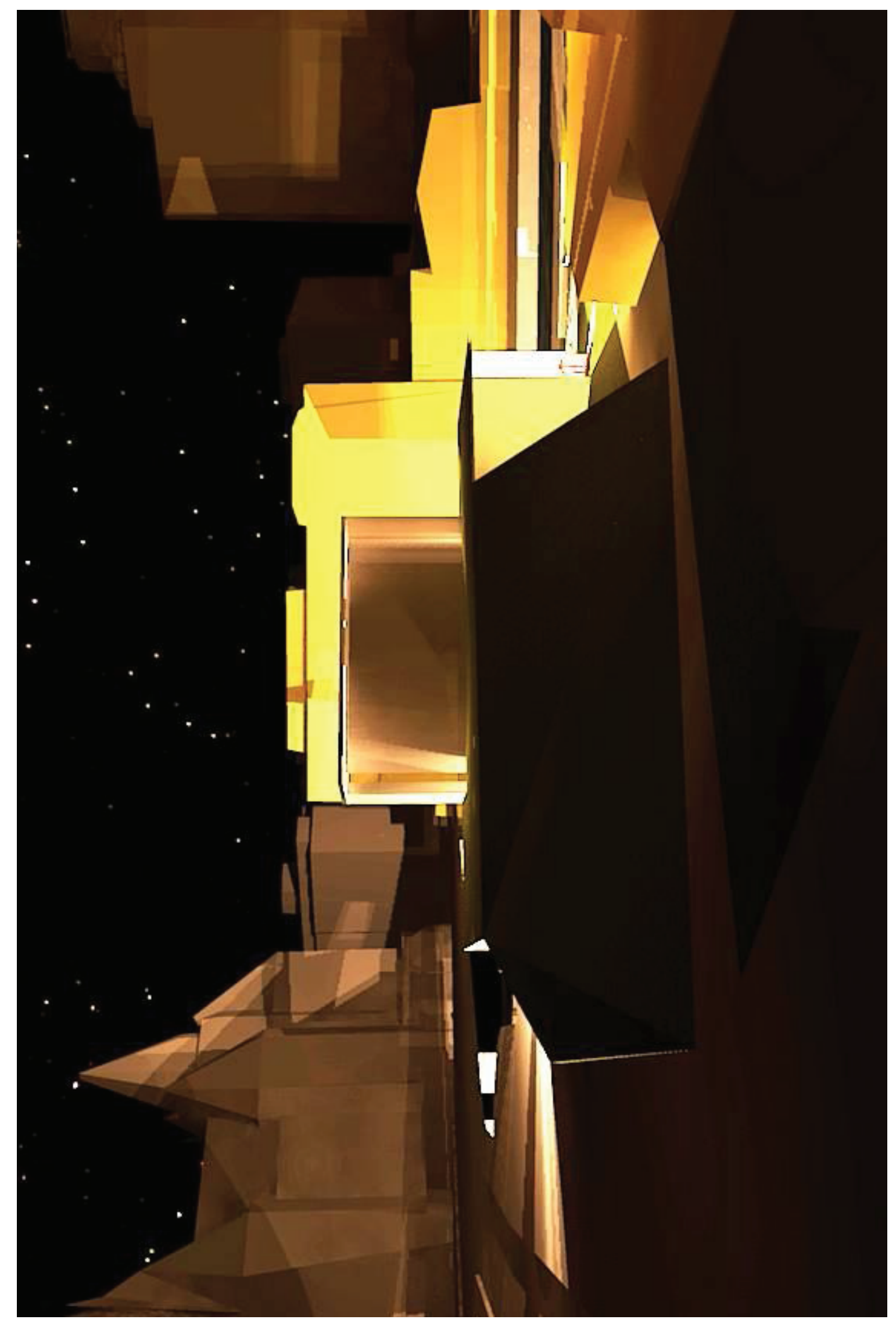




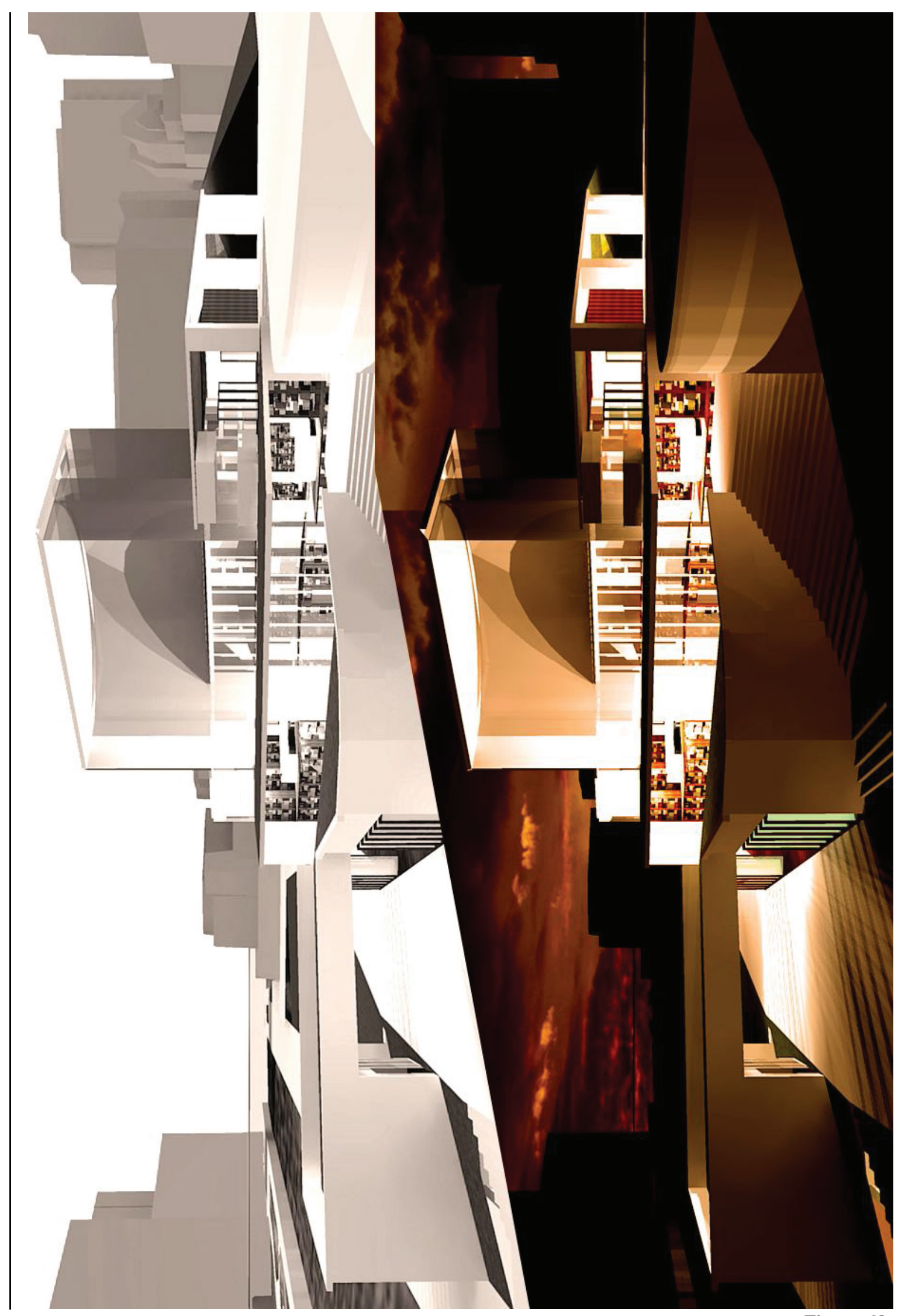

Figure 63 


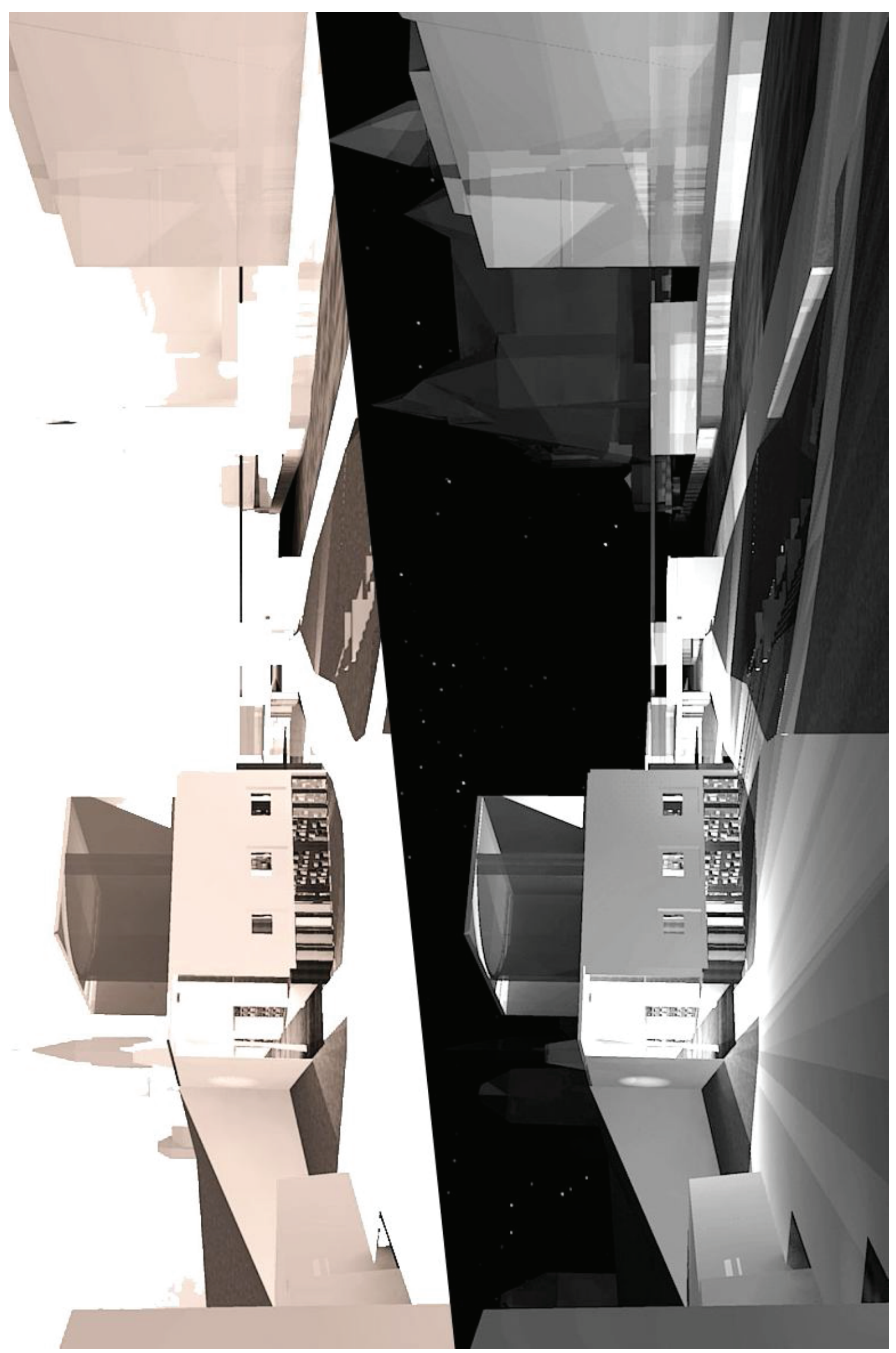

Figure 64 


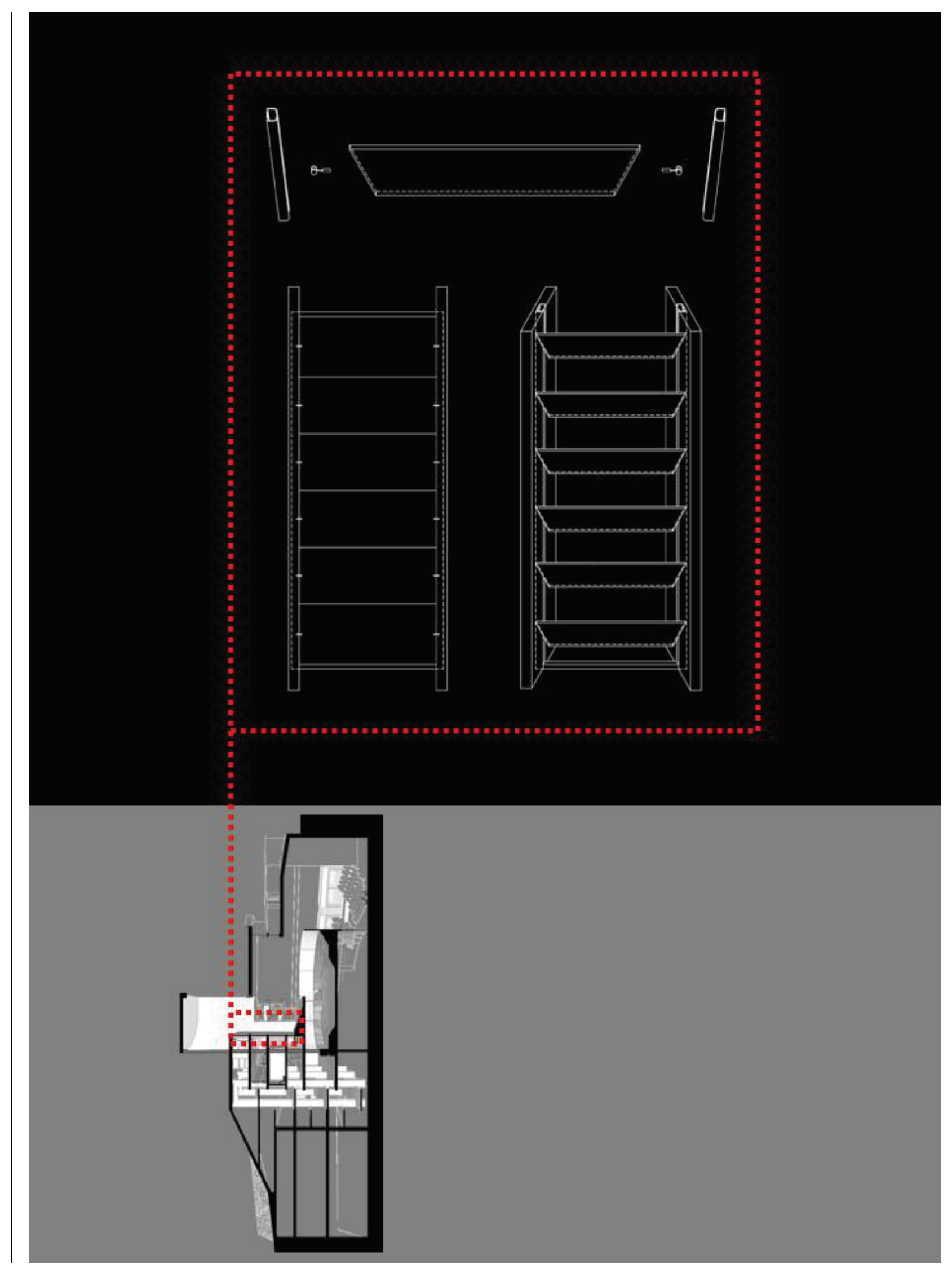

Figure 65 

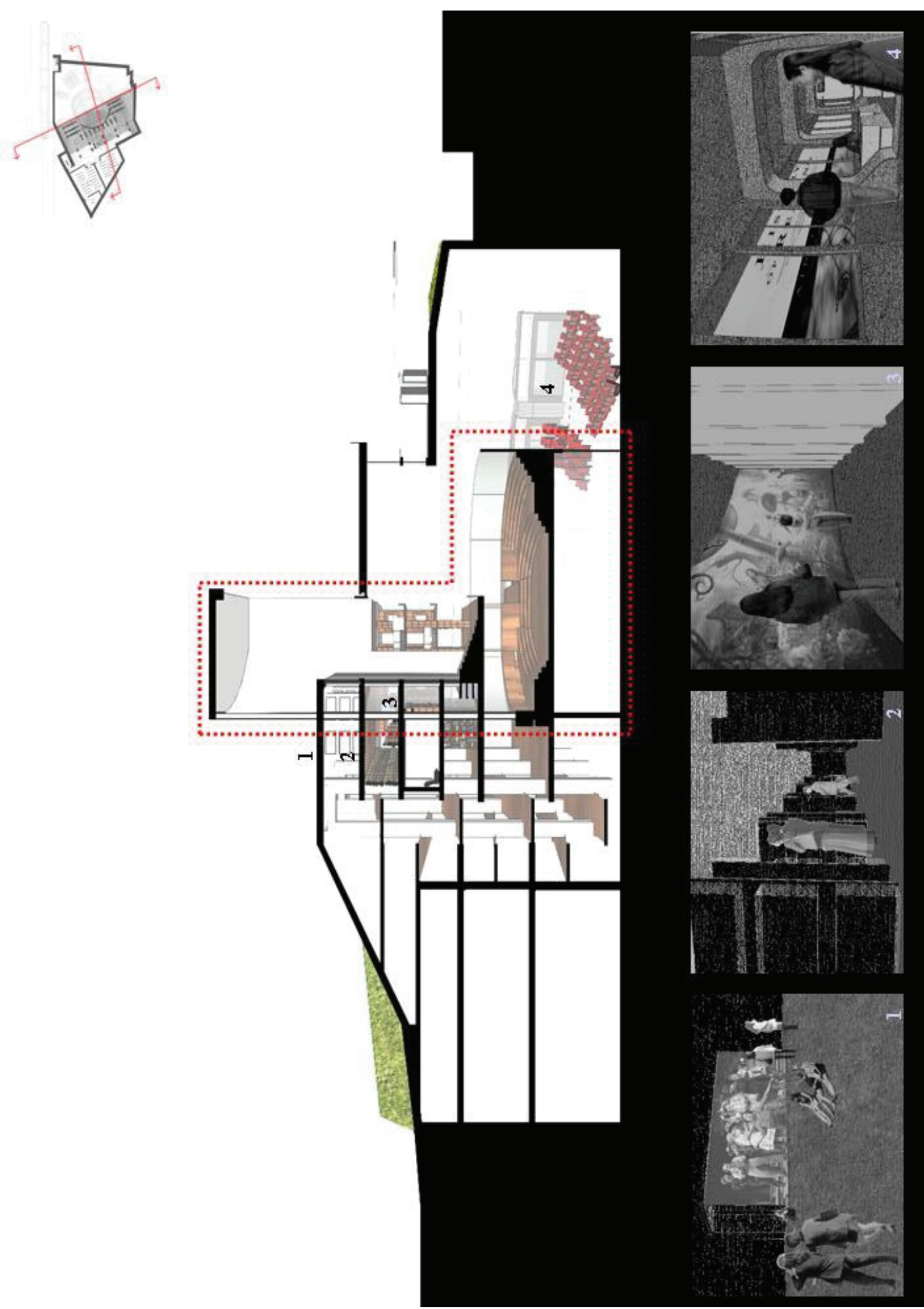

Figure 66 

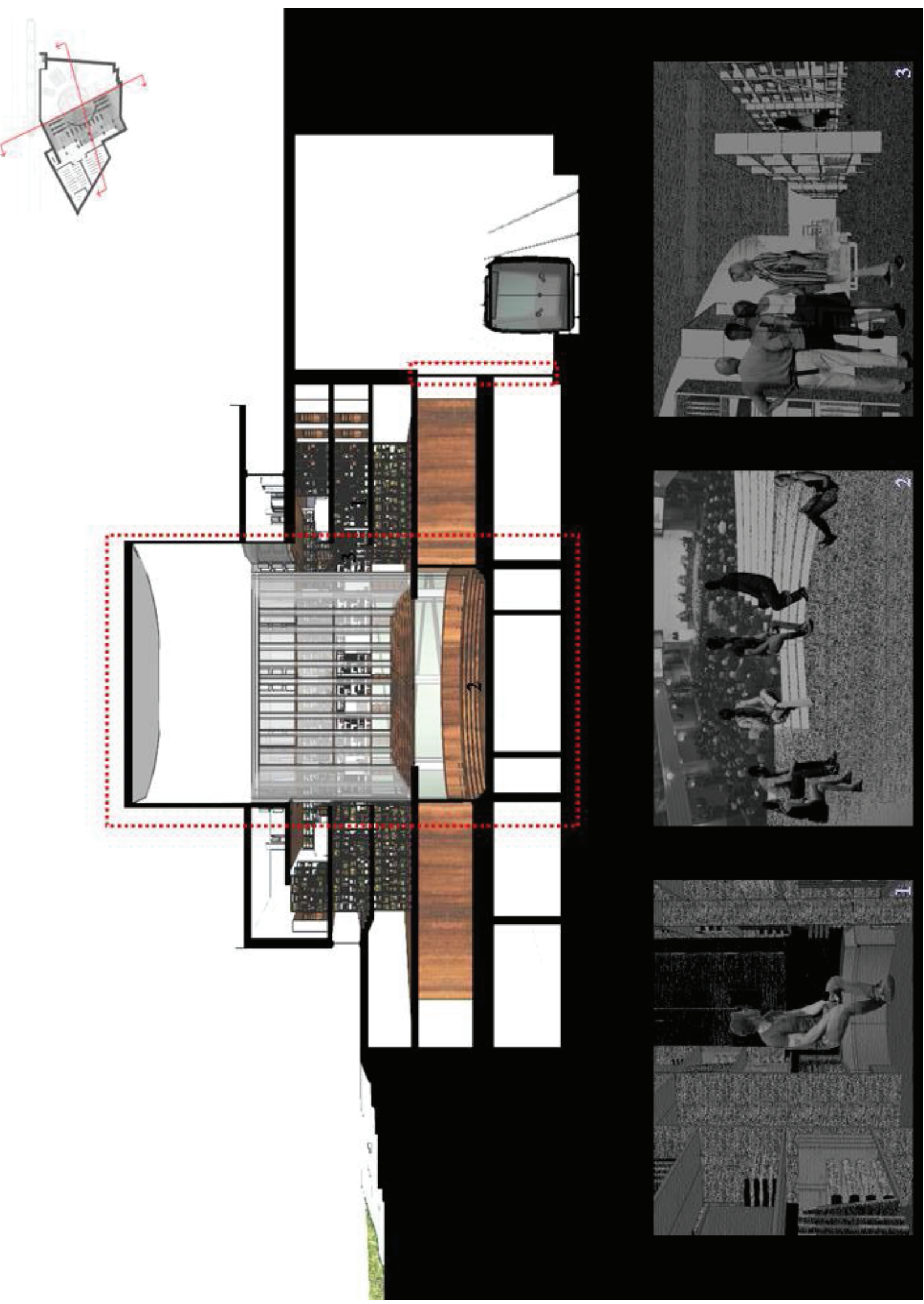

Figure 67 
View from street

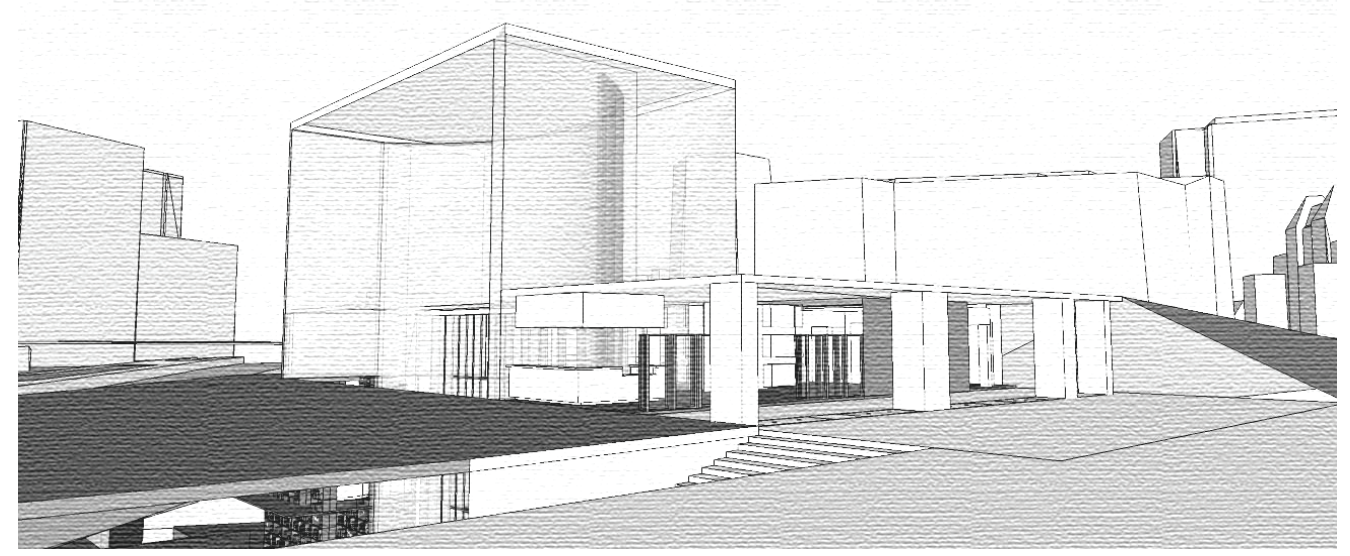

Figure 68

Circulation spine

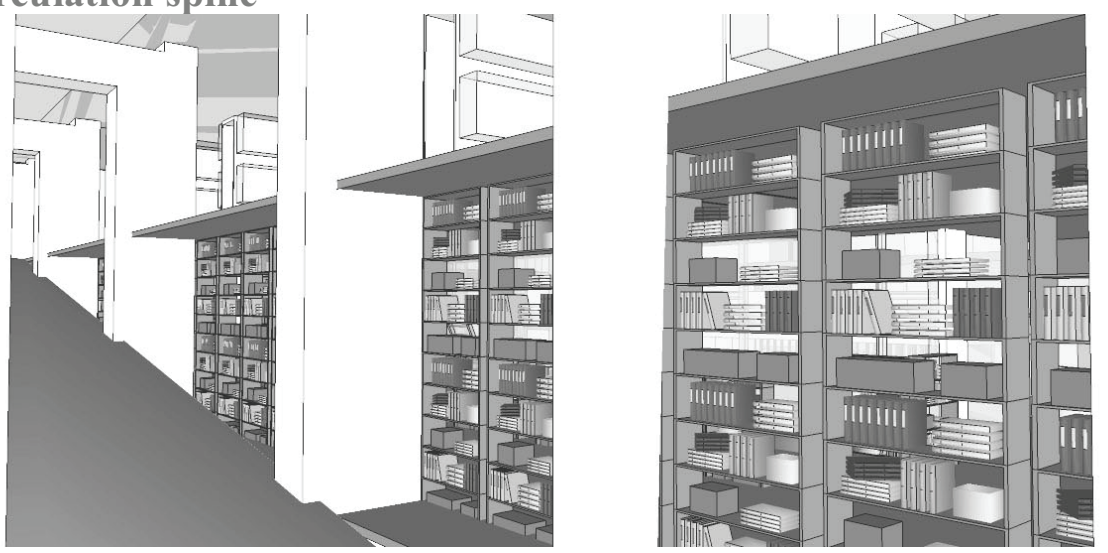

Figure 69

View from canal

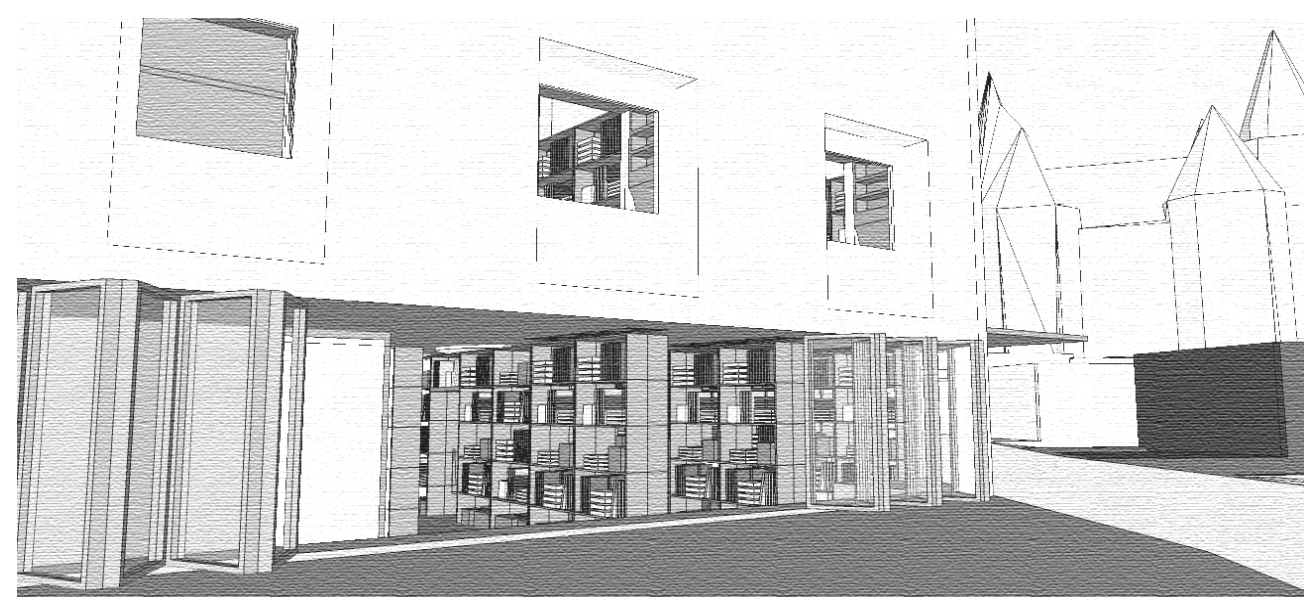

Figure 70 


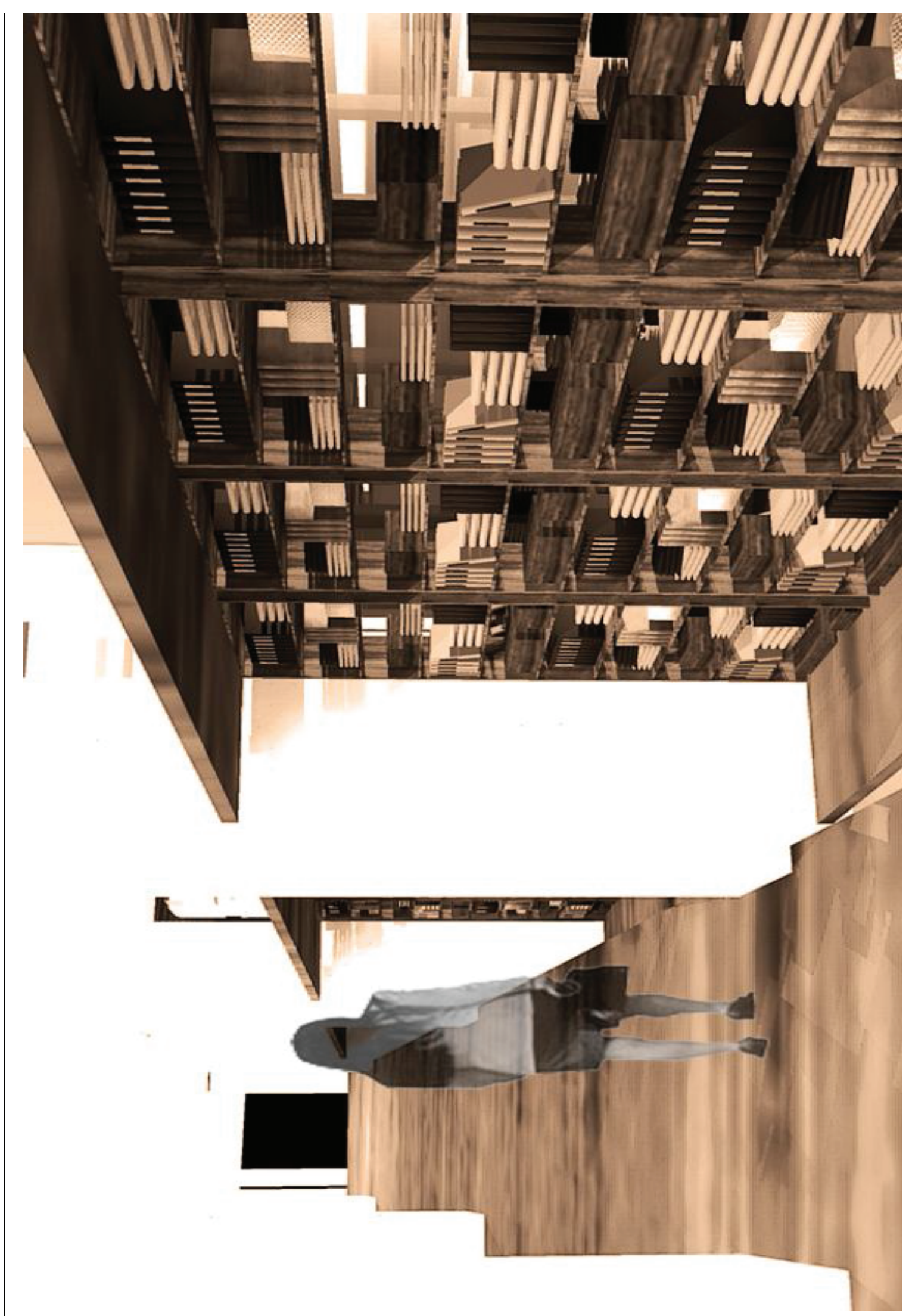

Figure 71 


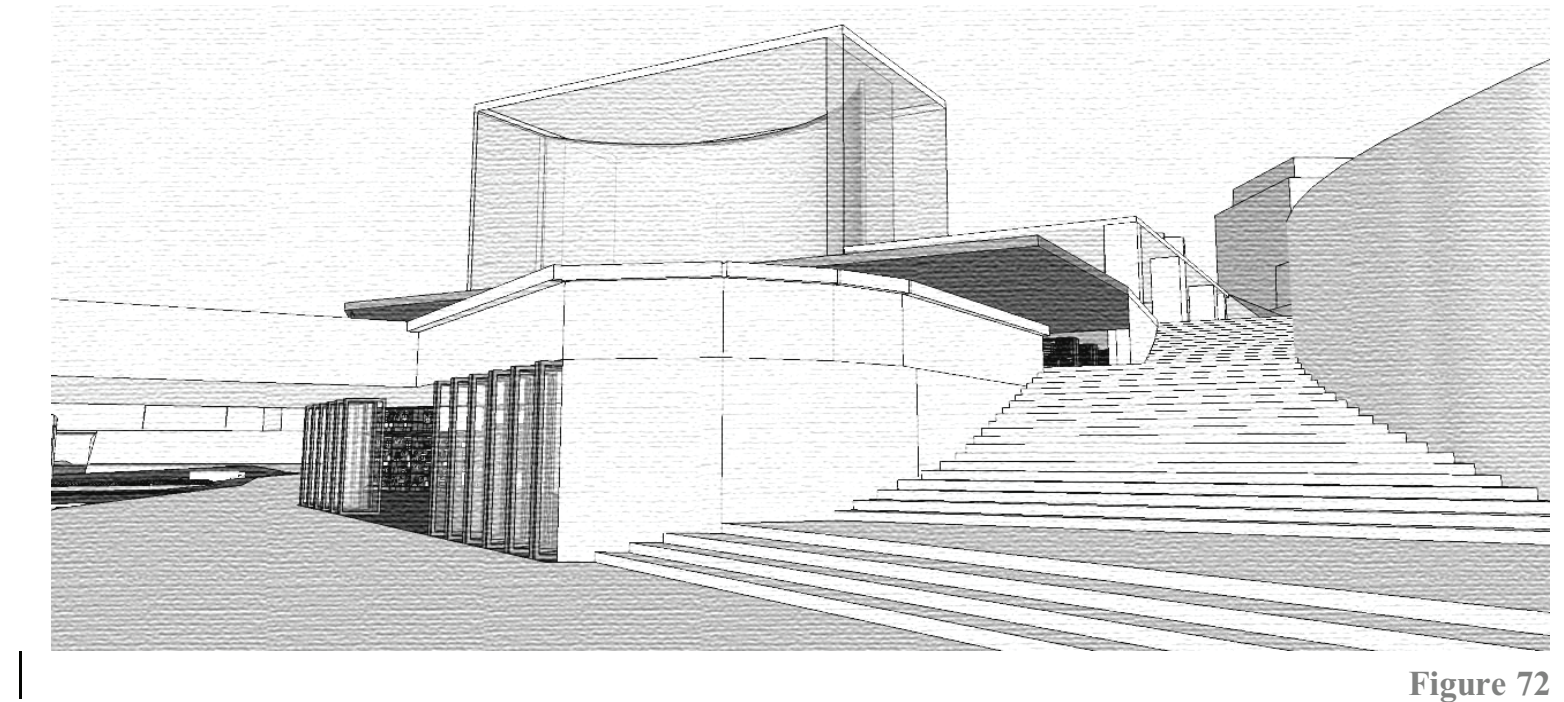

Sitting areas and cafe

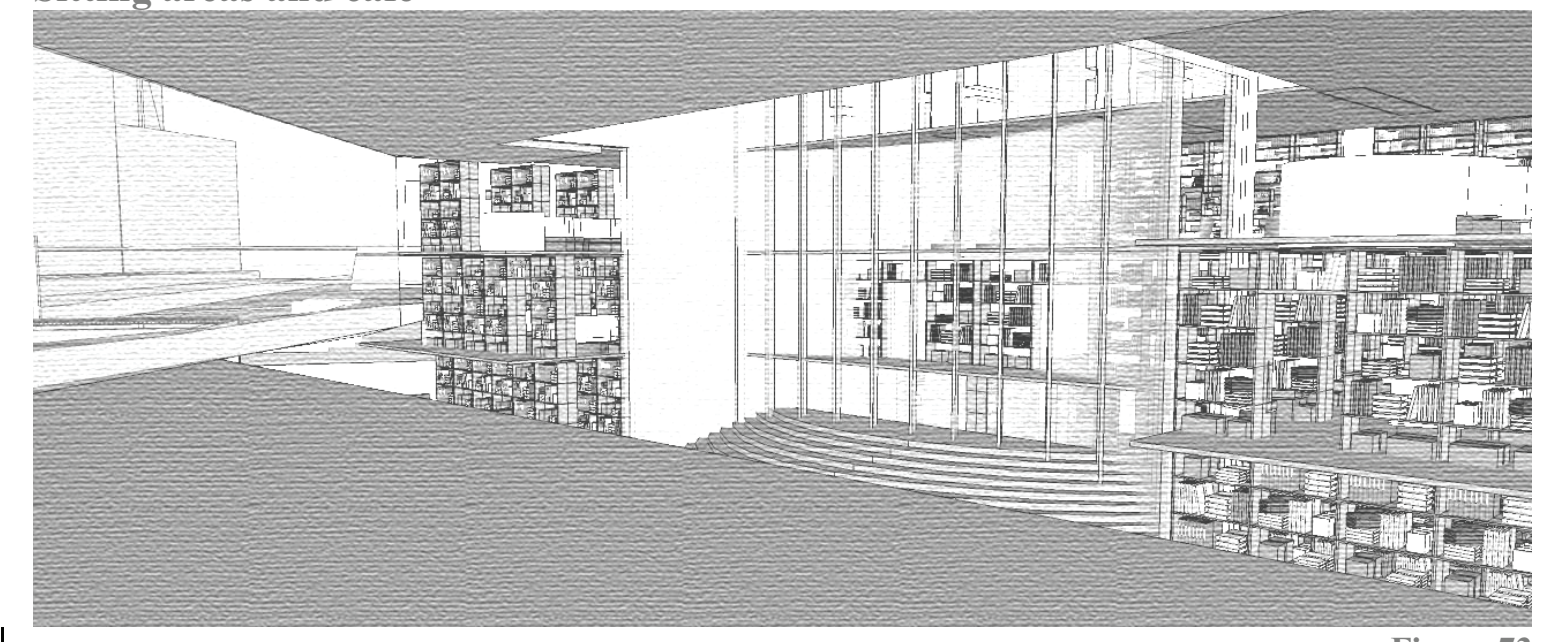

Figure 73

\section{Outdoor sitting areas}

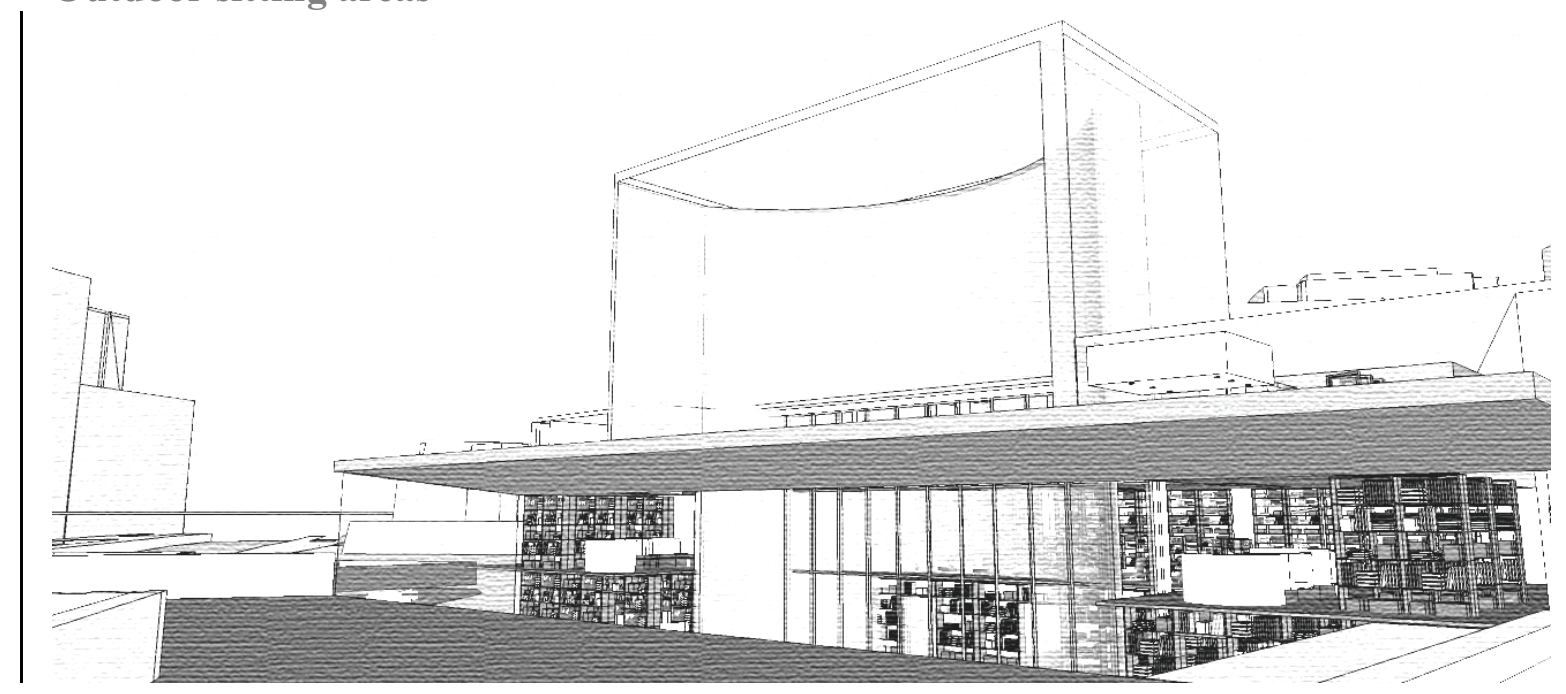

Figure 74 


\subsection{Type of collections and their use}

The collections from the nodes are displayed in exhibition areas in the Hub. The exhibition areas also exhibit and display recycled works from the underground archive library. Exhibition areas have two different speeds. This is important because different viewing speeds may be preferable when a work is on display. One exhibition is acknowledging slow movement and being able to leisurely walk around the work at your own pace and the other is viewing the works at faster speeds. Since speed is important to us as discussed earlier, the exhibitions and their accessibility need to be flexible to address all needs. The different speeds of exhibiting are important for the public because the site has various paths and means of traversing and connects different types of libraries (see fig. 75).

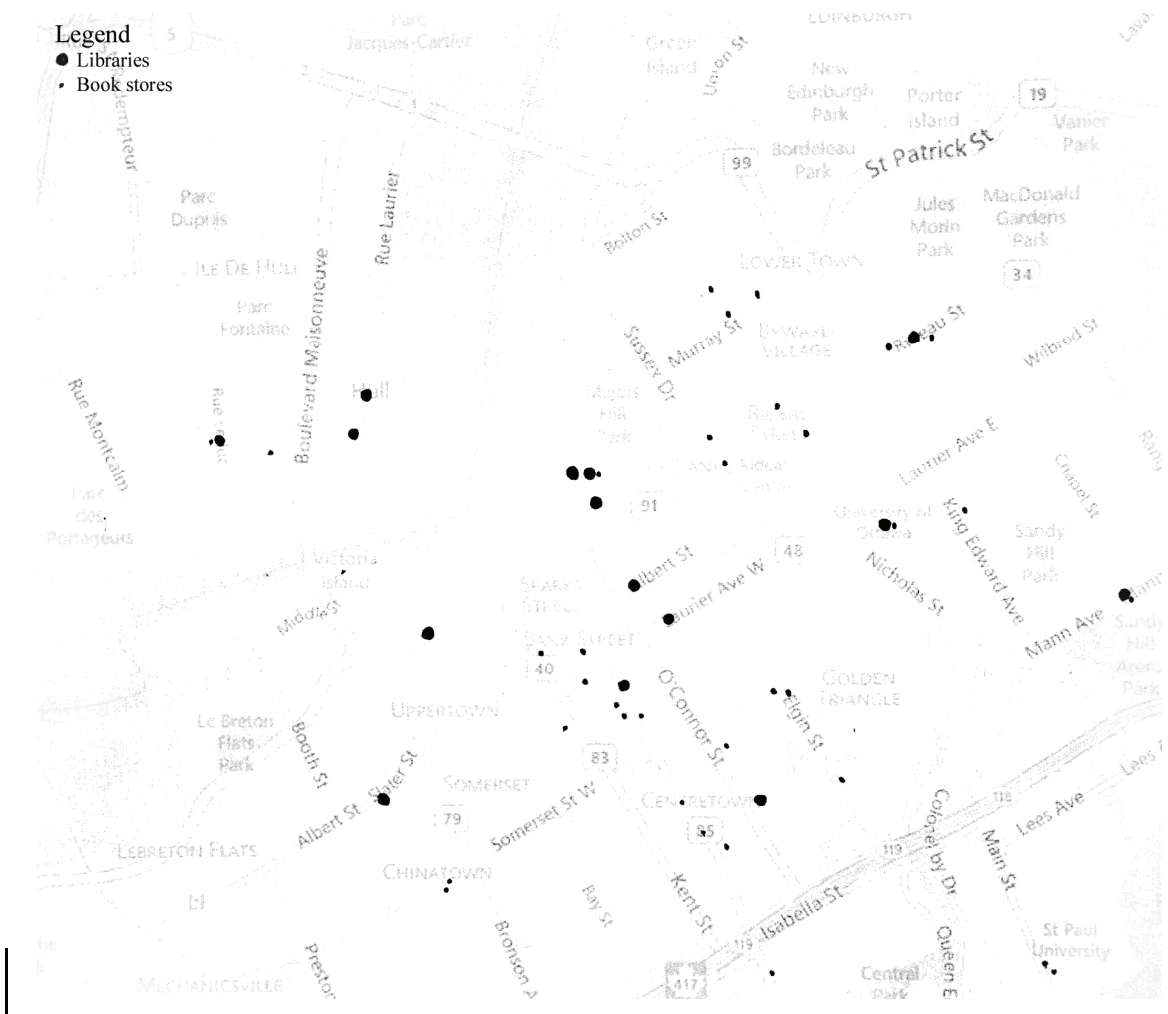

Figure 75
Libraries

- Ottawa Library

- Friends of the Ottawa Public Library Association

- Bibliothèque municipale de Gatineau

- Carleton University: MacOdrum Library

- University of Ottawa Library

- Algonquin College Learning Resource Centre

- Université du Québec en Outaouais: Bibliothèque

- Canadian Museum of Civilization Library \& Archives

- Canadian War Museum Military Research Centre

- Library and Archives Canada

- Friends of Library and Archives Canada

- National Capital Region Library Directory

- Blog: Special Info \& Musings for Ottawa IM Professio

Independent Book Stores

- After Stonewall (370 Bank)

- Agora Bookstore (145 Besserer)

- Book Baskets Canada

- Book Bazaar (417 Bank)

- Books Canada

- Bytown Bookshop

- Canterbury House Book Store

- Central Computer Books

- Coin Du Livre (1657 Cyrville Rd)

- Collected Works (Wellington @ Holland)

- Dragon Tail Bookshop

- Haven Books (43 Seneca)

- Librairie du Centre (435 Donald)

- LIbrairie du Soleil (33 George)

- National Gallery of Canada Book Store

- Octopus Books

- Perfect Books

- Place Bell Books

- Polish Bookstore in Ottawa

- Renouf Books (1-5369 Canotek Rd

- Salem Storehouse)

- Serendipity BOoks and Gifts (1337-B Wellington)

- Singing Pebble Books (202-A Main)

- Weekend Reader (1315 Wellington)

- World of Maps and Travel Books (1235 Wellington)

- Book Den (263 MacLaren)

- Shirley Leishman Books (Westgate Mall)

- The New Octopus Bookstore (116 Third Ave

- Girol Spanish and Portuguese Books (120 Somerset W

- All Books (327 Rideau)

- Livres Disques Etc. (450 Rideau)

- Daniel Leclerc 1116 Wellington)

- Bay Used Books (68-A Robertson Rd)

- Ecclesiastical Bookstore/Librairie Ecclesiastique (223

Main)

- Crosstown Traffic (593-C Bank)

- Perfect Books (258-A Elgin)

- Birder's Corner (101-2 Beechwood Ave)

- Garden of Light (163 Laurier Ave E)

- Sunnyside Bookshop (113 Murray)

- Health Sciences Book Store (501 Smyth)

Comic Books

- Dark Age Comics

- Myths Legends \& Heroes

- Silver Snail

- Back Copies

- Cave Comics

- Entertainment Inké

- Fandom II, 162 Laurier Avenue West

- Infinte Earths Collectables

- Infinity Entertainment

- The Comic Book Shoppe

- The Wizard's Tower

Antiquarian \& Used Books

- The Book Gallery

- Book Market

- GKLibri

- Patrick McGahern Books

- R. R. Knott

Campus Book Stores

- Agora Bookstore (145 Besserer)

- Algonquin College First Class Bookstore

- Carleton University book store

- University of Ottawa book store

OttawaStart Internet Services. 1998-2013.

http://ottawastart.com/books.php. (accessed on 09/20/2013) 
Categorizing, storing and accessing exponentially expanding amounts of information is a significant challenge for libraries today. Since the pace of information is constantly accelerating, the traditional library ordering system is being augmented with other categorizing systems. Most libraries presently adopt the Dewey system, an alphabetical system and a category system. These all depend on the genre and the type of medium on which the information is stored. This allows for more flexible spaces in which to store information because the collections and range of documents that are housed may vary greatly. For example as discussed in Chapter 2, the flexible space can give the people working in the library an opportunity to organize the collections depending on their need at that particular time.

The question of what is going to be of immediate use versus what is going to be held in storage is another consideration to resolve when faced with large quantities of information. The collections that are housed in the archive change and is dependent upon demand and the recirculation of material that people find important at any given time. The changing materials on display keep people going back to the physical place because the display varies from time to time. The different mediums are mixed and display of specific information varies depending on the viewing speeds, mediums and particular content that people are connected to at a certain moment. The large variety of information is connected to all parts of the city allowing people to share information. 
The slow viewing exhibition is above ground. The exhibition areas invite people from the sidewalk on both the canal and the city side to enter the library, adding to the already existing paths. This exhibition is located along the circulation spine and at the street level attracting passersby. There are temporary and permanent works displayed. There is no hierarchical logic for the displays allowing viewers to explore at their own pace. Visitors can slow down and pause at any time to enjoy and discover the collection. The project has different levels of transparency to create closed and open spaces that create a variety of relationships between users and the work being displayed.

The fast viewing exhibitions are located on the street side as a large scale digital screen that can capture people's attention while they are traveling on a bus or in a car. The other fast viewing exhibition is located below ground as a digital window that contains information panels playing real time news, events, or library recordings and is attached to the new Confederation line light rail system.

Discussion pavilions are areas that are part of the Hub. Since a library can now be accessed remotely, the pavilions have different exhibitions and viewing mediums as a result of the unique and varied content that could potentially take place. They facilitate and exhibit live chats and discussions from around the city and tie back into the Hub so that content recorded in other places throughout the city can be replayed. In this way people are able to deposit/record their own experiences, stories and ideas to establish a connection to others in cafes, light rail stops and other places in the city.
Slow viewing Exhibitions

Fast viewing

Exhibitions

Discussion Pavilions 
The simulation rooms provide an interactive environment that projects digital architecture into the 3-dimentional space. This creates an architecture where different communications planes intersect with one another. As analyzed earlier the physical cathedral is experienced through spatial, verbal and human interaction with the actual environment while the virtual cathedral is experienced through verbal and images simulation. The simulation rooms in this library provide for the integration of virtual reality with the physical building environment. In this way the architecture becomes a container whose surfaces can be projected via electronic sensors displaying information. This creates a space that differs from what we have become accustomed to as the reality of the physical world. It is a structure that incorporates advancements in technology and adds a new level of perception to particular senses. In this way the space and surface have a significant role. It brings the visitor into a story and allows interaction in the space while experiencing that story. This is accomplished while providing information in an entertaining environment where people can interact. The person, content and created environment are brought together. In this space children can enjoy being immersed in a 3-dimensional story and adults can be taken back to their childhood where things can be oversized. This allows them to move in an imaginative way beyond an everyday experience of reality. Creation experience within space is important especially in this case where the physical space is nearly non-existent since it is dependent upon the material that will be simulated and their different times. Virtual space does not have the same dimensions as an actual room because it can be made into anything. These rooms need surfaces that will allow for sound 
protection and absorption for varying, textures and temperatures and different spatial manipulations.

\subsection{Structure and Space}

Due to the integration of different mediums, at certain points the Hub can become structurally ambiguous. This is due to the difficulty in distinguishing exterior from the interior, and surface from volume, favoring interconnections of the different mediums and the spaces they have the potential to create, instead of providing clear distinctions and spatial organization.

The structure, organization and materials express the importance of integration of the physical with the digital landscape. The Hub has a simple and modest urban façade on the street side, which opens up towards the Canal. The structure is in concrete, and it is only visible around the circulation spine, blending into the books and digital screens. This is important because the books and digital screens act as supporting references for each other in the central space. This architecture is not only an ordered display of walls that are put in a sequence but a spatial construction, which invites interpretation and involvement. For this reason, the spaces themselves become the expression of techniques, context, scale and orientation by all the information mediums.

As discussed in chapter 1, senses play an important role in the way we experience a place. In Pallasmaa's essay on the human senses and architecture, the author discusses the implications of distancing humans from reality by creating architecture that favors 
the sense of sight over the other senses such as touch and sound. Some of the approaches that can be taken to prevent this distancing could include encouraging physical interaction with the building surfaces, scale and proportion in relation to its context, day and night transitions of light and shadow, sound qualities of spaces, and surprise.

The 'Hub Library' containing different information mediums provides different spatial experiences. These experiences include senses such as touch, hearing, sight etc. The three libraries are constantly colliding and becoming immersed in one another. This further strengthens our interaction with the Hub by engaging our senses through bodily experiences of silence and noise, dark and light, hot and cold, scale and space. Silence and darkness by contrast, can give a greater appreciation/understanding of sound and light.

The acoustic properties within a space are created by the occupants and designers of the space and are part of acoustic science and social science that deals with the occupant's behavioral, mood, social cohesion and privacy. Both sciences include physical and social aspects. ${ }^{10}$ Silence and noise are emphasized in different areas of the Hub to bring attention to one in opposition to the other. The spatial experience of this contrast can create greater awareness of the sounds that are heard away from the urban complexity of acoustics and that consists of different mobile and stationary sound sources. This can be achieved when one enters from the busy city streets into the silence and solitude of smaller scaled spaces. In another instance, parts of the building capture different sounds around the site to show them

\footnotetext{
${ }^{10}$ Blesser and Salter 2007: 26.
} 
in opposition, An example is in being able to see the lightrail and its rapid movement while being in a quiet space. An additional example is in reading inside a resonant alcove's curved surface of panels that absorb noise depending on the desirable frequencies of sound. In the columns that display digital content one can hear people's recordings while being immersed within the columns.

We require different atmospheres created by controlling lighting to be able to focus on different tasks (see figs. 76, 77, 78 \& 79). Some may prefer task lighting within an otherwise dimly lit space, while others may prefer a bright space. It is proposed that once underground one can see light coming from the lightwell above leading to smaller private spaces where one can be alone with a book. These smaller spaces that create ambiguity as a setting for imaginative contemplation of the book are created through certain surfaces and volume and have the ability to diffuse and expand a space. Since water has a dense consistency it can mute noise from the outside and absorb light if it is in motion to create a mystical space. When the water is still it acts as a wall that can light up the space by reflecting the diffused light source. While the water brings spatial and aural texture and references to the canal outside, the wood panels that are a dark colour within the space help to absorb light. Columns pierce the ground to display digital content that light up the space so one can be immersed in the digital stories displayed on the columns or read traditional books in a small space with task lighting. 


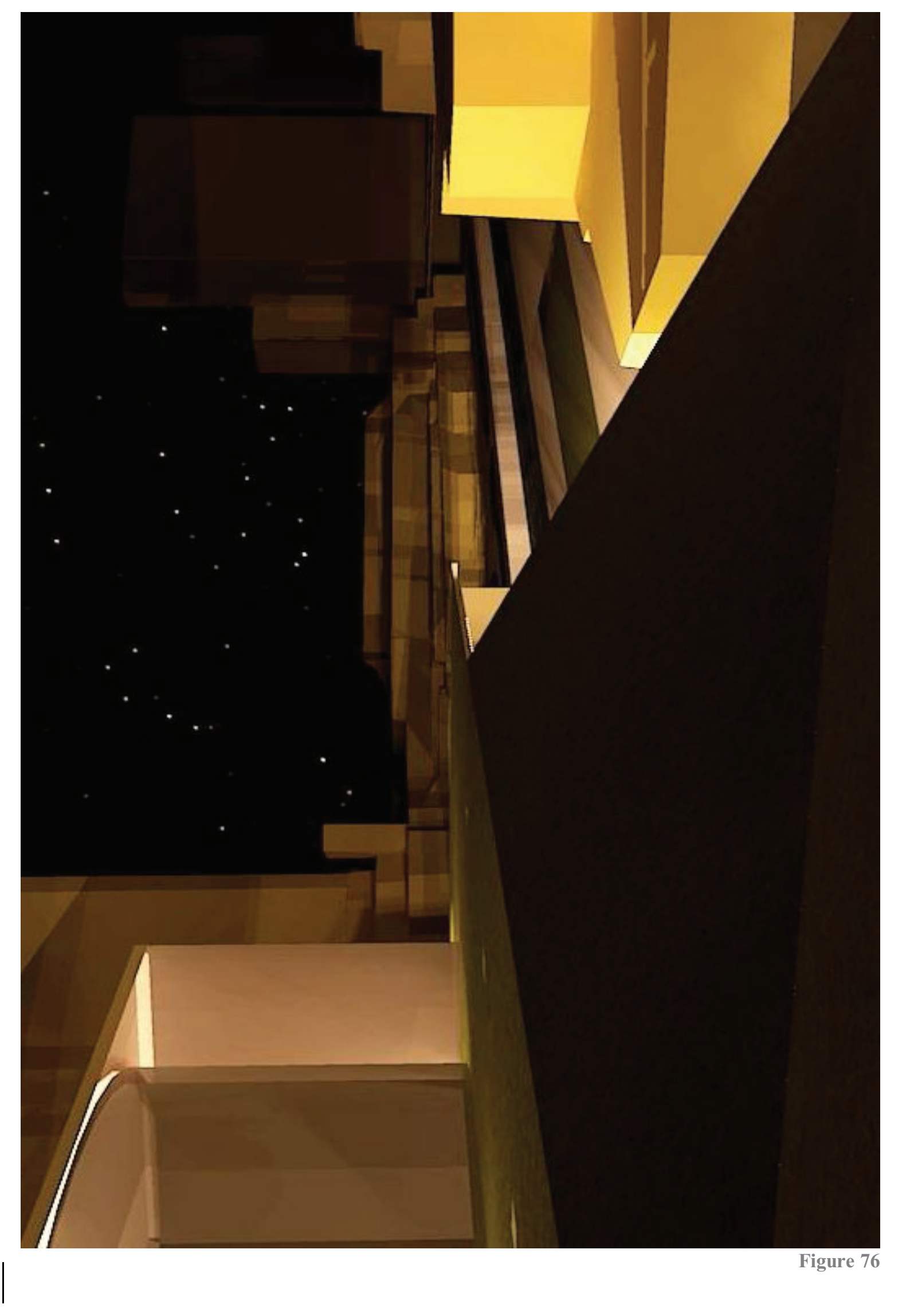

113 
Social distances are important for understanding and evaluating spaces. An example of this is a public large space versus a private communication in an intimate and small space. Social expectations suggest size and social behavior within the space. A large space would contradict expectations of a small private space. ${ }^{11}$ Different scales of spaces provide different atmosphere settings for the enjoyment of different books and size of collections. Some of the small spaces are more private individual areas where one can add their own story. The large spaces are public and encourage group discussion and activities. Some of the spaces can have a changing and varying effect because spaces and their scales can expand into cyberspace which has no physical boundaries within the digital projections. The various sizes of spaces create different environments that people can inhabit depending on their task, illustrating the importance and mystery of physically visiting a place. People learn and retain information in different ways. The Hub provides diverse environments in which one can learn and teach along side people in different disciplines.

\footnotetext{
${ }^{11}$ Blesser and Salter 2007: 34.
} 


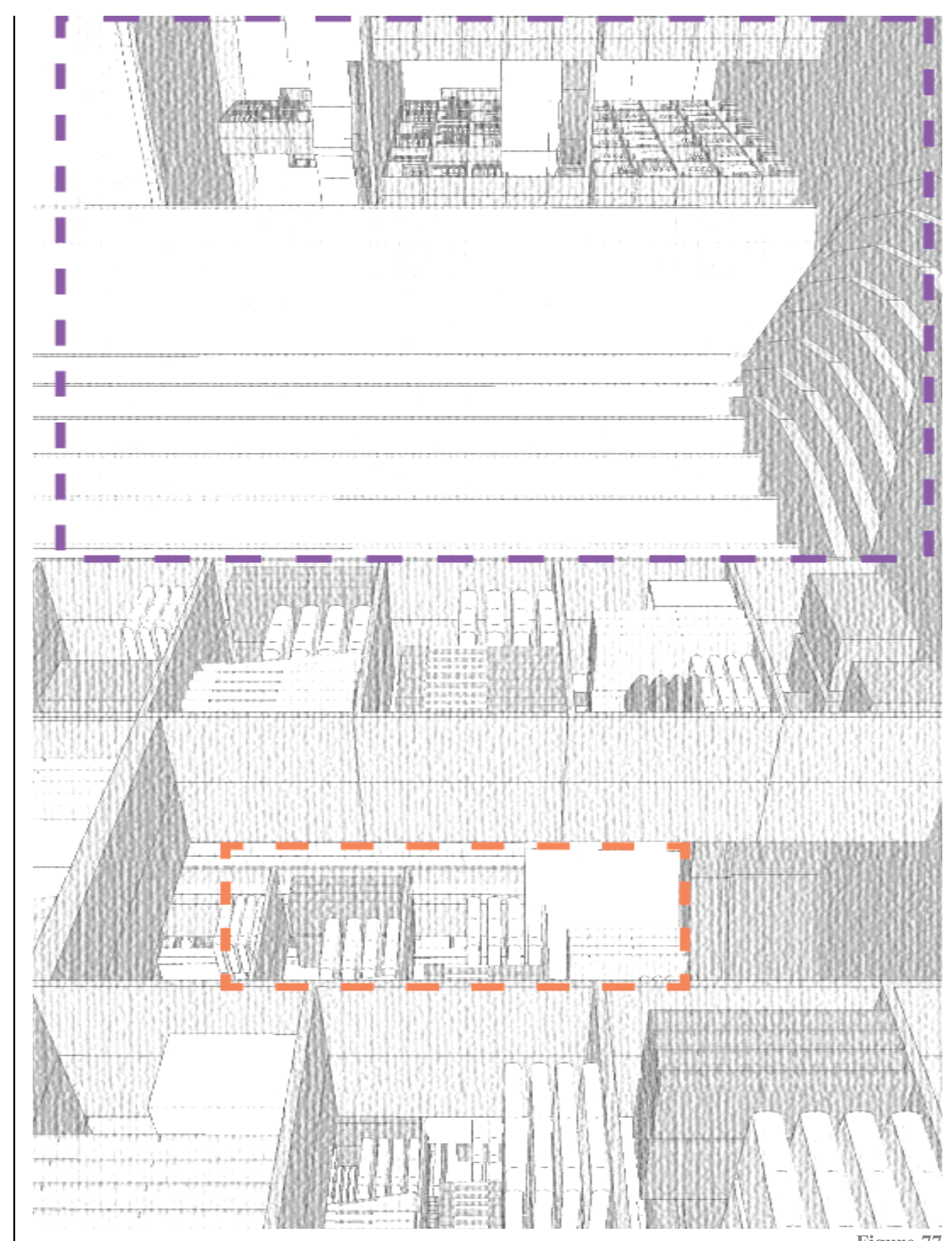

Figure 77 


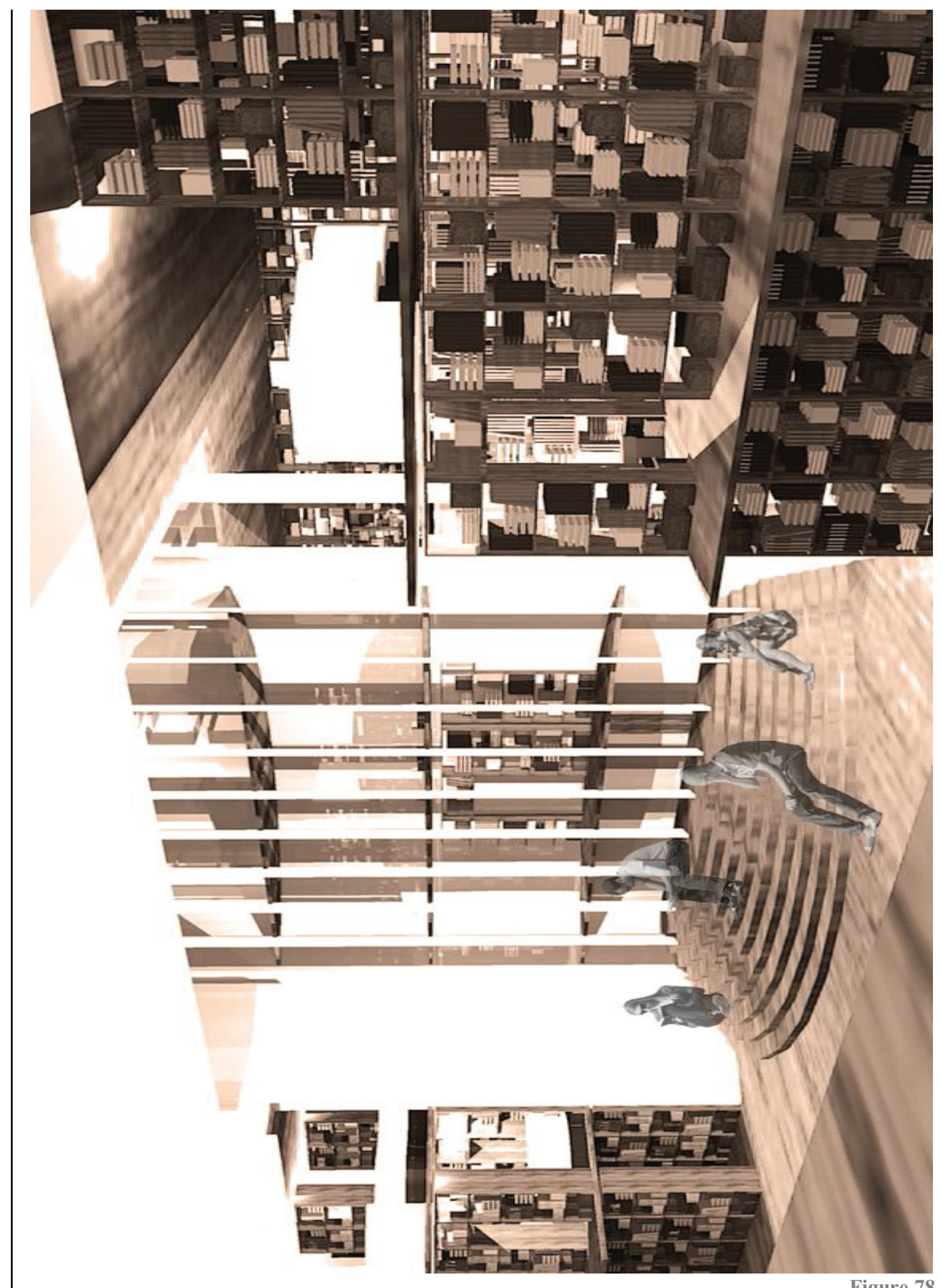

Figure 78 

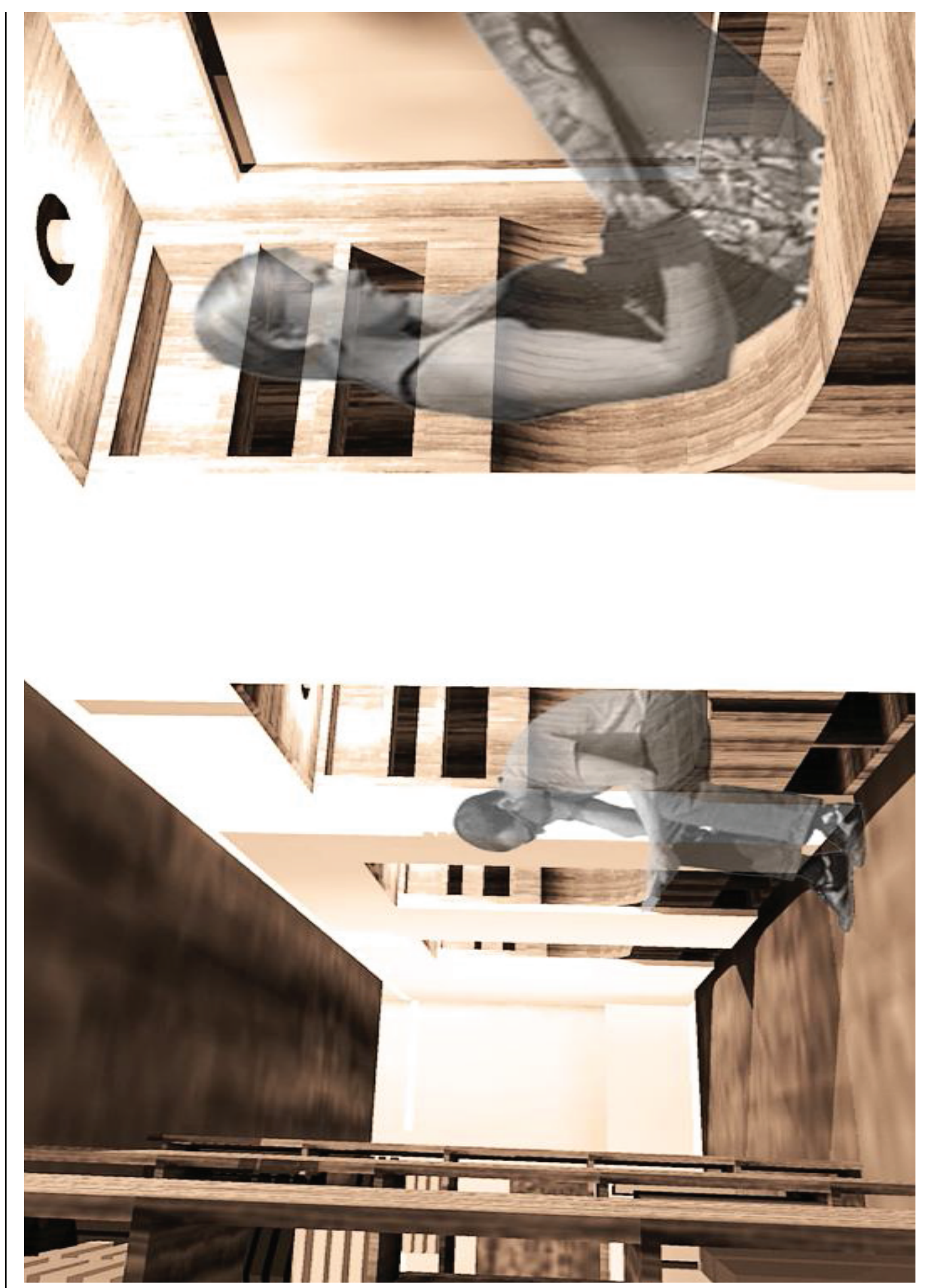
Technology has many connections and no particular physical place while architecture has a physical presence and is grounded in place and location. The contemporary library should be a hybrid, a place where all mediums can co-exist. The library is constantly expanding the amount of information that it tries to house so the physical structure grows from underground trying to manifest and blend into the dynamic city with the library's solid walls becoming transparent and opaque in different areas. This does not store the majority of its content within solid walls but displays it to lure people inside for a closer look. This is done by the transparency of physical expression on the building container above the street level and transfers the observer's gaze from the container to its content. During the day parts of the building appear to be solid/opaque and at night they have the potential to become transparent because of the light emitted from within. The proposed library becomes a junction where mediums are joined creating different spaces and a juxtaposition of different material mediums allows for the passage of information. 


\subsection{Materials}

Within a library all our senses are in use and technology doesn't necessarily hinder this connection. A library sets up an opportunity/setting for us to dream and contemplate. It has the potential to engage all our senses through contact with materials in the physical world and within a particular place. The exterior materials are simple and include the topography of the site and the screens that act as a digital window.

Loss of solidity in creating architecture that favors the sense of sight and a perfect image can lead to a physical architecture that lacks tectonic value. When working with physical materials, it is clear that there are imperfections that are inherent when architecture is created. Since technology is used to advantage ourselves it becomes important to heighten awareness of the different mediums (physical medium and information medium). For example, the building's façade is not only a projection screen that acts as hardware that can only be viewed as a digital window but the screens are also a sort of software that encourages flexibility allowing light to filter into different spaces creating opportunities to interact with them (see fig. 80). This expresses the tension between the physical reality of the body and immaterial transient materials of technology.
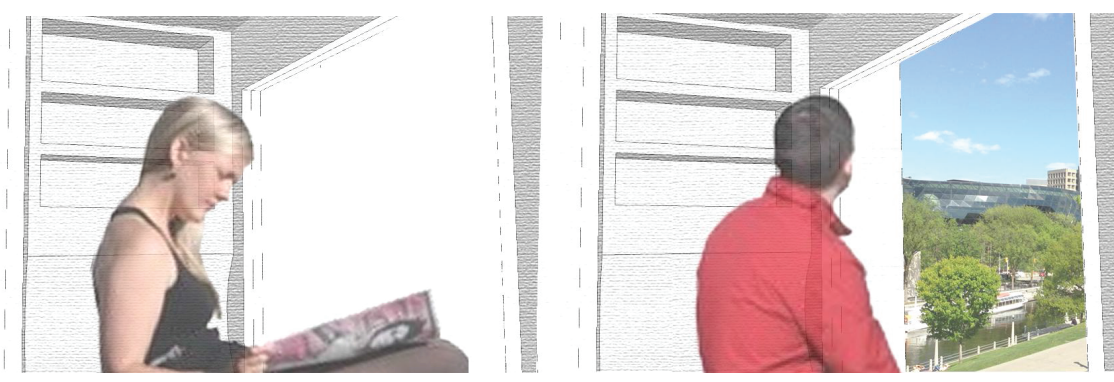

Figure 80 
The tactile qualities of the human skin are an important part of the manner in which we interact with and experience our surroundings. The skin acts as a mediator between us and the world sending messages of texture, temperature and solidity. This allows us to compare previous experiences with new discoveries that may contradict the reality we have come to know. The topography which is the skin of the site (see fig. 81) is lifted and acts as an extension of the previous site topography and allows an experience that would otherwise not be possible. In this way the geological landscape houses the worldwide connectivity of digital information. The topography of the site is expanded and spaces are created within it so that it can be used during different seasons. It visually links the busy city and the canal as a surface creating a sense of space continuity. This is important because the hub containing the three libraries is not trying to compete with its context but to co-exist with it. The libraries intersect each other, creating a contrast of opposites such as transparency/opacity, solid/void, and heaviness/lightness. The contrast in the materials tries to express the ambiguous appearance/disappearance of physical architecture. The use of reflective and transparent screens attempts to express the dematerialization of physical architecture that resulted from the evolution of technology. Architecture here is trying to be absorbed into its context, camouflaging its boundaries into its surrounding on the busy street side of Wellington and Elgin while opening up onto the city's quiet side of the canal. From either side the people are invited inside the building and transported to view the surroundings.

Since the building is in a central location where many festivities take place, it is important for the Hub to encourage social interaction and use in all seasons (see figs. $82 \& 83$ ). One

\section{Skin}

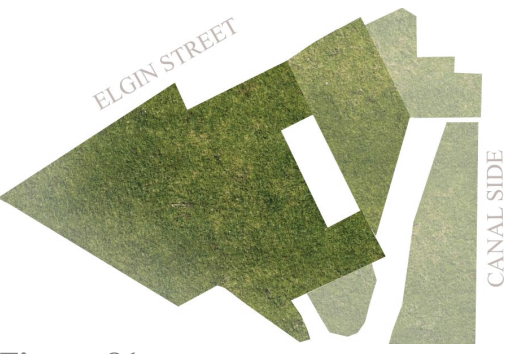

Figure 81

\section{Canal 2013}

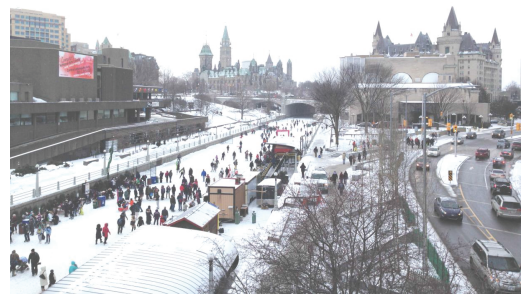

Figure 82

\section{Canal 2013}

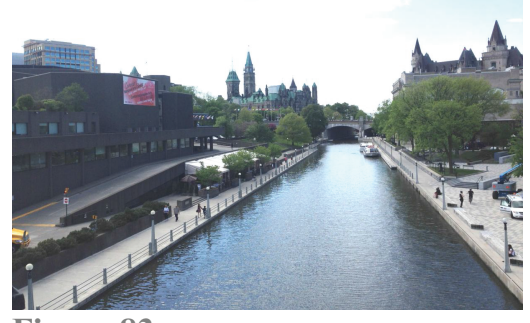

Figure 83 
way in which the Hub tries to do this is by providing certain objects during the winter and warm seats/surfaces to enjoy social activities outside. For example in the winter people enjoying a skate along the canal can stop and have a warm seat outside, making an activity more enjoyable in the cold. Since we cannot avoid using technology, some of the heat that the technology generates can be used productively to heat surfaces in the winter. In the summer, the surfaces become cooler and there are several water features available to cool people off when running or biking along the canal. Parents and children can learn and gather information. Children are able to interact with others kids whether playing in the water or sharing stories, while parents can attend to their own tasks in the same location at the same time. The grey water that is used for the interactive water features is recycled to water the landscape/topographic skin for conservation purposes.

The use of local materials that relate to site context, neighbouring buildings and local history are important in the Hub. The organization of the materials includes the stone on the ground level and represents the stability of our history. Wood is used in the middle level and central spaces of the Hub to express/heighten the current human presence in the world. It allows for interaction with current material conditions in a physical place. The digital screens are expressing technological growth. They manifest themselves from the bottom and middle levels in certain areas and grow as the Hub gets higher in order to be seen above the building as a fragile, immaterial screen on the top level, reflecting the temporality of the digital medium that displays the ever changing content of a dynamic city.
Local

Materials

Parliament Hill from rear showing locks and Entrance Bay (Circa1880)

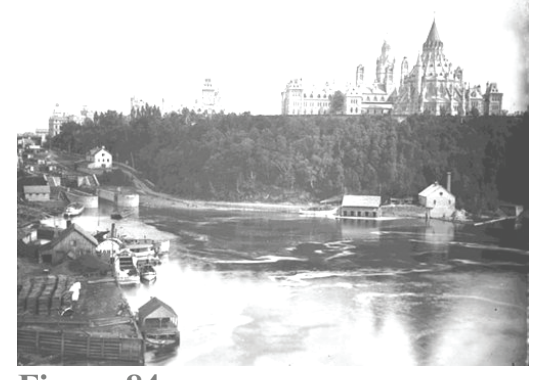

Figure 84 
Stone has an important connection to Ottawa's past and is important to Ottawa because of its location on the Canadian Shield. ${ }^{12}$ Materials, such as stone root us back to the natural world expressing the duration of architecture beyond our lifespan.

Ottawa was originally a lumber town and it saw a large Wood boom in the lumber and paper industries because of its location in a forested area and was at the juncture of the Ottawa, Gatineau and Rideau rivers. ${ }^{13}$ Wood as a material has a particular connection to the City going back to a time when the material was worked by hand. Now that information can be accessed from anywhere and the device we view it from can be small while displaying a large quantity of information. For this reason, the digital content becomes physically lighter than the weight of the same amount of information within books. Physical materials are unique and express the story of their use, age and much more. All the places within the Hub that contain physical books and physical communication have wood surfaces in order to reflect this connection. In the proposed library the materials are not hiding their inherent imperfections. Wood is placed and exposed in spaces where humans are in contact with the architecture. The warmth of the wood is pleasant to the touch and invites people to interact with it by walking, sitting and touching. It is left unfinished to show the imperfections of the people working with it, and its surface and physical characteristics. Unique wood characteristics can include knots, age rings, bowing cupping, smell, and the way in which it adapts to its environment through changes in its moisture content. Once wood is placed into a particular place it adapts and moves responding to its environment. Since architecture mediates

\footnotetext{
${ }^{12}$ Taylor 1975: 3.

${ }^{13}$ Taylor 1975: 3.
} 
between us and the natural world, the characteristics of wood are exposed.

Information is projected on external surfaces announcing events and turning surfaces into transmitter-receivers. The digital window acts as a multi-purpose physical surface, boundary and structure that can showcase changing digital content such as projections of real time news, events, or library recording. The building has a virtual presence because of the changing content of the display on the building itself. This Digital window is important because it is the physical hardware that acts as an information medium between us and the world. The window can be used to manipulate visual space since it acts as a mediator between the observer and the space outside. From the outside the digital window acts as a solid surface with a changing content. This catches the attention of people passing by, inviting them in. An open window combines social and visual spaces together, bringing visual and acoustic public space into a private space inside. A person in the Hub's private nooks at the perimeter of the building can control access of their view to the outside or be shut off from the outside to focus on a reading task. On the inside the digital window surface starts to manifest itself into other parts within the three libraries. The screen provides the potential for unexpected relationships with the materials and different spaces. It can act as a backdrop or be engaged with. For example, the screen co-exists with the exhibitions of collections and manifests itself into interior partitions creating secondary rooms whose surfaces can be used for projections while at the same time acting as acoustic surfaces providing greater privacy. The walls lose materiality, becoming screens that in turn can be anything they choose to be depending on the choice of content at the time. 
The materials that are part of the technological web/digital display include materials such as glass and screens whose content is consistently changing. Natural materials such as wood and stone are changed by people's contact with them, displaying wear and tear on the surface over time. At different points they come together and show the contradiction of solid and void, light and heavy, rough and smooth. Objects, surfaces, and geometries create different spatial settings and in turn experiences due to sound reflections and lighting effects. Materials that are soft such as wood, hard such as glass, or materials that either absorb or reflect light and sound, or materials that feel warm or cold to the skin contribute to the different user experience. 


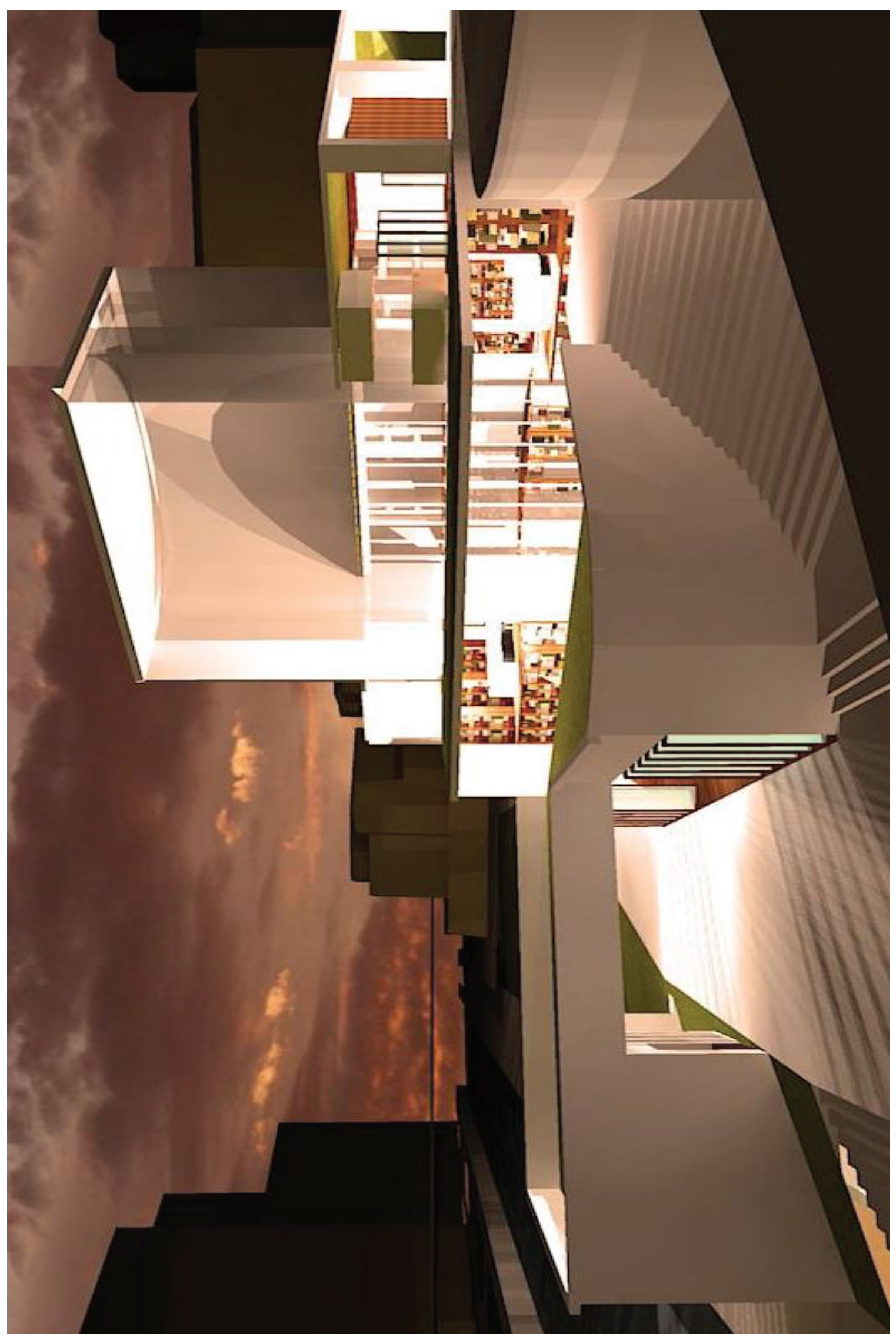




\section{Conclusion}

Whether a building, a book or digitally produced data, different transmission methods for passing along knowledge have varied throughout history. The knowledge we have of the physical world is filtered by the way we perceive our surroundings. The perceptions gathered by walking through Notre Dame Cathedral are different from a virtual experience of the same space. The evolution of one medium does not mean the disappearance of another. Virtual reality and digital evolution allows for a different expression and for explorations that would otherwise not be possible in the physical world. The shift towards digital media necessitate a shift in the design and use of traditional book structure libraries. 'Place Matters' means that a physical location is constructed over time and produces meaning. It is a link that sustains social interaction and physical connection with the transfer of knowledge while still embracing advancements in technology. Although the future is unknown and our methods of gathering information will greatly vary depending on our social, cultural and building habits, the proposed Hub is one possibility of addressing the shift in the method we choose to gather information. The Hub creates a physical connection to the place for the underground Archive Library, the Book Library and the Digital Library. Together they form the Hub and create the backdrop for social interaction by offering one expression of the greater message. The forum within the Hub is important because it is a place for liberation from the constraints of reading silently or being disconnected physically. The Hub will allow the 'three libraries' to live together, promoting a cross-fertilization, resulting in a hybrid library. In this hybrid, each library serves some purpose and reinforces the importance of the others. While one library may 
serve to attract the passerby or people within the City, the other serves to educate and inform within a space of experience. Container and content together create a hybrid, marrying new and old mediums of information. This hybrid allows people to gather knowledge along the path in the Hub and then share it with one another in the Hub's forum. Due to the convergence of the mediums, the forum can hold individual, local and national discussions. There will always be individual libraries and nodes of information gathering that are meaningful to us whether a computer with a personal library of music, books photos etc., a coffee shop where one can read a book, or a library building. Although the collections and mediums can vary, the way we organize them and experience them creates different associations for the viewers. The Hub aims at sustaining the co-existence of the different nodes and their mediums together by connecting people through various experiences, creating a meaningful connection to a place. 


\section{Post Script}

The proposed contemporary library is situated along Ottawa's ceremonial grand route in response to the changes currently underway at the National Archives. These changes include the removal and transfer of some collections that are part of the Nation's heritage. The chosen location's accessibility brings awareness to the disappearance of vital collections and the collective knowledge. The architecture does not necessarily have to be bold to express its message. This project focuses on bringing awareness and providing access to knowledge as a part of our everyday life. It is not a museum where artifacts are viewed at a respectful distance or a location that requires a ceremonial gesture but strives instead to be incorporated as part of everyday activity, swooping the citizen off the streets while they are going about their everyday tasks. This is an expression of the free flowing manner with which we choose to gather information in the current technological age. The building does not have to be as grand or as imposing as cathedrals once were. The contemporary library invites us in, not as beings beseeching an omnipotent God, but as equal beings sharing knowledge with another. This project is not as large as most national libraries because it expresses itself as a place that roots us back to our history of physical medium while expressing the temporality of the technological medium as a fragile screen of knowledge created and shared for us by us. 


\section{Terms}

Architecture:

Built form that has physical material and whose form can be inhabited.

\section{Contemporary:}

Current condition.

\section{Hub:}

Central space, whose goal is to bring people together, share and record knowledge in varying scales of information mediums and discussions. It ties different nodes that are dispersed throughout the city.

\section{'Three libraries':}

Express the unity and co-existence, different scales and structure of old and new mediums of recording information. These include underground archive, physical books library, and digital library.

\section{Archive library:}

Acts as a conservatory for written text and artifacts as recordings of the past for future viewing.

\section{Book library:}

Large reservoir of books in the multi-level space of the Hub.

\section{Digital library:}

Screen paneling that weaves throughout entire building and permits various digital content to be displayed on its surface.

\section{Nodes:}

Collections of books or objects from private library collections, museums, and galleries that are connected together through exhibition within the Hub. The nodes have access to the Hub and vice versa.

\section{Place/Physical location:}

Physical architecture or a location that creates an experience for people and consists of physical materials that create a sense of place between us and the world and redefines our existence within it.

\section{Social interaction:}

Communication with other people in a physical place by sharing experiences, interests and information.

\section{Self:}

"The self is not the body but arises in social experience." Macionis 2007: 81.

\section{Physical connection:}

Experience with all senses for materials and people within a physical place.

\section{Experience:}

How we understand unique qualities through senses when visiting a place or communicating with others. Knowledge that is transformed into a network of impression of the places we visit and of these experiences.

\section{Senses:}

We perceive the world with all our senses. These include touch, taste, sight, and sound.

\section{Physical Library:}


Container of collections that acts as a mediator between the inside and the outside and that houses information in a written form and with objects.

\section{Content:}

What the container houses. These can be events or collections.

\section{Virtual library:}

Collection of information recorded and stored in cyberspace that can be accessed wirelessly through a digital hardware from many different locations.

\section{Virtual Reality:}

"is a computer-generated world involving one or more human senses and generated in real-time by participants actions." Bertol and Foell 2002: 67.

\section{Reality:}

"is defined as a collection of objective experiences which surround our life in contrast to dreams, fantasy, hallucinations...." Bertol and Foell 2002: 69.

\section{Cyberspace/Virtual Space:}

"') an infinite artificial world where humans navigate in information-based space (Benedikt, Michael, ed. 1991. Cyberspace. Cambridge: MIT Press.)" its physical existence as a world of computers linked by telecommunication lines." Bertol and Foell 2002: 59.

\section{Transfer of knowledge:}

Communication of experience and ideas to others. Could be verbal, textual, digital.

\section{Knowledge:}

Our individual experience of the world that is constantly updated by our sense signals.

\section{Information:}

Individual learns from what others recorded. Allows us to expand our knowledge beyond the senses and allows others to access at different times.

\section{Information technology:}

Use of electronic devices to transmit, retrain and store information such as computer, Internet, and print.

\section{Culture:}

A way of organizing life, of thinking and conceiving the underlying assumptions about the family and state, the economic system, and man himself. It is saturated with both emotion and intelligence. Hall 1959: 190.

\section{Time in Western culture:}

"...people are tied together and isolated from each other by invisible threads of time. Time is treated as a language, an organizer for activities, handling priorities and categorizing experience." Hall 1983:3.

"We have managed to objectify or externalize our imagery of passage of time, which makes us feel we can manage time, control it, spend it, save it, or waste it." Hall 1983: 36.

\section{Web:}

Space that stores information, allows interaction to take place such as chats, games, emails etc. It belongs to all and precludes no sense of the past. It stresses velocity and collects snippets of news and bytes of facts.

\section{Cloud:}

The term "cloud" is used to refer to a function of a data center.

Glanz 2012: 〈http://www.nytimes.com/2012/09/23/technology/data-centers-waste-vast-amounts-of-energy-belying-industryimage.html?_r=1\&partner=rss\&emc=rss . 


\section{Data center:}

Building that houses information that is being generated by people using Internet, storing files etc. It requires rows of servers that take up significant space.

\section{Repository:}

Place for storing and retrieving information from past generations and relaying them to the present and future generations that will view them.

\section{Digital window/digital screen:}

Multi-purpose physical surface, boundary and structure that showcases changing digital content such as projections of real time news, events, or library recording etc.

\section{Cathedral Window:}

Window that communicated through its craft and biblical stories of human needs, thoughts and knowledge in that particular time and religion for the people that were viewing it.

\section{Physical medium:}

Physical surface and elements that we can interact with that has characteristics such as texture, lighting, sound, temperature etc.

\section{Digital medium:}

Physical surface/hardware that can showcase ever-changing digital content and media that is housed within cyberspace.

\section{Digital content/Media:}

Real time news, events, or library recording information displayed on a surface and that can be changed.

\section{Loose spatial links:}

Access to information from homes, Internet cafés, and mobile phones that are no longer bound to a single place, like the library, to get our information.

\section{Topography skin:}

Topography of the site that acts as an extension of that which already existed on the site. 


\section{Bibliography and References}

\section{Printed Sources:}

Benjamin, Walter. 2002. Selected Writings: The Storyteller, observations on the Works of Nikolai Leskov. Volume 3, 1935-1938. Cambridge and London: The Belknap Press of Harvard University Press.

Bertol, Daniela, and David Foell. 1997. Designing Digital Space: An Architect's Guide to Virtual Reality. New York, United States of America: John Wiley \& Sons, Inc.

Blesser, Barry and Lind-Ruth Salter. 2007. Spaces Speak, are you Listening? Experiencing Aural Architecture. Cambridge: Massachusetts Institute of Technology.

Broadbent, Geoffrey, Richard Bunt, and Charles Jencks. 1980. Sign, Symbols, and Architecture. Chichester, New York : John Wiley \& Sons, Ltd.

Brownlee, David B. and David G. DeLong. 1997. Louis I. Kahn: In the realm of Architecture. Los Angeles, United States of America: The Museum of Contemporary Art.

Buttiker, Urs, and Translation by David Bean. 1994. Louis I. Kahn: Light and Space. New York, United States of America: Whitney library of design an imprint of Watson-Guptill Publications.

Cooke, Lynne, Peter Wollen, and Stephen Bann. 1995. Visual Display: Culture Beyond Appearances. Shrines, Curiosities, and the Rhetoric of Display. New York, United States of America: Bay Press,

Dal Co, Francesco. 2010. Tadao Ando, 1995-2010. New York, United States of America: Prestel Verlag.

Davies, Penelope J. E., Walter B. Denny, Frima Fox Hofrichter, Joseph Jacobs, Ann M. Roberts, and David L. Simon. 2007. Janson's History of Art; the Western Tradition. 7th ed. Upper Saddle River, New Jersey. United States of America: Pearson Education Inc., Prentice Hall.

Fazio, Michael, Marian Moffett, and Lawrence Wodehouse. 2009. Buildings across Time: An Introduction to World Architecture. 3rd ed. United States of America: McGraw-Hill Companies, Inc.

Gast, Klaus-Peter. 1998. Louis Kahn: The Idea of Order. Basil, Switzerland: Birkhauser Verlag. 
Hall, Edward Twitchell. 1984. The Dance of Life: The Other Dimension of Time. Garden City, New York, United States of America: Anchor Press/Doubleday \& Company.

Hall, Edward Twitchell. 1966. The Hidden Dimension. Garden City, New York, United States of America: Anchor Press/Doubleday \& Company.

Hall, Edward Twitchell. 1959. The Silent Language. Garden City, New York, United States of America: Anchor Press/Doubleday \& Company.

Hendrix, John. 2011. Architecture as Cosmology: Lincoln Cathedral and English Gothic Architecture. New York, United States of America: Peter Lane Publishing. Inc.

Honour, Hugh, and John Fleming. 2005. The Visual Arts: a History. 7th ed. Upper Saddle River, New Jersey. United States of America: Prentice Hall, Inc. Fleming-Honour Ltd.

Kazukiyo Matsuba. 1998. Ando: Architect. New York, United States of America: Tokyo, Kodansha International.

Lobell, John. 1979. Between Silence and Light: Spirit in the Architecture of Louis I. Kahn. Colorado, United States of America: Shambhala Publications, Inc.

Macionis, John J., Nijole V. Benokraitis, and Bruce Ravelli. 2007. Seeing ourselves: Classic, Contemporary, and Cross-Cultural Readings in Sociology. 2nd ed. Toronto, Ontario: Pearson Education Canada, Pearson Canada Inc.

Mack, Gerhard and Valeria Liebermann. 2000. Eberswalde Library: Herzog \& de Meuron. London: Architectural Association and the Authors, AA Publications.

Maitland, Leslie. 1990. Historical Sketches of Ottawa. Peterborough: Broadview Press Ltd.

Manguel, Alberto. 2007. The Library at Night. Toronto, Canada: Vintage Canada, a division of Random House of Canada Limited.

McLuhan, Marshall. 1962. The Gutenberg Galaxy: The Making of Typographic Man. Toronto, Canada: University of Toronto Press. 
Mitchell, William J. 2003. Me++: The Cyborg Self and The Networked City. Massachusetts, United States of America: Massachusetts Institute of Technology.

Ord, Douglas. 2003. The National Gallery of Canada: ideas, art, architecture. McGill-Queen's University Press.

Sennett, Richard. 2008. The craftsman. New Haven: Yale University Press.

Taylor, Christopher James. 1975. Manuscript Report number 268: Some Early Ottawa Buildings. Parks Canada Department of Indian and Northen Affairs. Ottawa: National Historic Parks and Sites Branch.

Trachtenberg, Marvin, and Isabelle Hyman. 2003. Architecture: from Prehistory to Post Modernity. 2nd ed. Upper Saddle River, New Jersey, United States of America: Prentice Hall, Inc.

Pallasmaa, Juhani. 2005. The Eyes of The Skin: Architecture and the Senses. Chichester, Wiley-Academy: Hoboken, NJ: John Wiley \& Sons, Ltd.

\section{Journal Sources:}

Beckman, Margaret, Dahms, Moshie and Lorne Bruce. "Libraries." The Canadian Encyclopedia. Historica Foundation, 2012.

〈http://www.encyclopediecanadienne.ca/articles/libraries $\rangle$. (Accessed on 12/02/2012).

Pattuelli, M. Cristina. The Warburg Library: Morphology of a Library as a 'Laboratory Of the Mind'. $19^{\text {th }}$ Annual Conference of the Society for the History of Authorship, Reading and Publishing (SHARP). Washington. New York: Pratt Institute. July 14-17, 2011.

\section{Newspaper Article Sources:}

Glanz, James. The Cloud Factories: Power, Pollution and the Internet. The New York Times, Technology. 22 Sept. 2012. 〈http://www.nytimes.com/2012/09/23/technology/data-centers-waste-vastamounts-of-energy-belying-industry-image.html?_r=1\&partner=rss \&emc $=$ rss. (Accessed on 22/10/2012). Web.

Roche, Kelly. Betting on Books: Visitors still spending time at libraries amidst digital revolution. Ottawa Sun. 26 May 2013. Print. 


\section{Interview Sources:}

Brule, Monique. Collections manager at the Ottawa Public Library. Personal interview 20 June 2013.

Roche, Kelly. Author of the Ottawa Sun article called Betting on Books: Visitors still spending time at libraries amidst digital revolution. Personal interview. 13 June 2013.

\section{Internet Sources:}

"Confederation Boulevard." Canada's Capital Region: Canadian, Just like You. Ottawa: The National Capital Commission. 〈http://www.canadascapital.gc.ca/places-to-visit/confederation-boulevard . (Accessed on 24/09/2012).

Confederation Line. City of Ottawa, 2012. 〈http://www.ottawalightrail.ca /\#\&panel1-5〉. (Accessed on 20/01/2013).

Ottawa Cycling Plan. City of Ottawa, 2001-2013. 〈http://ottawa.ca/en/residents/ transportation-and-parking/cycling/ottawa-cycling-plan>. (Accessed on 25/10/2012).

Photos: Notre Dame Cathedral. Sacred Destinations, 2005-13. 〈http://www.sacred-destinations.com/france/paris-notre-damecathedral/photos . (Accessed on 26/03/2013).

Rideau Canal: A post-War of 1812 waterway built at a huge human cost.

Canada's History magazine, online extension. Canadian Heritage, 2013. 〈http://www.canadashistory.ca/Magazine/OnlineExtension/Articles/Canal-Rideau.aspx>. (Accessed on 03/02/2013).

Rougier, Eric. Virtual tour: Notre Dame. From Paris, The City of Light. 〈http://www.fromparis.com/virtual-tour-notre-dame/〉. (Accessed on 26/10/2013). 